\title{
Bubble Size Control to Improve Oxygen-Based Bleaching: Characterization of Flow Regimes in Pulp- Water-Gas Three-Phase Flows
}

\author{
Final Report
}

Submitted to:

Institute of Paper Science and Technology at Georgia Tech Atlanta, GA

Principal Investigator:

S.M. Ghiaasiaan

G.W. Woodruff School of Mechanical Engineering

Georgia Institute of Technology

Atlanta, GA 30332-0405

Room 308, MRDC II

Telephone: (404) 894-3746

Fax: (404) 894-8496

E-mail: seyed.ghiaasiaan@me.gatech.edu 


\section{SUMMARY}

This document reports on the results of a research program aimed at the elucidation of various hydrodynamic aspects of low consistency paper pulp-water-gas three-phase flows, conducted jointly by the G.W. Woodruff School of Mechanical Engineering, Georgia Tech, and the Institute of Paper Science and Technology.

Hydrodynamic flow characteristics of solid-liquid-gas slurry made by intimately mixing fibrous paper pulp with water and air were first investigated in a short, vertical circular column. The pulp consistency (weight fraction of pulp in the pulp-water mixture) was varied in the low consistency range of $0.0 \sim 1.5 \%$. The test section was $1.8 \mathrm{~m}$ long, with $5.08 \mathrm{~cm}$ inner diameter. Mixing of the slurry prior to entering the test section was done using a patented mixer with controlled cavitation that generated finely dispersed micro-bubbles. Flow structures, gas holdup (void fraction), and the geometric and population characteristics of gas bubbles in the gas-pulpliquid three-phase flow were experimentally investigated, using visual observation, Gamma-ray densitometry, and flash X-ray photography. Superficial velocities of the gas and liquid/pulp mixture covered the ranges $0 \sim 26 \mathrm{~cm} / \mathrm{s}$ and $21 \sim 51 \mathrm{~cm} / \mathrm{s}$, respectively.

Five distinct flow regimes could be visually identified. These included dispersed bubbly, characterized by isolated micro-bubbles entrapped in fiber networks; layered bubbly, characterized by bubbles rising in a low consistency annular zone near the channel wall; plug; churn-turbulent; and slug. The dispersed and layered bubbly regimes could be maintained only at very low gas superficial velocities or gas holdups. Flow regime maps were constructed using phasic superficial velocities as coordinates, and the regime transition lines were found to be sensitive to consistency.

The cross section-average gas holdup data showed that both the dispersed and the layered bubbly regimes could best be represented by the homogeneous mixture model. The drift flux model could best be applied to the reminder of the data when the plug and churn-turbulent flow regimes were treated together, and the slug flow was treated separately. The drift flux parameters depended on the pulp consistency.

The feasibility of using artificial neural networks (ANNs) for the identification of the flow regimes in the aforementioned three phase gas/liquid/pulp fiber systems, using the statistical characteristics of pressure fluctuations measured by a single pressure sensor, was then examined. The aforementioned experimental test facility was used for this purpose. Experiments were carried out in the transparent, vertical circular column. The pulp consistency (weight fraction of 
pulp in the pulp-water mixture) was varied in the low consistency range of $0.0 \sim 1.5 \%$, and flow structures and other hydrodynamic characteristics were experimentally investigated. Local pressure fluctuations at a station $1.2 \mathrm{~m}$ above the test section inlet were also recorded using a highsensitivity pressure transducer that was installed in a manner not to cause flow disturbance. Various statistical characteristics of the pressure fluctuations, as well as the characteristics of their auto correlations, were examined as potential input parameters for ANNs trained to recognize the flow regimes solely based on these statistical pressure fluctuation characteristics. Three-layer, feed-forward ANNs could learn to identify four major flow patterns (bubbly, plug, churn, and slug) well, using the standard deviation, coefficients of skewness and kurtosis, and several time shift auto-correlations of normalized pressure signals as input. The results indicated the feasibility of using ANNs for flow regime identification in three-phase gas/liquid/pulp flow systems.

In view of the promising results obtained with the aforementioned ANNs, the feasibility of a transportable artificial neural network (ANN) - based technique for the classification of flow regimes in three phase gas/liquid/pulp fiber systems by using pressure signals as input was examined. Using the aforementioned test facility, local pressure fluctuations were recorded at three different stations along the column using three independent but principally similar highsensitivity transducers. An ANN was designed, trained and tested for the classification of the flow regimes using as input some density characteristics of the power spectrum for one of the normalized pressure signals (from Sensor 1), and was shown to predict the flow regimes with good accuracy. A voting scheme was also examined in which the three sensors fed separately trained ANNs, and a correct flow regime would require a vote from at least two of the three ANNs. This scheme improved the agreement between the model predictions and the data.

The ANN trained and tested for Sensor 1 predicted the flow regimes reasonably well when applied directly to the normalized pressure power spectrum density characteristics of the other two sensors, indicating a good deal of transportability. For further improvement of transportability, an ANN-based method was also developed, whereby the power spectrum density characteristics of other sensors were adjusted before they were used as input to the ANN that was based on Sensor 1 alone. The method was shown to improve the accuracy of the flow regime predictions. This method requires in practice, that the "replacement" sensor to which regime identification is transported will be, for some while, in simultaneous use with the sensor to be replaced; then the training of the "input-adjusting" ANN would be possible in industry practice. Such a situation is realistic for sensitive processes, where redundant sensors are implemented for fault tolerance. 
In view of the promising results obtained with the aforementioned ANNs, the feasibility of a transportable artificial neural network (ANN) - based technique for the classification of flow regimes in three phase gas/liquid/pulp fiber systems by using pressure signals as input was examined. Using the aforementioned test facility, local pressure fluctuations were recorded at three different stations along the column using three independent but principally similar highsensitivity transducers. An ANN was designed, trained and tested for the classification of the flow regimes using as input some density characteristics of the power spectrum for one of the normalized pressure signals (from Sensor 1), and was shown to predict the flow regimes with good accuracy. A voting scheme was also examined in which the three sensors fed separately trained ANNs, and a correct flow regime would require a vote from at least two of the three ANNs. This scheme improved the agreement between the model predictions and the data.

The ANN trained and tested for Sensor 1 predicted the flow regimes reasonably well when applied directly to the normalized pressure power spectrum density characteristics of the other two sensors, indicating a good deal of transportability. For further improvement of transportability, an ANN-based method was also developed, whereby the power spectrum density characteristics of other sensors were adjusted before they were used as input to the ANN that was based on Sensor 1 alone. The method was shown to improve the accuracy of the flow regime predictions. This method requires in practice, that the "replacement" sensor to which regime identification is transported will be, for some while, in simultaneous use with the sensor to be replaced; then the training of the "input-adjusting” ANN would be possible in industry practice. Such a situation is realistic for sensitive processes, where redundant sensors are implemented for fault tolerance.

Finally, the interfacial surface area concentration in the aforementioned short vertical column, when it was subject to the through flow of a solid-liquid-gas slurry made by mixing aqueous fibrous paper pulp with a nitrogen-carbon dioxide gas mixture, was measured in the study. The objective was to examine the effects of fiber consistency, and other major hydrodynamic parameters, on the column average interfacial surface area concentration. The gas absorption technique was applied, using $\mathrm{CO}_{2}$ as the transferred species and sodium hydroxide as the alkaline agent in water. The flow regimes in the experiments were visually identified, and the test section void fraction was measured using Gamma-ray densitometery. The ranges of experimental parameters were as follows: liquid-pulp superficial velocity $15 \sim 94 \mathrm{~cm} / \mathrm{s}$; average gas-superficial velocity $17 \sim 54.5 \mathrm{~cm} / \mathrm{s}$; pulp consistency in the water/pulp mixture $0.0 \sim 2.18 \%$; and average mole fraction of carbon dioxide in the gas mixture $0.19 \sim 0.95$. A total of 33 data points were obtained, each representing the average of 3 to 9 tests that confirmed reasonable 
repeatability. Statistical analysis of the experimental data indicated strong dependence of interfacial area on average gas superficial velocity and void fraction; and a relatively weak dependence on pulp consistency and liquid superficial velocity. The effect of pulp consistency on the interfacial area concentration in the test section was particularly interesting. The test section average interfacial surface area concentration decreased with increasing consistency up to a consistency of $1.6 \%$, but increased significantly when consistency was further increased to $2.18 \%$. The experimental data were empirically correlated. 


\section{TABLE OF CONTENTS}

$\begin{array}{ll}\text { Summary } & 1\end{array}$

$\begin{array}{ll}\text { Table of Contents } & 4\end{array}$

Chapter 1: Flow Regimes and Gas Holdup $\quad 6$

$\begin{array}{ll}\text { Notation } & 7\end{array}$

$\begin{array}{lr}1.1 \text { Introduction } & 8\end{array}$

$\begin{array}{ll}1.2 \text { Test Loop } & 11\end{array}$

$\begin{array}{ll}1.3 \text { Experimental Procedures } & 12\end{array}$

$\begin{array}{ll}1.4 \text { Results and Discussions } & 14\end{array}$

1.4.1 Flow Regimes 14

1.4.2 Flow Regime Maps 15

1.4.3 The Gas Holdup 16

$\begin{array}{ll}1.5 \text { Concluding Remarks } & 18\end{array}$

1.6 References for Chapter $1 \quad 30$

Chapter 2: Flow Regime Identification Based on Pressure Fluctuations using $\begin{array}{ll}\text { Artificial Neural Networks } & 34\end{array}$

Notation $\quad 35$

2.1 Introduction 36

2.2 Experimentals 38

2.3 Flow Regimes 40

2.4 Neural Network Models $\quad 41$

2.5 Performance of the Trained ANNs 43

2.6 Concluding Remarks 44

2.7 References for Chapter 2

Chapter 3: Flow Regime Classification Based on Frequency Domain Analysis of Pressure Signals 56

Notation $\quad 57$

$\begin{array}{ll}3.1 \text { Introduction } & 58\end{array}$ 


\section{TABLE OF CONTENTS (Cont'd)}

3.2 Experiments 61

3.3 Spectral Analysis 63

3.4 Neural Network Model for Regime Identification Using Power Spectral Characteristics of Pressure 65

3.5 Transportability 69

3.6 Concluding Remarks 71

3.7 References for Chapter $3 \quad 84$

Chapter 4: Experimental Study of the Gas-Liquid Interfacial Surface Area Concentration $\quad 88$

Notation $\quad 89$

4.1 Introduction 90

4.2 Experimental Apparatus 91

4.3 Experimental Procedures 93

4.4 Data Analysis 94

4.5 Results and Discussions 96

4.5.1 Test Matrix and Data 96

4.5.2 Parametric Dependencies 97

4.5.3 Empirical Correlation of the Data 99

4.6 Concluding Remarks 100

$\begin{array}{ll}4.7 \text { References for Chapter } 4 & 107\end{array}$ 
Chapter 1: Flow Regimes and Gas Holdup 


\section{Notation}

$C_{0} \quad$ Drift flux distribution coefficient

D $\quad$ Channel diameter (m)

I Gamma-ray count

$I_{G}, I_{L} \quad$ Gamma-ray counts with pure gas and pure liquid, respectively

$K_{L, i} a_{i}^{\prime \prime} \quad$ Interfacial volumetric mass transfer coefficient $\left(\mathrm{kg} / \mathrm{m}^{3} \mathrm{~s}\right)$

$K_{L, P} a_{P}^{\prime \prime} \quad$ Interphase-liquid bulk volumetric mass transfer coefficient $\left(\mathrm{kg} / \mathrm{m}^{3} \mathrm{~s}\right)$

$l \quad$ Chord length (m)

$N \quad$ Total number of counts in Gamma-ray densitometry

$\mathrm{O}_{2} \quad$ Oxygen

$\mathrm{O}_{3} \quad$ Ozone

$U_{G S} \quad$ Superficial gas velocity $(\mathrm{m} / \mathrm{s})$

$U_{L S} \quad$ Superficial pulp-water liquid velocity $(\mathrm{m} / \mathrm{s})$

$V_{G J} \quad$ Gas drift velocity $(\mathrm{m} / \mathrm{s})$

\section{Greek letters}

$\varepsilon \quad$ Gas holdup (void fraction)

$\bar{\varepsilon} \quad$ Cross section-average gas holdup

$\varepsilon_{i} \quad$ Chord-average void fraction for chord i

$\xi_{i} \quad$ Uncertainty in $\varepsilon_{i}$

$\zeta \quad$ Statistic defined in Equation 7 


\subsection{Introduction}

Gas/liquid-pulp slurry three-phase flows occur in a number of systems in paper production and recycling, including flotation deinking, delignification and bleaching (Smook, 1992). Production of paper from wood chip involves several stages, including chemical or mechanical processing of pulp, bleaching, and wet and dry end operations of paper manufacturing. Recycling of paper, furthermore, involves the deinking process, which is usually performed by flotation.

Pulp bleaching is achieved by promoting chemical reaction between the lignin (an undesirable amorphous and highly polymerized substance) and a highly oxidizing gas. Bleaching is done in most of the existing plants using chlorine as the oxidizing agent. The solubility of chlorine in water is relatively high, which simplifies chlorine-based bleaching. Due to environmental concerns, however, oxygen and ozone are increasingly replacing chlorine (Rutkowski, 1997).

For bleaching to occur, the oxidizing gas must be dissolved in water, be transported towards the pulp, diffuse towards the pulp-liquid interface, and finally chemically react with lignin (Dence and Reeve, 1996). Bleaching thus requires intimate mixing between the oxidizing gas and the pulp slurry, accompanied by large gas-liquid interfacial area concentrations. Fine mixing is particularly important for oxygen and ozone due to their relatively low solubility in water. Good understanding of the hydrodynamics of the pulp-liquid-gas three-phase flow systems is essential for the design of efficient oxygen and ozone bleaching systems. Ozone hydrodynamics and mass transfer in two-phase bubble columns have been investigated only recently (Bin et al., 2001). Little is known about the three-phase gas-liquid-pulp slurry hydrodynamics, furthermore.

Pulp fibers in an aqueous suspension swell by absorbing water, and in the simplest interpretation a pulp-water mixture can be considered a yield-pseudoplastic fluid (Duffy and Titchener, 1975; Duffy et al., 1976; Bennington et al., 1995), acting as a solid when shear stress is below some threshold, and as a non-Newtonian liquid otherwise. Some characteristics of pulp suspensions, including the drag reduction effect of fibers (Lee and Duffy, 1976; Duffy and Lee, 1978), and the turbulence characteristic of such suspensions (Bose et al., 1997), have been studied in the past. The literature dealing with gas-non-Newtonian liquid two-phase flow is rather extensive (Oliver and Young Hoon, 1968; Mahalingam and Valle, 1972; Farooqi and Richardson, 1982a, b; Chhabra et al., 1984; Bishop and Deshpande, 1986a, b, 1993; Lyczkowski and Wang, 1992; Das et al., 1989, 1991; Johnson and White, 1993; Carew et al., 1995; Welsh et al, 1999). 
However, pulp-liquid-gas mixtures exhibit hydrodynamics that are much more complex than what is observed in typical gas-non-Newtonian liquid two-phase flows.

Flocculation (entanglement of fiber groups to conformations that possess mechanical strength, usually called flocs), is the main cause for the complexity in pulp slurries as well as in pulp slurry-gas three-phase flow systems. Flocculation can be observed at consistencies (weight fractions of dry pulp in the water-pulp mixture) as low as $0.5 \%$. Pulp slurries are classified as low consistency (LC), for consistencies lower than about 8\%; medium consistency (MC) for 8\% to 20\%; and high consistency (HC) when the consistency is higher than 20\% (Bennington, 1989). In a LC slurry-gas system, at consistencies higher than about 1\%, three-dimensional networks of pulp form in the mixture (Bennington, 1989): they can be broken down by high shear only, they can trap small bubbles (Walmsley, 1992), and often they lead to the channeling phenomenon in flotation devices whereby the gas preferentially flows through inter-floc areas (Lindsay et al., 1995). Entrapment of small bubbles results in a small residual void fraction in the liquid, a phenomenon observed in mud as well (Johnson and White, 1993). Poor mixing of gas bubbles with the pulp can evidently lead to poor bleaching. The size and strength of flocs increase as consistency is increased. Flocculation thus renders pulp suspension slurry-gas systems behave drastically different than other gas-solid-liquid three-phase systems, as well as non-Newtonian liquid-gas two-phase flows.

Little is known about the hydrodynamics of gas-pulp slurry flows. Lindsay et al. (1995) studied the flow regimes and gas holdup in a column containing a vertical and quiescent pulp slurry $0.66 \mathrm{~m}$ high and $12.7 \mathrm{~cm}$ in diameter, and in a vertical column $1.5 \mathrm{~m}$ long and $13 \mathrm{~cm}$ in diameter that had through-flow of pulp slurry and air. They used Gamma-ray densitometry for the measurement of multiple chord-average void fractions. With the quiescent column (no throughflow of pulp-liquid slurry), the pulp promoted transition from bubbly flow to churn flow by enhancing bubble coalescence. With a slurry through-flow (co-current flow), tests were performed with $0 \%$ and $1 \%$ consistency. Although flow regimes could only be seen at the near-wall zone of the test section, bubbly, plug, and a transition regime separating them could be recognized. Bubbly flow was seen at very low gas superficial velocities only, primarily when $U_{G S} \leq U_{L S}$, where bubbles were entrapped in and carried by flocs. A more detailed experimental study of the hydrodynamics of gas-sparged pulp slurry columns (without a pulp slurry through-flow) was performed more recently by Reese et al. (1996). A cylindrical column $10.7 \mathrm{~cm}$ in diameter and 2.2 $\mathrm{m}$ high, and a $7.5 \mathrm{~cm} \times 3.9 \mathrm{~cm}$ rectangular column $1.0 \mathrm{~m}$ high, were used with pulp slurry 
consistencies in the $0 \sim 1 \%$ range. An intrusive light transmission probe, and a particle image velocimetry (PIV) system were used in the two test sections for studying the bubble characteristics. They noted that even at a consistency as low as $0.1 \%$, bubbles behaved differently than those in pure water.

Heindel (1999) and Heindel and Garner (1999, 2000) used flash X-ray photography to study the bubble size characteristics in gas-cellulose fibrous slurries with consistencies up to 1.5\%. They could divide the bubbles into the two large and small categories. The relative number of large bubbles increased with increasing fiber consistency. The size distribution of the small bubbles, however, was approximately log-normal, and was independent of fiber consistency.

The oxidation of pulp in bleaching devices is a complicated multi-step process, as mentioned earlier. The oxidant species $\left(\mathrm{O}_{2}\right.$ or $\left.\mathrm{O}_{3}\right)$ must first dissolve in water at the gas-slurry interface, and then be transferred from the interface to the liquid bulk. The oxidant species transport from the liquid bulk to the fiber-water interface must then take place, followed by the chemical reaction at the fiber surface. It is not certain at this time which one of these steps is controlling the pulp bleaching reaction rate. Enhancement of the gas-slurry interfacial area concentration or volumetric mass transfer coefficients would, nevertheless, obviously lead to improved transfer of $\mathrm{O}_{2}$ or $\mathrm{O}_{3}$ by reducing the overall mass transfer resistance between the gasliquid interface and the liquid bulk, and such enhancement can be achieved by maintaining a bubbly flow regime. Gas absorption techniques have been used extensively in the past for the measurement of interfacial area concentrations and volumetric mass transfer coefficients (Luo and Ghiaasiaan, 1999). Using the latter techniques, Bennington and co-workers have recently measured the overall interface-liquid bulk mass transfer coefficients ( $\left.K_{L, i} a_{i}^{\prime \prime}\right)$ associated with low and medium consistency pulp slurries in a high-shear mixer (Bennington et al., 1997; Rewatkar and Bennington, 2000), using the cobalt-catalyzed sulfite oxidation technique (Reith and Beck, 1973; Thibault et al., 1990).

In this chapter we report on a detailed experimental investigation of the flow patterns, void fractions, and the bubble characteristics of gas-aqueous pulp slurry three-phase flows in a vertical, upward column, with gas and slurry through flows. The investigation is novel, and examines the hydrodynamics of gas-pulp slurries over a relatively wide range of phasic superficial velocities not investigated in the past. The volumetric mass transfer coefficients $K_{L, i} a_{i}^{\prime \prime}$ and $K_{L, P} a_{P}^{\prime \prime}$, measured and correlated in the same test facility, will be published in the future. 


\subsection{Test Loop}

A schematic of the experimental facility is shown in Figure 1.1. The main components of the loop include a feed tank, a receiving tank, a re-circulation pump, a Hydrosonic pump (also known as a Shock Pulse Generator or SPG), and the test section. Pulp of the proper consistency is first loaded into the feed tank and the receiving tank. The pulp used in this study was washed, unbleached softwood. Since dilute cellulose fiber suspensions have the propensity to separate when left stagnant for an extended time period, the fiber slurry is gently stirred by a variable speed Lightnin mixer in each tank to maintain the fiber consistency at a constant value. The two consecutive tanks are $0.144 \mathrm{~m}^{3}$ in volume, and are both exposed to atmosphere. The long residence time of fluid in these tanks provides for entrained gas to leave the system. The water/fiber mixture is then circulated at a continuous basis by a 1-hp, 1725-rpm Discflo pump, which is tested to operate at up to $11 \%$ consistency with no plugging. The pulp flow rates are monitored with a Krohne IFC080 Smart magnetic flow meter and encompass a range of 0 2.0 l/s.

Filtered air from the building is injected into the flowing liquid in a $2.5 \mathrm{~cm}$ diameter tube prior to the Hydrosonic pump. The air flow rate is measured by two Top Trak flow meters. One of them has a measurement range of $0 \sim 40 \mathrm{slpm}$ (standard liter per minutes), while the other with a range of 0-1 slpm. They can be switched from one to the other in order to accommodate different gas flow rates.

The test section is a PVC schedule 40 pipe that is $1.80 \mathrm{~m}$ in length and has a $5.08 \mathrm{~cm}$ inner diameter. A differential pressure transducer (Validyne DP15) is attached to the bottom and the top of the test section, which measures the pressure drop in the test section.

The gas/water/fiber mixture exiting from the column is channeled by a conical constriction at the top of the test section into an $8 \mathrm{~cm}$ diameter pipe. The pipe is constructed as a "T" section with one end open to atmosphere in order for gas to escape, and the other end is connected to a 10 cm o.d. PVC pipe, which is lower than the column exit to allow for the mixture to enter the receiving tank.

The hydrosonic pump (Hydrodynamics Inc., Rome, Georgia) is a patented mixer design that uses a proprietary technology for mechanical-to-thermal energy conversion based on shock waves. Pressurized air is introduced to the hydrosonic pump. In converting mechanical to thermal 
energy at a very high and efficient rate, the hydrosonic pump generates intimate mixing of the gas and liquid, and breaks down the gas phase into micro-bubbles.

The column is mounted on a sturdy pipe frame. A guided carriage is also affixed rigidly to the pipe frame by a stainless steel elbow screw. The guided carriage has been designed to travel along the length of the test section, and houses a Gamma-ray densitometer. The Gamma-ray densitometer, described previously by Lindsay et al. (1995), is used for the measurement of chordaverage void fractions at various locations in the test section. The densitometer includes a $45 \mathrm{mCi}$ Americium-241 source and an Ortec Model 276 detector. The sealed source and detector are positioned within a few millimeters of opposite sides of the PVC pipe. The narrow beam of radiation (approximately 5 millimeters in diameter) follows a source-to-detector pathway that directly traverses the PVC pipe and its contents. The sealed source and detector can be moved manually in both lateral directions via thumbscrews so that measurements can be made at various chord positions across any given cross sectional plane of the PVC pipe. By performing void fraction measurement on several chords at a given location, the cross section-average void fraction can be calculated, and radial distribution of void fraction can be estimated (Lindsay et al., 1995).

\subsection{Experimental Procedures}

Flow regimes and gas holdup values were recorded over $21 \leq U_{L S} \leq 51 \mathrm{~cm} / \mathrm{s}$ and $0<U_{G S} \leq 26 \mathrm{~cm} / \mathrm{s}$ ranges. In each test series the pulp-water mixture superficial velocity would be set at a constant and stable value. The gas superficial velocity would then be increased in steps, starting from a very small value. The flow patterns were visually identified. For each selected $U_{L S}$ value, once the predominant and easily distinguishable regimes (to be described later) were identified, sufficiently fine adjustments to the flow rate were done to make sure that each regime was spanned by at least 3 or 4 data points.

Gas holdup measurements were performed by the Gamma-ray densitometer at a height of $1.45 \mathrm{~m}$ above the test section inlet. These measurements were done in the tests where flow regimes and their transition conditions were the objective, as well as in separate tests meant to examine repeatability. Chord-average void-fraction was measured at the following 5 lateral positions: the test section cross-section center line $\left(l_{1}=\mathrm{D}=5.08 \mathrm{~cm}\right.$, with $l_{1}$ representing the chord length); $1 \mathrm{~cm}$

to the left and right of the centerline $\left(l_{2}=l_{4}=4.67 \mathrm{~cm}\right)$; and $2 \mathrm{~cm}$ to the left and right of the centerline $\left(l_{3}=l_{5}=3.13 \mathrm{~cm}\right)$. The cross-section average gas holdup, $\bar{\varepsilon}$, was then calculated from: 


$$
\bar{\varepsilon}=\frac{\sum_{i=1}^{5} \varepsilon_{i} l_{i}}{\sum_{i}^{5} l_{i}}
$$

A detailed discussion of the principles of Gamma-ray densitometry can be found in Hewitt (1978), and a method for the estimation of the uncertainty in the measured void fractions resulting from photon statistical fluctuations can be found in Honan \& Lahey (1978) and Vince \& Fincke (1983). Accordingly, the chord-average void fraction is related to Gamma-ray counts as:

$$
\varepsilon=\frac{\ln \left(I / I_{G}\right)}{\ln \left(I / I_{L}\right)}
$$

where $I_{L}, I_{G}$, and $I$ respectively represent the Gamma-ray counts (all measured over the same time period) with pure water, pure gas, and the three-phase mixture of interest. (The small solids fraction suspended in the liquid can in our case be neglected.) Gamma-ray counts were recorded for periods of 10 seconds, and were repeated 10 times at each chord. The uncertainty in the measured $\bar{\varepsilon}$ could be estimated from (Lindsay et al., 1995):

$$
\xi_{i}=\frac{\Delta \varepsilon_{i}}{\varepsilon_{i}}=\frac{1}{\sqrt{N}} \frac{\left[2\left(1-\varepsilon_{i}+\varepsilon_{i}^{2}\right)\right]^{1 / 2}}{\varepsilon_{i} \ln \left(I_{G} / I_{L}\right)}
$$

where, $\mathrm{N}$ is the product of the number of counts and number of repeated count measurements. In view of Equation (2), the uncertainty in the cross section-average gas holdup is estimated by:

$$
\frac{\Delta \bar{\varepsilon}}{\bar{\varepsilon}}=\frac{1}{\bar{\varepsilon}} \frac{\sum_{i=1}^{5} \varepsilon_{i} l_{i} \xi_{i}}{\sum_{i=1}^{5} l_{i}}
$$

All gas holdup calculations were based on the reasonable assumption that Gamma-ray attenuation was not affected by the pulp (Lindsay et al., 1995).

As mentioned earlier, the hydrosonic pump generates fine mixtures of micro-bubbles and slurry at the test section inlet. Bubble size characteristics in the test section have been measured by flash X-ray photography (Rezak et al., 2002). The X-ray flash photography system used for this purpose has been discussed previously (Lindsay et al., 1995; Rezak et al., 2002), and will not be described here. Figure 1.2 depicts typical cumulative number-based bubble size distributions, obtained from the analyses of X-ray images taken from the test section at a height of $145 \mathrm{~cm}$ above its entrance. The displayed figures of course only depict the bubbly flow pattern. The typical visible bubble size is of the order millimeters, however, indicating that at the time of 
observation the initial gas dispersion to micro-bubbles has evolved by bubble coalescence to reasonably large bubble sizes. In a clear water suspension the micro-bubbles generated by the mixer have the appearance of a fog that makes the suspension appear "cloudy", while these measured bubble sizes represent clearly distinguishable individual bubbles.

The typical and maximum uncertainties associated with phase superficial velocities were $\pm 3.0 \%$ and $\pm 4.5 \%$ for $U_{L S}$; and $\pm 9.6 \%$ and $\pm 33.0 \%$ for $U_{G S}$, respectively. The uncertainties in gas holdup associated with Gamma ray densitometry were everywhere small in comparison with the gas holdup data scatter.

\section{4 Results and Discussions}

\subsubsection{Flow Regimes}

Five distinct flow patterns could be identified. These flow patterns are schematically displayed in Fig. 1.3.

At very low gas superficial velocities the dispersed bubbly regime, depicted in Fig. 1.3(a) was observed. Fine bubbles with small diameters that appear to be trapped in fiber networks, rise in the test section, without any visible breakup or coalescence. Bubbles were not uniformly distributed in the test section, however. This regime was not observed at very low $U_{L S}$ or very low consistencies. The entrapment of bubbles in fiber networks is consistent with previously reported observations (Pelton, 1992; Lindsay et al., 1995), and can evidently occur only when the bubbles remain small and network structures large enough to entrap such bubbles are present.

With increasing gas superficial velocity, the dispersed bubbly regime would be replaced by the layered bubbly flow, displayed schematically in Fig. 1.3(b). This flow regime is not typically observed in gas-liquid two-phase flows, and was characterized by a flocculated core and an essentially fiber-free annular zone that was 3 4 mm thick. Dispersed bubbles trapped in the flocculated core could be sporadically seen, while the fiber-free annulus contained distorted bubbles moving in rectilinear fashion. Bubble collisions occasionally occurred, without apparent coalescence. Furthermore, the flocculated core was periodically disturbed by tightly grouped bubble clusters, typically with 1 2 Hz frequency.

Further increasing $U_{G S}$ would lead to the plug flow pattern, displayed in Fig. 1.3(c) and 1.3(d). The flow pattern in Fig. 1.3(c), referred to here as the incipient plug flow pattern, represents transition from bubbly to plug. It is characterized by clusters of small bubbles, and 
large, irregular-shaped gas plugs with 2-3 cm in dimension that move in swirling spiral manner and disturb the flow field. Swarms of small bubbles often trail the air plugs, and the small bubbles do not coalesce. The air plugs could even be seen very near the test section entrance, and appeared to dominate the flow field. The plugs would collect solitary bubbles that sporadically appeared to be caught in fiber networks. At higher $U_{G S}$ the plug flow pattern had the appearance depicted in Fig. 1.3(d). Large air plugs with dimensions comparable with the channel diameter totally dominated the flow field, although isolated small bubbles could be also seen. The plugs mostly stayed near the channel wall. With increasing $U_{G S}$, the spiral motion of plugs would gradually give way to straight, upward motion. The plugs caused churning and back-mixing.

The churn-turbulent flow pattern, displayed in Fig. 1.3(e), represented the transition from plug to slug flow. This flow pattern is consistent with the known hydrodynamic characteristics of churn-turbulent flow in gas-liquid two-phase channel flow (Collier and Thome, 1994) and twophase flow in bubble column (Deckwer, 1985), and is characterized by irregular-shaped large gas pockets near the channel centerline that carry smaller bubbles in their wakes, repeatedly collide and coalesce with smaller bubbles, and cause an oscillatory and unstable flow field. This flow pattern could be considered as the channel entrance region flow field for the development of slug flow, in accordance with the observation of Taital et al (1978) for gas-liquid flow, as described below.

With further increasing $U_{G S}$, the slug flow pattern, depicted in Fig. 1.3(f) is established. The flow field in this regime is dominated by bullet-shaped bubbles that resemble Taylor bubbles in gas-liquid two-phase flow. Transition from churn-turbulent regime to slug flow was gradual, i.e., as $U_{G S}$ was increased, bullet-shaped bubbles resulting from the coalescence and growth of smaller bubbles could first be recognized near the exit of the test section. The location of regime transition from churn-turbulent to slug flow moves downwards in the test section as $U_{G S}$ is increased.

\subsubsection{Flow Regime Maps}

The flow regime data, based on phasic superficial velocities as coordinates, are shown in Figs 1.4(a), (b) and (c), for 0.5\%, 1.0\%, and 1.5\% consistencies, respectively. The incipient plug and plug flow patterns are presented together, since clear demarcation of a boundary between the two is difficult. Dispersed bubbly and layered bubbly regimes only occupy very small portions of the regime maps, and are encountered at very low gas superficial velocities. Plug, churn and slug 
flow patterns, in combination, occupy virtually the entire flow regime maps for $U_{G S} \geq 1 \mathrm{~cm} / \mathrm{s}$. Absent in the flow regime maps is annular flow, which would need gas superficial velocities significantly higher than the upper limit of $U_{G S}$ in our experiments.

The flow regime transition lines are sensitive to consistency, in particular when the $0.5 \%$ consistency data are compared with data representing higher consistencies. All regime transitions evidently take place at considerably lower gas superficial velocities for $0.5 \%$ consistency slurry than for higher consistency slurries. In comparison, the regime transition lines for 1\% and 1.5\% slurries are relatively close. Nevertheless, overall, increasing consistency monotonically shifts the regime transition lines towards higher $U_{G S}$ values. Transition from dispersed bubbly to layered depends primarily on the capability of the fiber networks to entrap bubbles and oppose their accumulation in the near-wall zone where the hydrodynamic resistance opposing bubble rise is lower due to lower fiber concentration. With $1 \%$ and $1.5 \%$ consistencies the fiber networks are evidently better capable of entrapping the small bubbles. Transition from bubbly to plug, furthermore, depends on the capability of fibers in preventing coalescence among bubbles and the consequent formation of gas plugs. It is therefore reasonable that the transition from layered bubbly to plug flow also occurs at higher $U_{G S}$ values for the higher $1 \%$ and $1.5 \%$ consistencies. The monotonic shifting of all other regime transition lines as consistency is increased can be also attributed to the stronger retardation of bubble coalescence as consistency is increased.

The subjective nature of visual identification of flow patterns should be emphasized, which inevitably leads to uncertainty with respect to the regime transition lines. Successful, objective flow regime identification methods have been demonstrated for gas-liquid two-phase flow, most of them based on the statistical characteristics of pressure fluctuation signals (Matsumi, 1984; Lin and Hanratty, 1986; Wambsganss et al., 1994; Cai et al., 1996). Artificial neural network-based methods for classification and recognition of statistical patterns of such signals associated to the major two-phase flow regimes have also been successfully demonstrated (Cai et al., 1994; Mi et al., 1998). These techniques have not been applied to three-phase pulp-liquid-gas flows thus far, however.

\subsubsection{Gas Holdup}

Gas holdup data presented and discussed in this section represent Gamma-ray densitometry measurements at $145 \mathrm{~cm}$ location along the test section from the inlet. Typical chord-average gas holdup distributions in the channel cross-section are depicted in Fig. 1.5. For bubbly and layered bubbly regimes the relatively uniform cross-sectional distributions of gas holdup is consistent with 
the presence of fiber networks which prevent mixing and the resulting migration of bubbles towards the channel center. The void fraction profiles for all other regimes have their familiar overall shapes with their maxima at the channel center, and confirm the mixing caused by churning and the motion of large gas plugs.

Figs. 1.6 and 1.7 depict the parametric effects of consistency and phase superficial velocities on the measured cross section-average gas holdups. Each data point in fact represents the average of 2 separate repetitions of the same experiment to ensure repeatability. At very low gas superficial velocities, where bubbly flow occurs, specific trends are difficult to identify due to the very small gas holdups and the relatively large data scatter. Clear trends can be recognized at higher gas holdups, however. With consistency maintained constant, $\bar{\varepsilon}$ increases monotonically with $U_{G S}$ when $U_{L S}$ is held constant, and it decreases monotonically with increasing $U_{L S}$ when $U_{G S}$ remains unchanged. The effect of pulp consistency on gas holdup is more complicated, however. The has holdup profiles for $1 \%$ and $1.5 \%$ consistency are in fact relatively close, and with the exception of the highest $U_{G S}$ depicted in Fig. 1.7, the cross section-average gas holdup for $1 \%$ consistency is everywhere only slightly lower than that for $1.5 \%$ consistency. This trend is reversed for $U_{L S}=51 \mathrm{~cm} / \mathrm{s}$ data, likely due to subtle changes in the characteristics of the slug flow pattern. The has holdup values obtained with $0.5 \%$ consistency, on the other hand, are everywhere significantly lower. It should be mentioned that the monotonic and smooth dependency of $\bar{\varepsilon}$ on consistency and phase superficial velocities observed in these experiments were possible since significant channeling (preferential flow of gas through low hydraulic resistance "channels” where fiber networks are weaker) did not occur in the experiments. More complicated parametric dependence of $\bar{\varepsilon}$ (and other related parameters such as interfacial area concentration and phasic residence time in the system) may occur at higher consistencies and/or larger-diameter columns, where strong and large three-dimensional fiber networks can easily form.

The cross section-average gas holdups were small and highly scattered for dispersed and layered bubbly regimes. Figure 1.8 compares the measured gas holdups for these flow patterns, with the predictions of the homogeneous flow model, which assumes that the two phases are well mixed and have the same axial velocity everywhere:

$$
\bar{\varepsilon}=\frac{U_{G S}}{U_{G S}+U_{L S}}
$$

The agreement, notwithstanding the large scatter in the data, is reasonable. 
Significant velocity slip occurs in other flow regimes. The Drift Flux Model (DFM) (Zuber and Findlay, 1965; Wallis, 1969) has been found useful for the correlation of gas holdup in gasnon-Newtonian liquid two-phase flow (Chhabra et al., 1984; Welsh et al., 1999). The gas holdup data for these flow regimes were therefore correlated using DFM, according to which:

$$
\bar{\varepsilon}=\frac{U_{G S}}{C_{0}\left(U_{G S}+U_{L S}\right)+V_{G J}}
$$

Correlations of the data representing the plug, churn-turbulent and slug flow regimes, in various combinations, was attempted. The DFM parameters are generally dependent on the liquid properties (Chhabra et al., 1984). The DFM parameters were thus found to be sensitive to consistency, and since only three consistencies were used in the experiments, separate correlations were attempted for each consistency. Excluding separate correlation parameters for each of the flow patterns (which would provide the most accurate correlations, at the expense of the largest number of empirically-adjusted parameters), the following was found to be the most reasonable combination. For each pulp consistency, the plug and churn flow regimes could be combined into one group, and represented by a single set of $C_{0}$ and $V_{G J}$ values. This can be interpreted to imply that the aforementioned regimes are similar, at least with respect to their phase velocity slip characteristics. The slug flow regime, however, was noticeably different from the other regimes, and was therefore correlated separately. A similar distinction between slug flow and other regimes is also common for non-fibrous slurries (Chhabra et al., 1984). Values of $C_{0}$ and $V_{G J}$ found in this way are summarized in Table 1.1, where the mean and standard deviation of the following statistic are also provided:

$$
\zeta=\left|1-\frac{\bar{\varepsilon}_{\text {model }}}{\bar{\varepsilon}_{\text {exp }}}\right|
$$

Figs. 1.9 and 1.10 compare the experimental and predicted gas holdups

\subsection{Concluding Remarks}

The hydrodynamics of co-current gas-aqueous pulp slurry mixtures in a vertical column were experimentally investigated. The column was $1.80 \mathrm{~m}$ in height, and $5.08 \mathrm{~cm}$ in diameter. Pulp consistencies in the $0 \sim 1.5 \%$ were studied. Flow regimes were identified visually, and by flash X-ray photography. Bubble characteristics were also studied using the latter technique. Gamma-ray densitometry was applied for the measurement of gas holdup. Air and pulp-water slurry superficial velocities covered the $0 \sim 26 \mathrm{~cm} / \mathrm{s}$ and $21 \sim 51 \mathrm{~cm} / \mathrm{s}$ ranges, respectively. Mixing 
prior to the inlet to the test section was achieved using a hydrosonic pump, a patented device that can produce mixtures of slurry and finely dispersed micro-bubbles.

Five distinct flow regimes could be identified, including dispersed bubbly, layered bubbly, (incipient plug and) plug, churn-turbulent, and slug. Bubbly flow occurred only at very low liquidpulp slurry superficial velocities. The flow regime transition lines were sensitive to consistency.

Cross section-average gas holdup agreed with the predictions of homogeneous flow model for bubbly and layered bubbly regimes. The Drift Flux Model (DFM) could be applied to other regimes, when plug and churn-turbulent regimes were treated together, and slug flow was treated separately. The drift flux parameters were functions of consistency, however. 


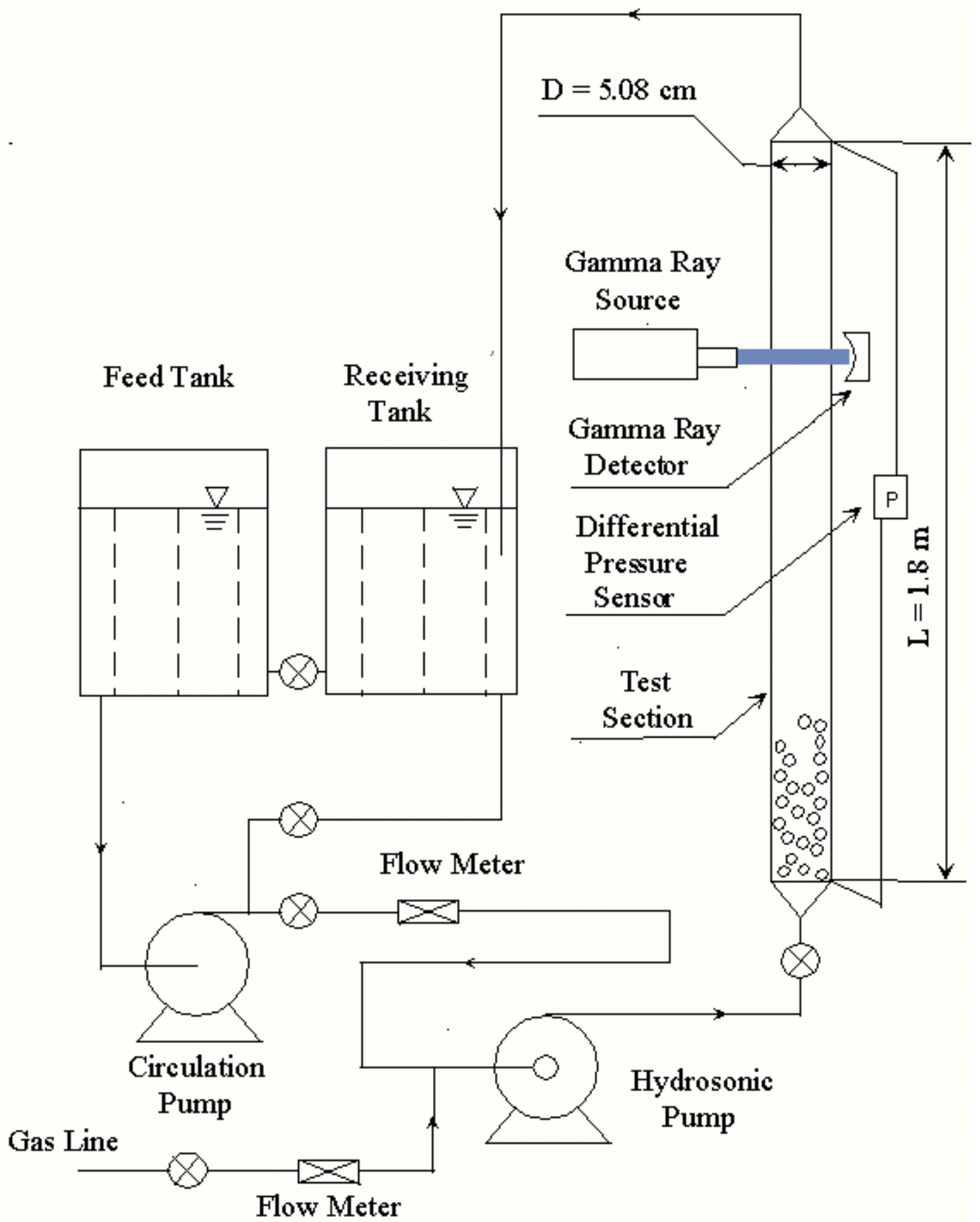

Figure 1.1: Schematic of the test loop 


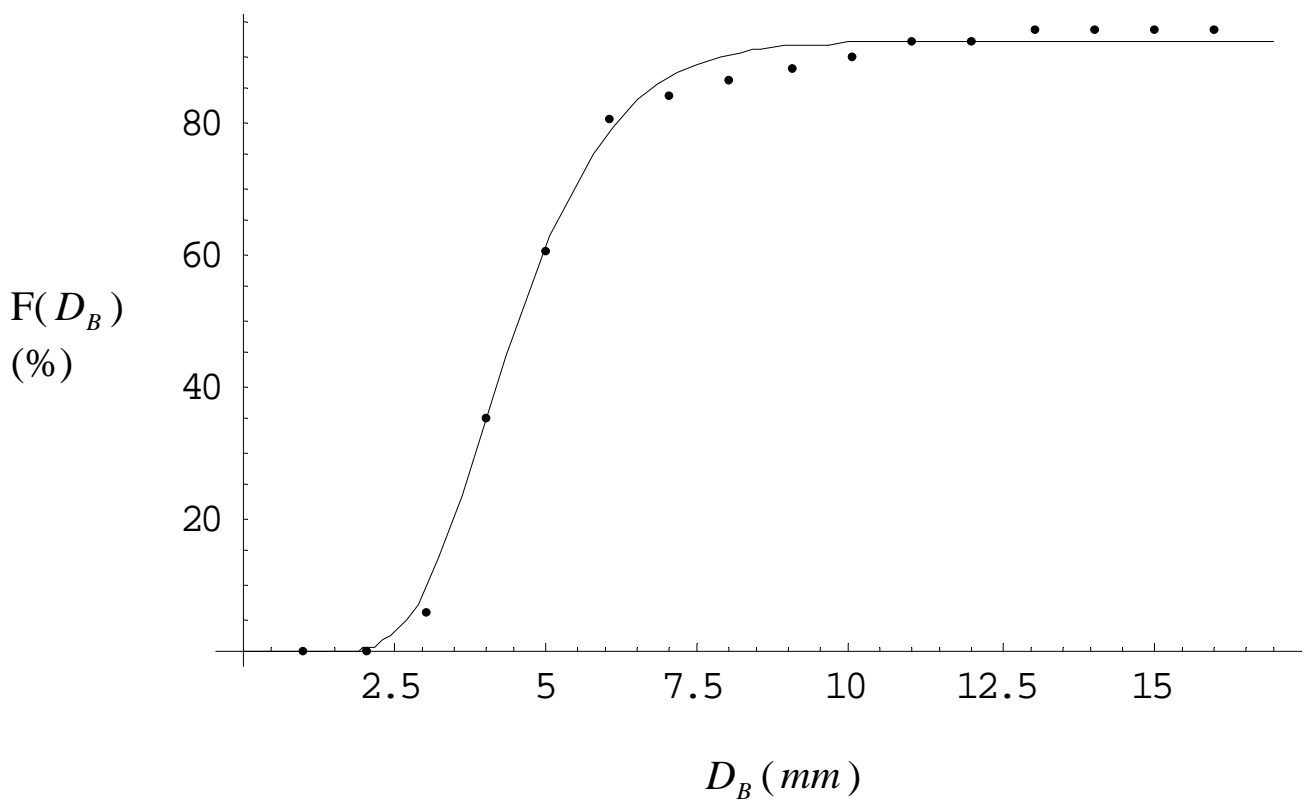

(a)

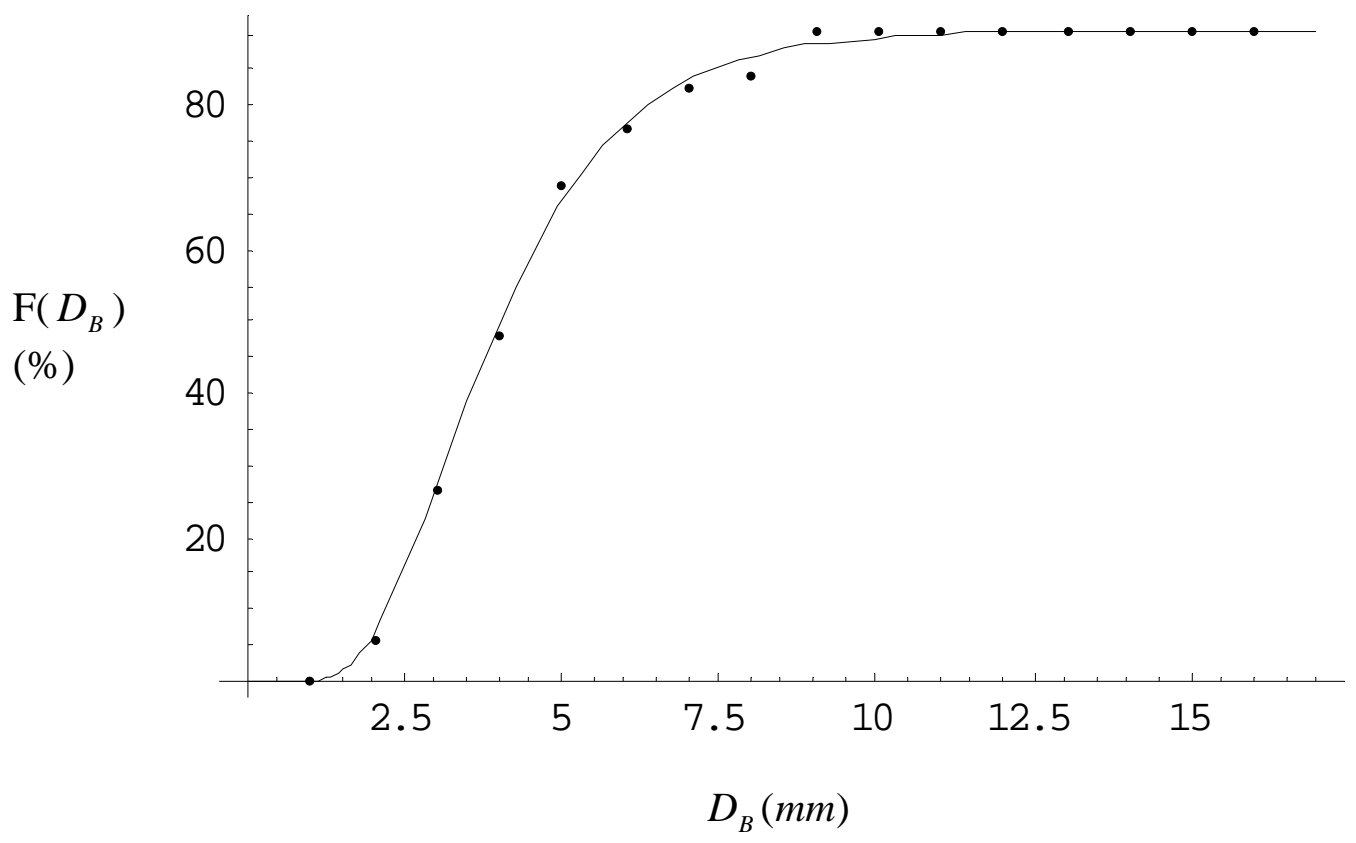

(b)

Figure 1.2: Typical bubble size distributions at $140 \mathrm{~cm}$ height, obtained by X-ray flash photography and image analysis (Rezak et al., 2002): (a) at 1.0\% pulp consistency, superficial gas velocity is $15 \mathrm{~cm} / \mathrm{sec}$; (b) at 2.0\% pulp consistency, superficial gas velocity is $15 \mathrm{~cm} / \mathrm{sec}$. (Axis X: bubble size (mm), Axis Y: cumulative distribution of the number of bubbles (\%).) 


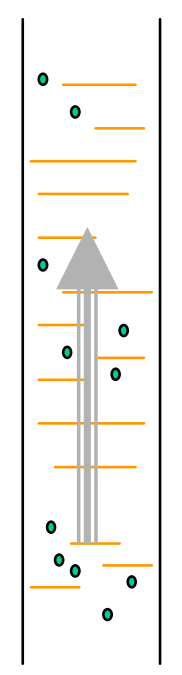

(a)

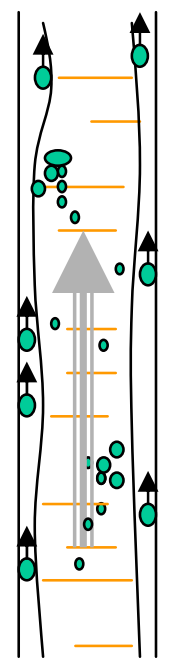

(b)

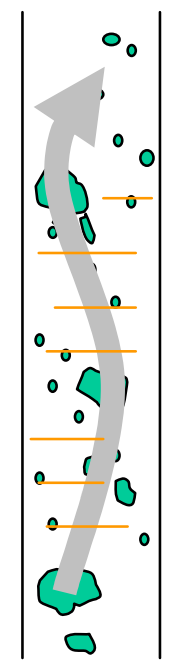

(c)

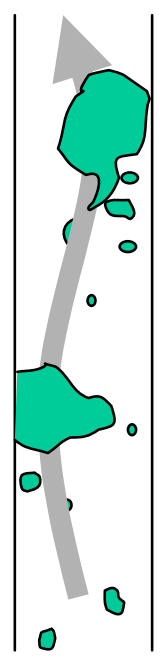

(d)

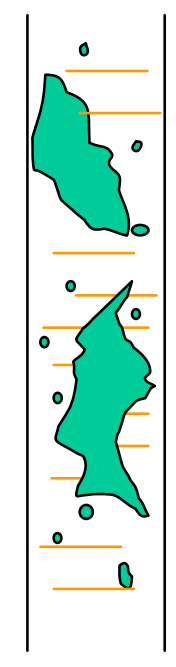

(e)

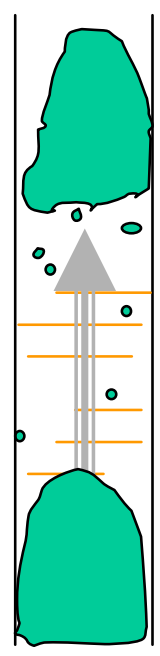

(f)

Figure 1.3: Schematic of the flow regimes: (a) Dispersed bubbly flow; (b) Layered bubbly flow; (c) Incipient Plug flow; (d) Plug flow; (e) Churn-Turbulent flow; (f) Slug flow. 


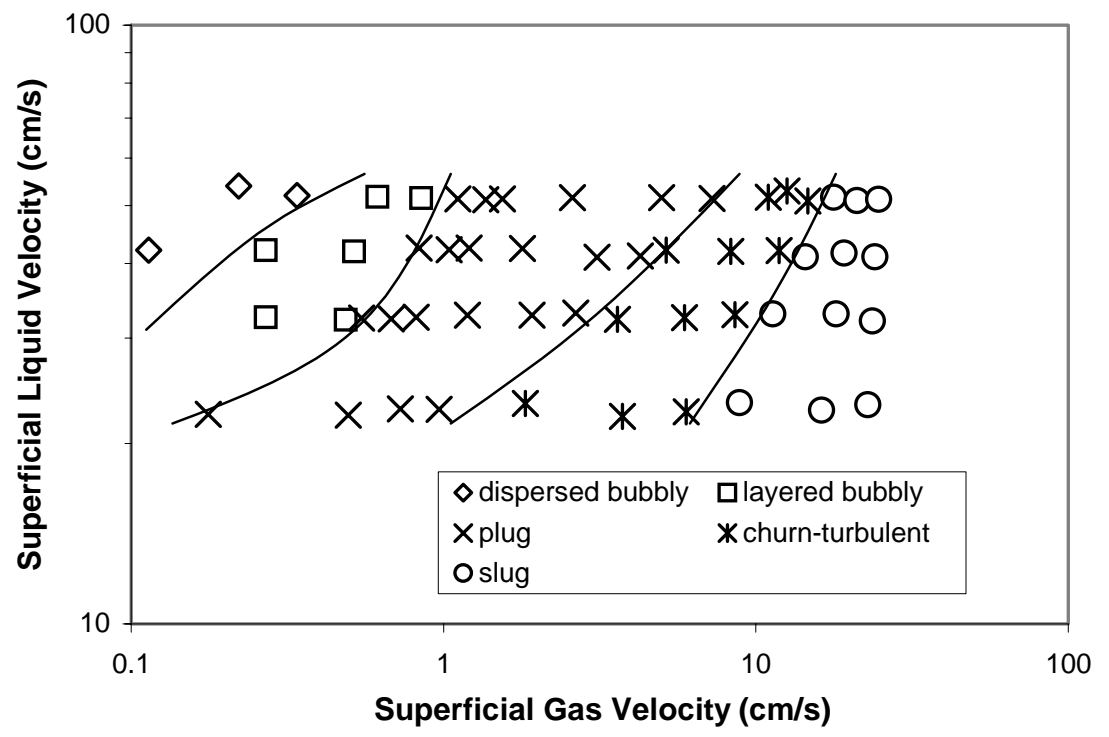

(a)

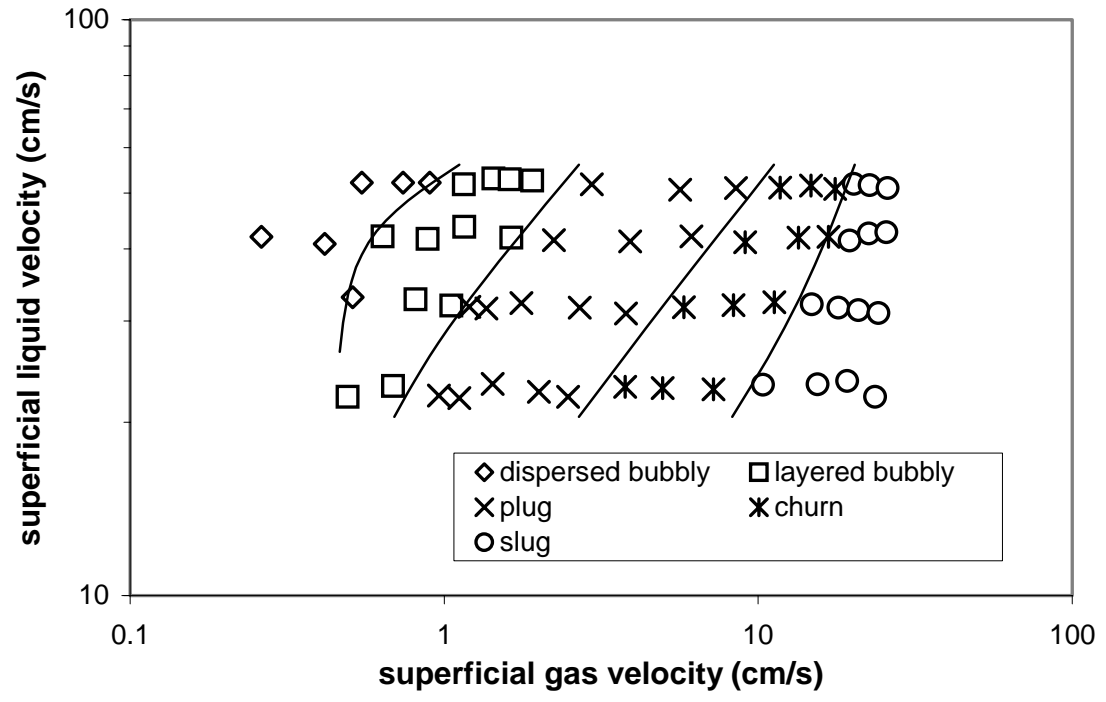

(b) 


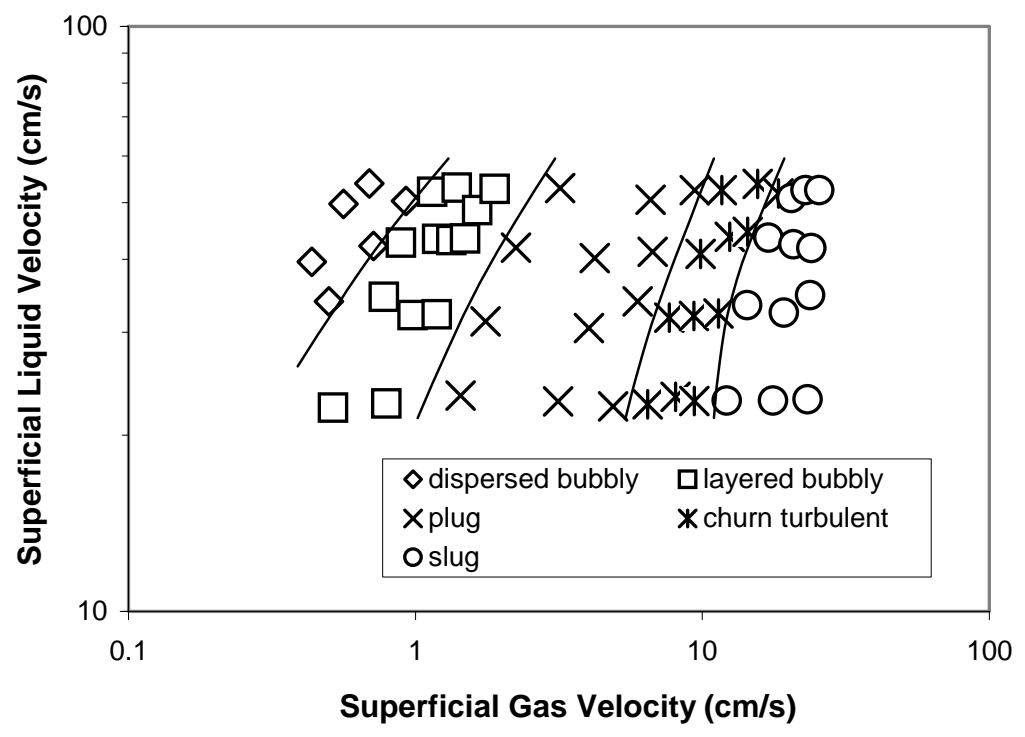

(c)

Figure 1.4: Flow regime maps: (a) pulp consistency = 0.5\%; (b) pulp consistency =1.0\%; (c) pulp consistency $=1.5 \%$. Logarithmic scales are used on each axis, which results in nearly linear transition boundaries. 


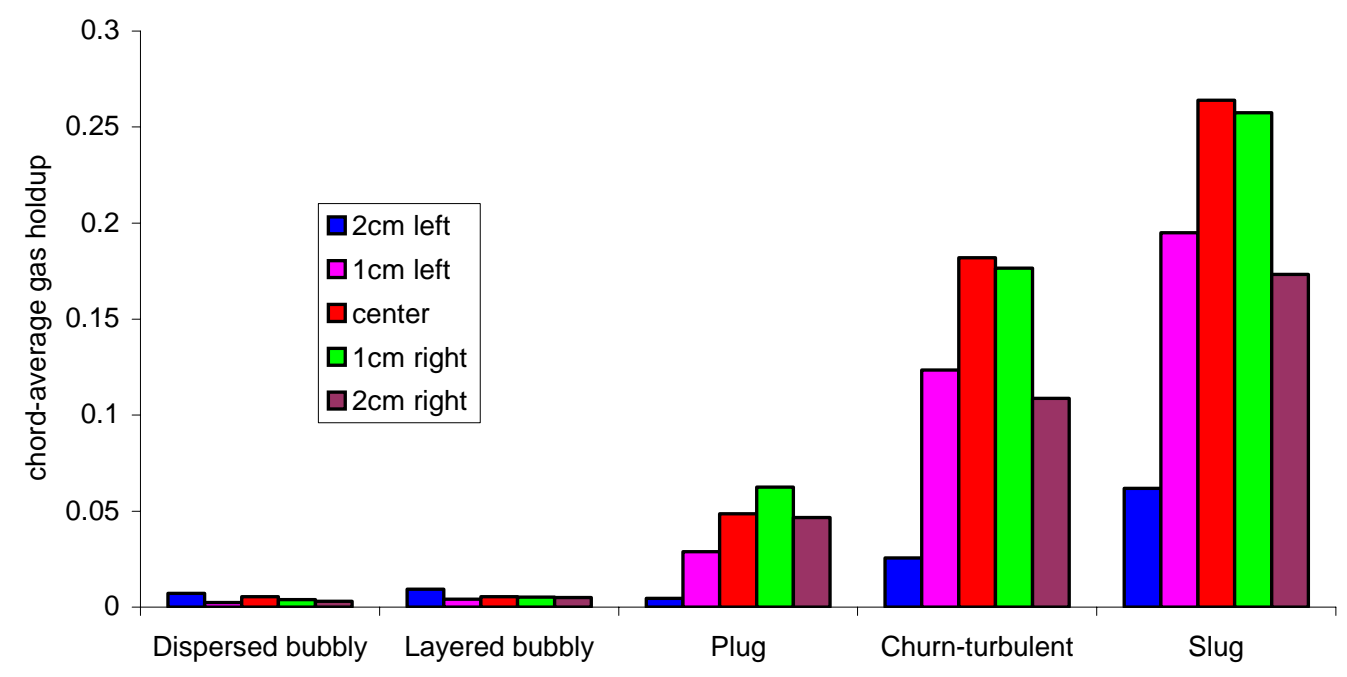

(a)

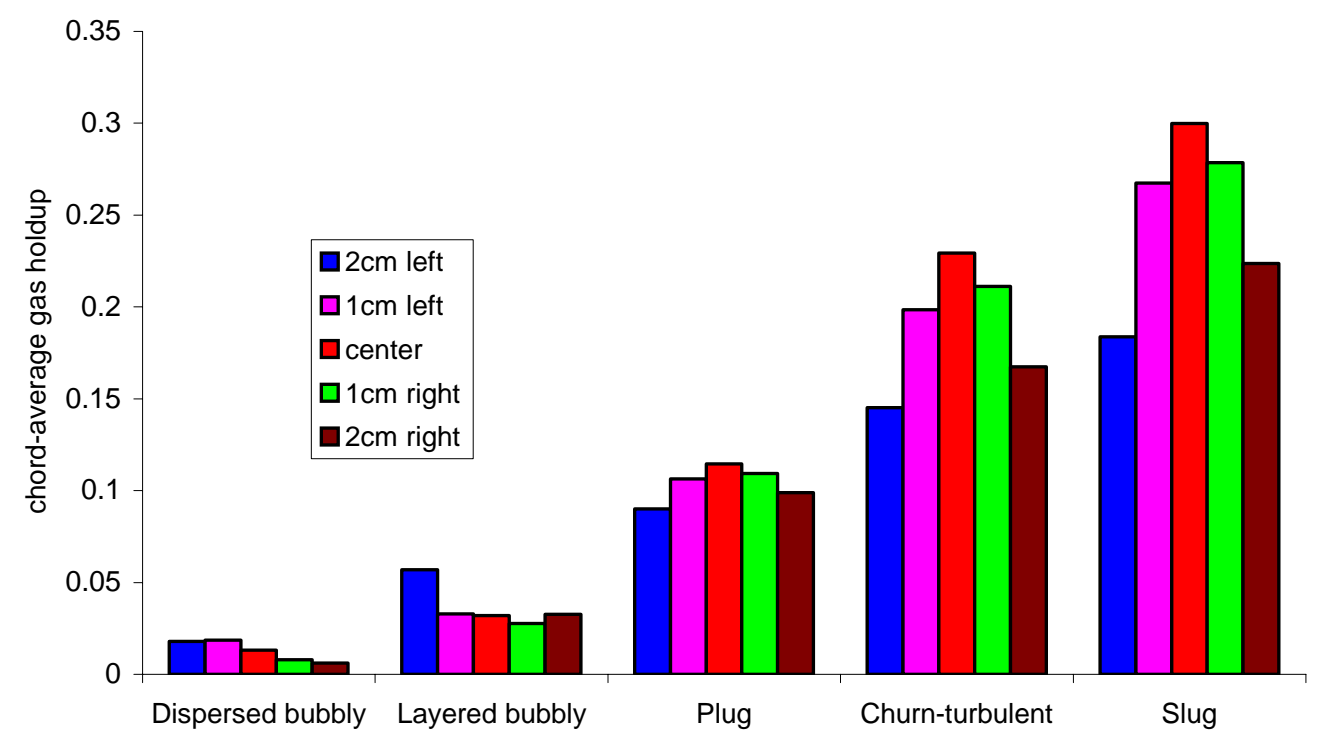

(b)

Figure 1.5: Typical chord-average gas holdup profiles: (a) for $0.5 \%$ consistency; (b) for $1.5 \%$ consistency. The non-symmetry of these profiles is significant relative to the measurement accuracy, and is an indication of non-symmetry of the entry flow into the cylindrically symmetric vertical bubble column. 


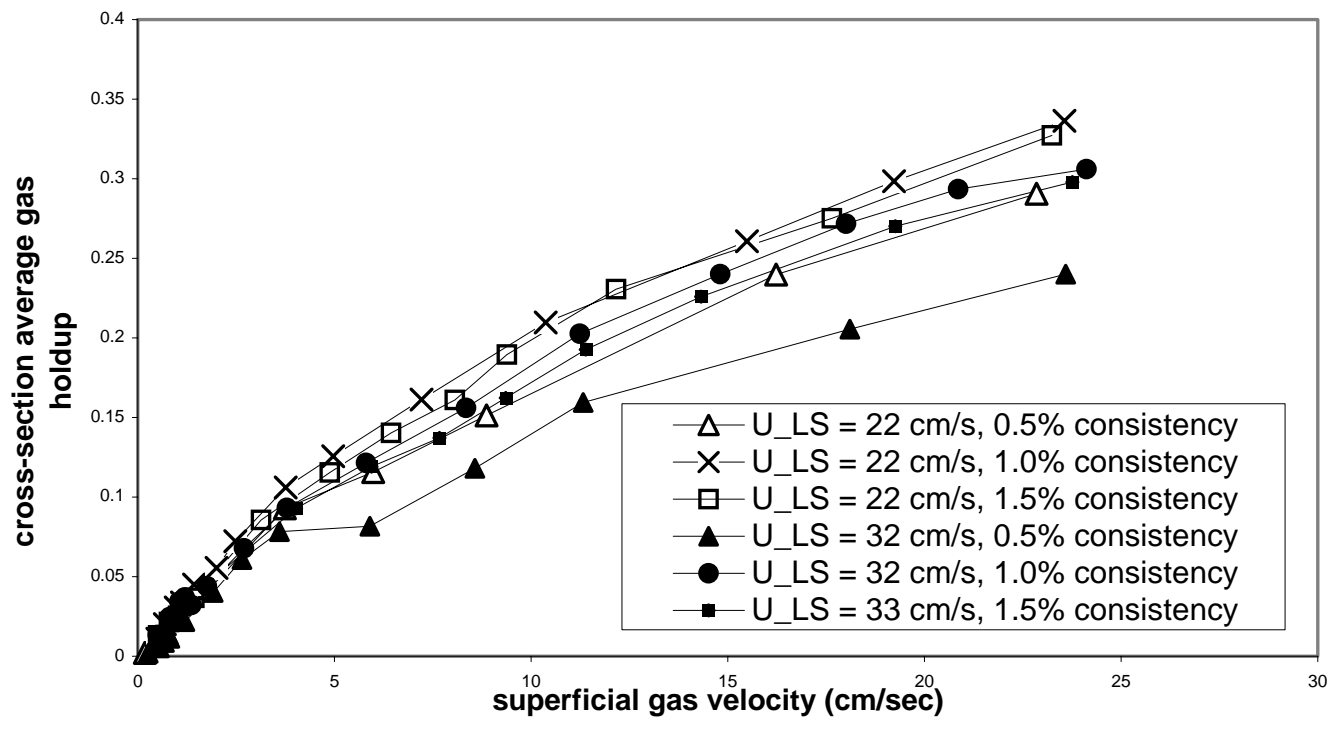

Figure 1.6: Cross-section average gas holdups

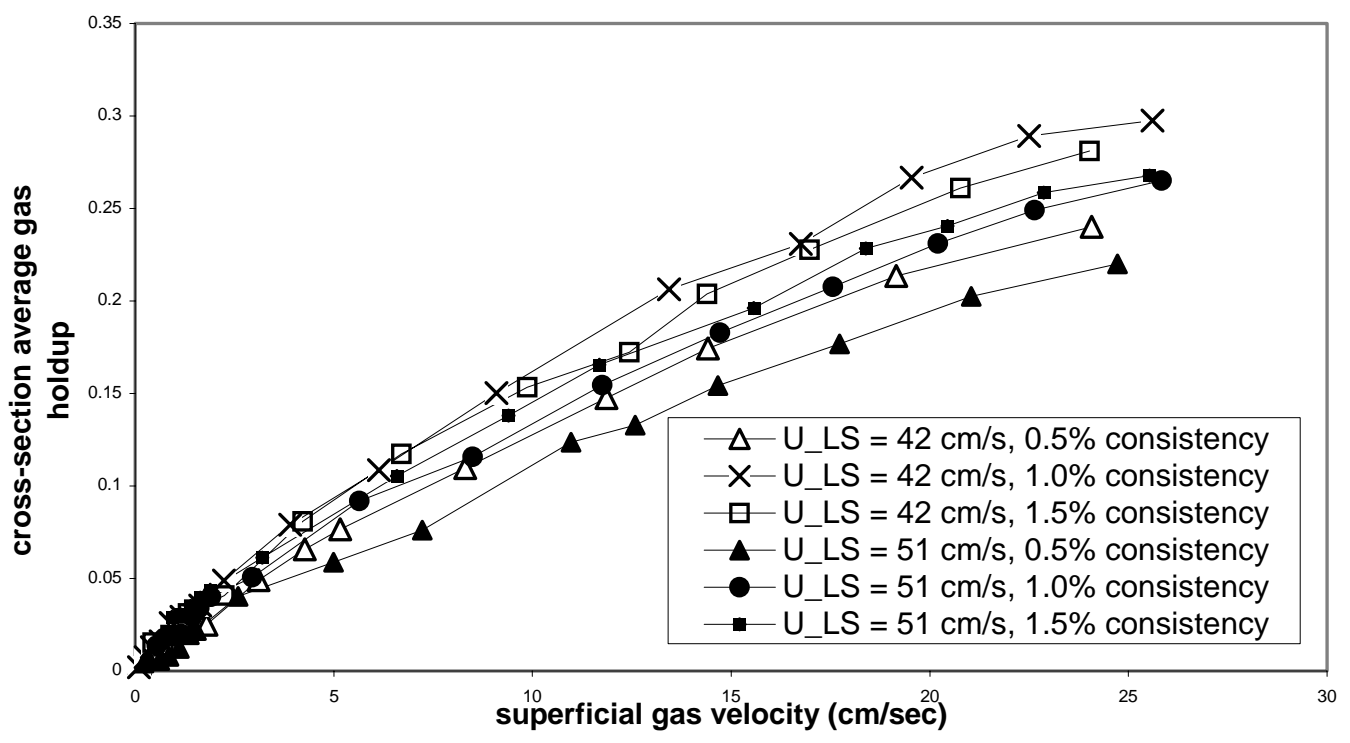

Figure 1.7: Cross-section average gas holdups 


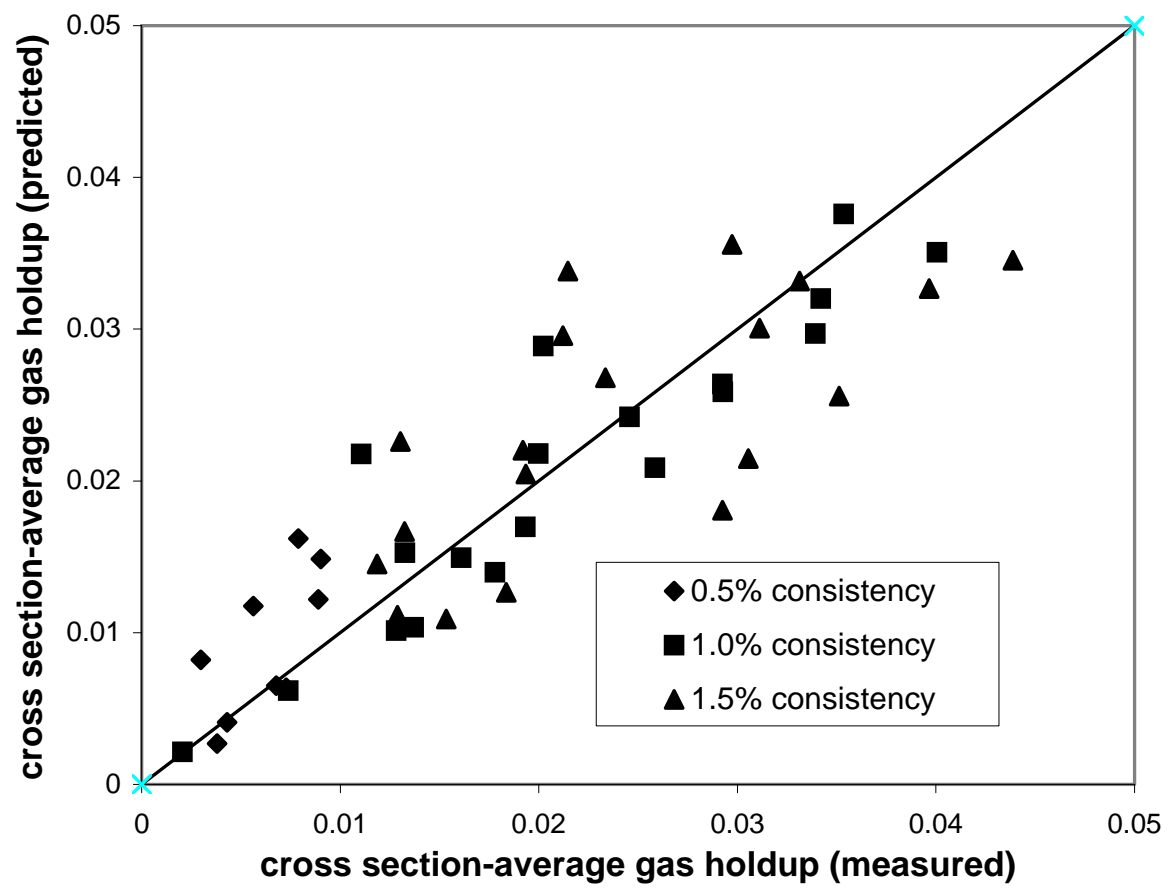

Figure 1.8: Comparison of gas holdups in dispersed bubbly and layered bubbly regimes with the predictions of homogeneous flow model 


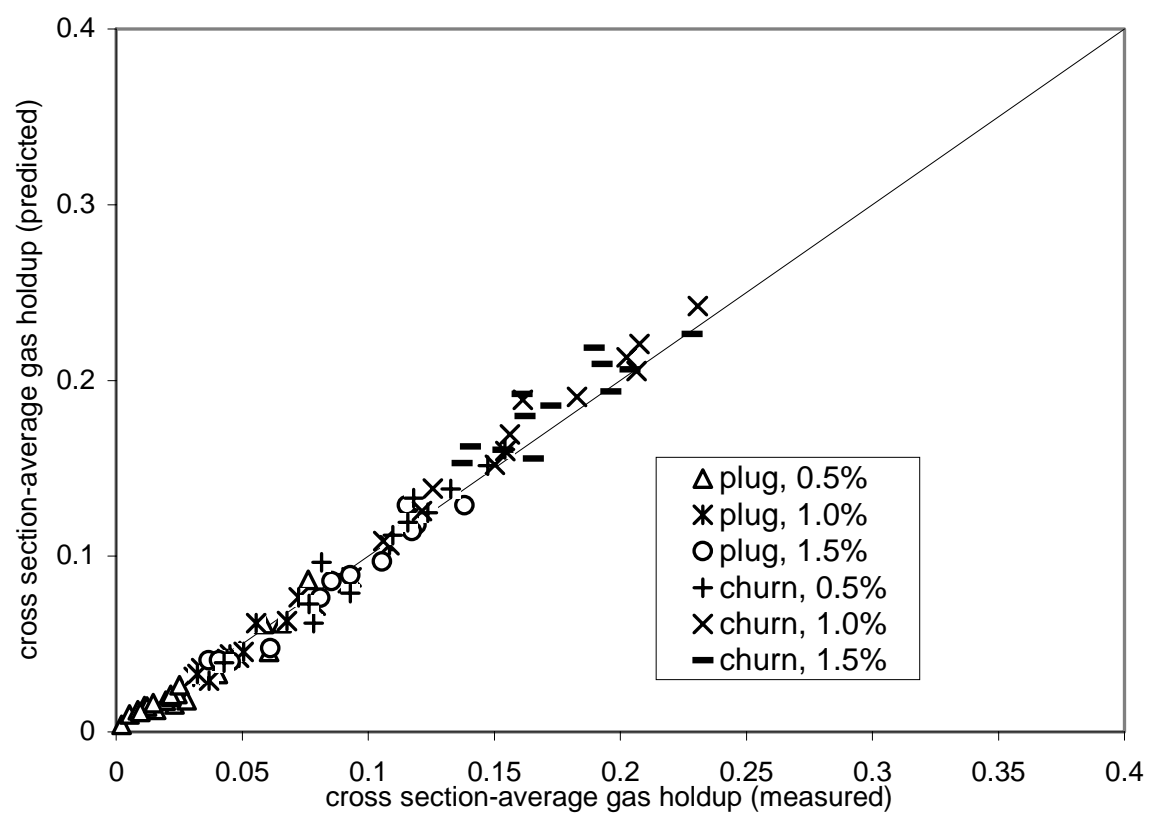

Figure 1.9: Comparison of gas holdups with the drift flux model predictions for plug and churn flow regimes

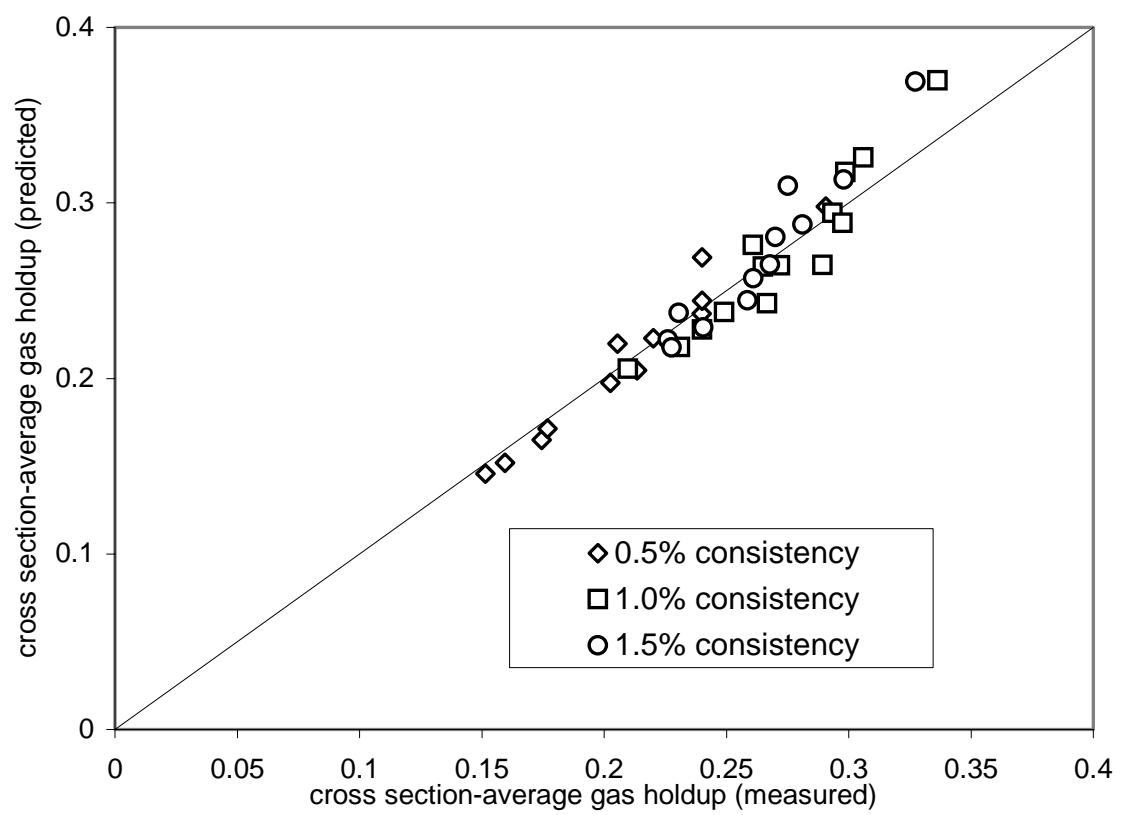

Figure 1.10: Comparison of gas holdups with the drift flux model predictions for slug flow regime

Table 1.1: Drift Flux Model parameter values 


\begin{tabular}{c|c|c|c|c|c}
\hline Regime & $\begin{array}{c}\text { Consistency } \\
(\%)\end{array}$ & $C_{0}$ & $\begin{array}{c}V_{G J} \\
(\mathrm{~cm} / \mathrm{s})\end{array}$ & $\begin{array}{c}\bar{\zeta} \\
(\%)\end{array}$ & $\sigma_{\zeta}$ \\
\hline \multirow{2}{*}{ Bubbly- } & 0.5 & 1.11 & 18.5 & 17.9 & 20.8 \\
Plug/Plug/Churn & 1.0 & 1.08 & 5.7 & 6.7 & 4.8 \\
& 1.5 & 1.01 & 10.3 & 7.8 & 6.2 \\
\hline \multirow{2}{*}{ Slug } & 0.5 & 1.15 & 23.7 & 4.1 & 3.0 \\
& 1.0 & 1.10 & 13.5 & 5.0 & 3.0 \\
& 1.5 & 1.05 & 14.4 & 4.9 & 3.9
\end{tabular}




\subsection{References for Chapter 1}

Bennington, C. P. J., Azevedo, G., John, D. A., Birt, S. M., and Wolgast, B. H. (1995). The yieldstress of medium- and high-consistency mechanical pulp fiber suspensions at high gas contents, J. Pulp Paper Science, 21, 111-118.

Bennington, C. P. J., Kerekes, R. J., and Grace, J. R. (1989). Mixing in pulp bleaching, J. Pulp Paper Science, 15, 186-195.

Bennington, C. P. J., Owusu, G., and Francis, D. W. (1997). Gas-liquid mass transfer in pulp suspension mixing operations, Can. J. Chem. Eng., 75, 53-61.

Bin, A. K., Duczmal, B., and Machniewski, P. (2001). Hydrodynamics and ozone mass transfer in a tall bubble column, Chem. Eng. Sci., 56, 6233-6240.

Bishop, A. A., and Deshpande, S. D. (1986a). Non-Newtonian liquid-air stratified flow through horizontal tubes - I, Int. J. Multiphase Flow, 12, 957-975.

Bishop, A. A., and Deshpande, S. D. (1986b). Non-Newtonian liquid-air stratified flow through horizontal tubes - II, Int. J. Multiphase Flow, 12, 977-996.

Bose, F., Ghiaasiaan, S. M., Heindel, J. T. (1997). Hydrodynamics of dispersed liquid droplets in agitated synthetic fibrous slurries, Ind. Eng. Chem. Res., 36, 5028-5036.

Cai, S., Toral, H., Qiu, J., and Archer, J. S. (1994). Neural network based objective flow regime identification in air-water two-phase flow, Can. J. Chem. Eng., 72, 440-445.

Cai, Y., Wambsganss, M. W., and Jendrzejczyk, J. A. (1996). Application of chaos theory in identification of two-phase flow patterns and transitions in a small, horizontal, rectangular channel, J. Fluids Eng., 118, 383-390.

Carew, P. S., Thomas, N. H., and Johnson, A. B. (1995). A physically based correlation for the effects of power law rheology and inclination on slug bubble rise velocity, Int. J. Multiphase Flow, 21, 1091-1106.

Chhabra, R. P., Farooqi, S. I., and Richardson, J. F. (1984). Isothermal two-phase flow of air and aqueous polymer solutions in a smooth horizontal pipe, Trans. Inst. Chem. Eng., 62, 22-32.

Collier, J. G., and Thome, J. R. (1994). Convective boiling and two-phase flow, $3^{\text {rd }}$ Ed., Oxford University Press, U. K.

Das, S. K., Biswas, M. N., and Mitra, A. K. (1989). Pressure losses in two-phase gas-nonNewtonian liquid flow in a horizontal tube, J. Pipelines, 7, 307-325.

Das, S. K., Biswas, M. N., and Mitra, A. K. (1991). Friction factor for gas-non-Newtonian liquid flow in horizontal bends, Can. J. Chem. Eng., 60, 179-187.

Deckwer, W. D. (1985). Bubble column reactors, John Wiley and Sons, New York. 
Dence, C. W. and Reeve, D. W., editors (1996). Pulp bleaching: principles and practice, TAPPI Press, Atlanta, GA.

Duffy, G. G., Lee, P. F. W. (1978). Drag reduction in the turbulent flow of wood pulp suspensions, Appita, 31, 280-286.

Duffy, G. G., Titchener, A. L. (1975). The disruption shear stress of pulp networks, Svensk Papperslidn, 13, 474-479.

Duffy, G. G., Titchener, A. L., Lee, P. F. W., Moller, K. (1976). The mechanism of flow of pulp suspensions in pipes, Appita, 29, 363-370.

Farooqi, S. I., and Richardson, J. F. (1982a). Horizontal flow of air and liquid (Newtonian and non-Newtonian) in a smooth pipe. Part I: A correlation for average liquid holdup, Trans. Inst. Chem. Eng., 60, 292-305.

Farooqi, S. I., and Richardson, J. F. (1982b). Horizontal flow of air and liquid (Newtonian and non-Newtonian) in a smooth pipe. Part II: Average pressure drop, Trans. Inst. Chem. Eng., 60, 323-333.

Garner, A.E., and Heindel, T.J. (2000). The effect of fiber type on bubble size. J. Pulp Paper Sci., 26, 266-269.

Heindel, T.J. (1999). Bubble size measurement in a quiescent fiber suspension. J. Pulp Paper Sci., 25, 104-110.

Heindel, T.J., and Garner, A.E. (1999). The effect of fiber consistency on bubble size. Nord. Pulp Paper Res. J., 14, 171-178.

Hewitt, G. F. (1978). Measurement of two phase flow parameters, Academic Press: New York.

Honan, T. J., Lahey, R. T. (1978). The measurement of phase separation in wyes and tees, U.S. Nuclear Regulatory Commission Rep. NUREG/CR-0557.

Hydrosonic pump operation manual, Hydrodynamics Inc., Rome, GA 30165.

Johnson, A. B., and White, D. B. (1993). Experimental determination of gas migration velocities with non-Newtonian fluids, Int. J. Multiphase Flow, 19, 921-941.

Lee, P. F. W., Duffy, G. G. (1976). Relationships between velocity profiles and drag reduction in turbulence fiber suspension flow, AICHE J., 22, 750-753.

Lin, P. Y., and Hanratty, T. J. (1986). Detection of slug flow regimes in vertical two-phase flow using differential pressure fluctuations, Nucl. Eng. Design, 95, 221-231.

Lindsay, J. D., Ghiaasiaan, S. M., and Abdel-Khalik, S. I. (1995). Macroscopic flow structures in a bubbling paper pulp-water slurry, Ind. Eng. Chem. Research, 34, 3342-3354. 
Luo, D., and Ghiaasiaan, S. M. (1997). Liquid-side interphase mass transfer in cocurrent vertical two-phase channel flows, Int. J. Heat Mass Transfer, 40, 641-655.

Lyczkowski, R. W., and Wang, C. S. (1992). Hydrodynamic modeling and analysis of two-phase non-Newtonian coal/water slurries, Powder Technology, 69, 285-294.

Mahalingan, R., and Valle, M. A. (1972). Momentum transfer in two-phase flow of gaspseudoplastic liquid mixtures, Ind. Eng. Chem. Fundam., 11, 470-477.

Matsumi, G. (1984). Identification of flow regimes in vertical gas-liquid two-phase flow using differential pressure fluctuations”, Int. J. Multiphase Flow, 10, 711-720.

Mi, Y., Ishii, M., and Tsoukalas, L. H. (1998). Vertical two-phase flow identification using advanced instrumentation and neural networks, Nuclear Eng. Design, 184, 409-420.

Oliver, D. R., and Young Hoon, A. (1968). Two-phase non-Newtonian flow. Part I: Pressure drop and gas hold-up, Trans. Inst. Chem. Eng., 46, 106-115.

Pelton, R., and Piette, R. (1992). Air bubble hold-up in quiescent wood pulp suspensions, Can. J. Chem. Eng., 70, 660-663.

Reese, J., Jiang, P. and Fan, L. -S. (1996). Bubble characteristics in three-phase systems used for pulp and paper processing, Chem. Eng. Sci., 51, 2501-2510.

Reith, T., and Beck, W. J. (1973). The oxidation of aqueous sodium sulphite solutions, Chem. Eng. Sci., 28, 1331-1339.

Rewatkar, V. B., and Bennington, C. P. J. (2000). Gas-liquid mass transfer in low- and mediumconsistency pulp suspensions, Can. J. Chem. Eng., 78, 504-512.

Rezak, S. (2002). Neural network system control for modeling the effect of operating parameters on bubble size distribution and its dynamic, Master Thesis, Institute of Paper Science and Technology, Atlanta, GA.

Rutkowski, J. (1997). Environmentally friendly pulp bleaching technologies, Cellulose Chem. Technol., 31, 485-497.

Smook, G. A. (1992). Handbook for pulp \& paper technologists, $2^{\text {nd }}$ Ed., Angus Wilde Publications, Vancouver, British Columbia.

Taitel, Y., Bornea, D., and Dukler, A. E. (1980). Modeling flow pattern transitions for steady upward gas-liquid flow in vertical tubes, AICHE J., 26, 345-354.

Thibault, J., Leduy, A., and Denis, A. (1990). Chemical enhancement in the determination of $K_{L} a$ by the sulfite oxidation method, Can. J. Chem. Eng., 68, 324-326. 
Vince, A. M., Fincke, J. R. (1983). The relationship between density and void fraction measurement uncertainty in radiation densitometry, Int. J. Multiphase Flow, 9, 447-449.

Wallis, G. B. (1969). One-dimensional two-phase flow, McGraw-Hill, New York.

Walmsley, M. R. W. (1992). Air bubble motion in wood pulp fiber suspension, Appita J., 45, 509515.

Wambsganss, M. W., Jendrzejczyk, J. A., and France, D. M. (1994) Determination and characteristics of the transition to two-phase slug flow in small horizontal channels, $J$. Fluids Eng., 116, 140-146.

Welsh, S. A., Ghiaasiaan, S. M., and Abdel-Khalik, S. I. (1999). Countercurrent gas-pseudoplastic liquid two-phase flow, Ind. Chem. Eng. Res., 38, 1083-1093.

Zuber, N., and Findlay, J. A. (1965). Average volumetric concentration in two-phase flow systems, J. Heat Transfer, Ser. C., 87, 453-468. 
Chapter 2: Flow Regime Identification Based on Pressure Fluctuations using Artificial Neural Networks 


\section{Notation}

$\begin{array}{cl}d & \text { Discrete time shift } \\ j & \text { Pressure time series coordinate } \\ T & \text { Correlation term } \\ U_{G S} & \text { Superficial gas velocity }(\mathrm{cm} / \mathrm{s}) \\ U_{L S} & \text { Superficial pulp-water mixture velocity }(\mathrm{cm} / \mathrm{s}) \\ p & \text { Pressure }(\mathrm{Pa}) \\ p^{*} & \text { Normalized pressure signal } \\ \tau & \text { Time shift }(\mathrm{s})\end{array}$

\section{Superscript}

Time average 


\subsection{Introduction}

Gas-liquid-pulp fiber slurry three-phase flows occur in a number of systems in paper making and recycling, including flotation deinking, delignification and bleaching ${ }^{1}$. In some of these systems, e.g., during bleaching and delignification, the objective is to promote mass transfer between the gas and liquid-pulp mixture, often accompanied by chemical reactions. In others, e.g., flotation deinking, microparticle contaminants initially attached to the fibers are picked up by small gas bubbles. Efficient operation of these systems depends on the degree of mixing, and the hydrodynamic characteristics of the flow patterns they support. Good understanding of the hydrodynamic behavior of the gas-liquid-fiber three-phase flow systems is essential for the design and operation of those systems. Furthermore, on-line, minimum-intrusive monitoring of flow regimes in these systems, using simple and rugged instruments, can be valuable for their diagnostics and control.

Gas-liquid-pulp mixtures exhibit hydrodynamics that are much more complex than what is observed in typical gas-non-Newtonian liquid two-phase flows. Pulp fibers in an aqueous suspension swell by absorbing water, and in the simplest interpretation a pulp-water mixture can be considered a yield-pseudoplastic fluid ${ }^{2-4}$, acting as a solid when shear stress is below some threshold, and as a non-Newtonian liquid otherwise. Flocculation (entanglement of fiber groups to conformations that possess mechanical strength, usually called flocs) is the main cause for the complexity in pulp slurries as well as in gas-liquid-pulp three-phase flow systems, and can be observed at consistencies (weight fractions of dry pulp in the water-pulp mixture) as low as $0.5 \%$. At consistencies higher than about 1\%, three-dimensional networks of pulp form in the mixture ${ }^{5}$ that can be broken down by high shear only, they can trap small bubbles ${ }^{6}$, and often they lead to the channeling phenomenon in flotation devices whereby the gas preferentially flows through inter-floc passages ${ }^{7}$. The size and strength of flocs increase as consistency is increased. Flocculation (facilitated by the high aspect ratio of fibers) thus renders gas-liquid-pulp systems drastically different in their behavior compared with other gas-solid-liquid three-phase systems, as well as non-Newtonian liquid-gas two-phase flows. Some rather complicated flow regimes are induced, even in uniformly aerated bubble columns. Basically, hydrodynamic and kinematic mechanisms vary with different flow regimes. For design and modeling of bubble columns, therefore it is of great interest to identify the flow regimes or flow patterns. In many engineering problems, it is imperative to have an objective and quantitative instrumentation-based indicator of flow regime. 
Attempts at the identification of flow patterns using a combination of subjective judgments and objective methods have been made in the past. For gas-liquid-solid fluidized beds, the statistical properties of the wall pressure fluctuations ${ }^{8}$, and the characteristics of bubbles measured by a two-element conductivity probe ${ }^{9}$, have been used for objective flow regime identification. In laboratory investigations, subjective judgments are usually made by visual observation of flow. This is not a realistic option when the bubble column is filled with opaque fluids, such as pulp suspension. Furthermore, hydrodynamic parameters, which are usually needed in order to use as input for flow regime maps and regime transition models, such as liquid and gas superficial velocities and void fraction ${ }^{10-12}$, are not measurable during most on-line operations. Objective methods of observation with opaque liquids include radiation-based techniques and use of other types of sensors. Radiation absorption techniques, such as the X-ray and gamma ray absorption methods (either used for imaging or to provide a time-sequence signal), can provide reliable measurements of void fraction fluctuation and have been studied ${ }^{7,13-14}$. However, due to safety and economic considerations, these radiation techniques are not preferred in industrial applications. While ultrasound measurements appear suited for opaque particle slurries, they may be rendered useless by large bubbles and high void fractions in multiphase flow. On the other hand, the patterns of cross-sectional average electric capacitance of the flow field ${ }^{15,16}$ and the variations and fluctuations of local absolute and differential pressures ${ }^{17-23}$, for example, have been found to be strongly regime-dependent. While the temperature effect when using the impedance technique still needs to be overcome ${ }^{24}$, the pressure fluctuations that result from the passage of gas and liquid pockets, and their statistical characteristics, are particularly attractive because the required sensors are robust, inexpensive, and relatively well-developed, and are thus more likely to be applied in the industrial systems ${ }^{25}$.

To avoid subjective judgment, artificial neural network (ANN) modeling and statistical analysis methods have been employed to implement non-linear mappings from measurable physical parameters to flow regimes ${ }^{16,24,26}$. Artificial neural networks are analytical tools that imitate the neural aspect of the human brain, whereby learning is based on experience and repetition rather than the application of rule-based principles and formulas. An ANN (in its most typical form, so-called feed-forward network) consists of a layered network of neurons (nodes), with each neuron connected to a large number of others. The input signal to the network is passed among the neurons, with each neuron calculating its own output using weighting associated with connections. Learning is achieved by the adjustment of the weights associated with inter-neuron connections. ANNs provide capabilities such as learning, self-organization, generalization 
(response to new problems using incomplete information), and training; and are excellent for pattern recognition and trend prediction for processes that are highly nonlinear, poorly-understood, and/or too complex for accurate first-principle mathematical modeling. They are thus ideal for application in multiphase flow systems, and when properly designed and trained, can be used for on-line monitoring and diagnostics.

Although the application of neural networks to multiphase flow problems has started only

recently, the published studies have clearly demonstrated their enormous potential. Mi et al. ${ }^{16,24}$ applied a neural network for two-phase flow regime identification in a vertical channel using signals from electric capacitance probes with excellent results. Gupta et al. ${ }^{27}$ successfully applied a hybrid method based on four neural networks along with simple first-principle models (the latter intended to render the model independent of specific device geometry), for prediction of the attachment rate constant in flotation columns.

In this chapter we use the results of a detailed experimental investigation of the flow patterns in gas-water-pulp three-phase flows in a vertical, upward column, with gas and pulpwater slurry through-flows, and develop a neural network-based methodology to conduct flow regime identification using the statistical characteristics from dynamic pressure signals obtained with a single pressure sensor. The results are encouraging and suggest the applicability of this approach to industrial systems, to provide an objective flow regime indicator.

\subsection{Experiments}

The experimental test loop used in this study has been described in detail in Chapter 1 , as well as in Xie et al. ${ }^{28}$, and will be reviewed here briefly. A schematic of the experimental facility is shown in Figure 2.1. The main components of the loop include a feed tank, a receiving tank, a re-circulation pump, a Hydrosonic pump (also known as a Shock Pulse Generator or SPG), and the test section. Pulp of the proper consistency is first loaded into the feed tank and the receiving tank, both $0.144 \mathrm{~m}^{3}$ in volume. The pulp used in this study was washed, unbleached Kraft softwood. The average fiber length was measured to be $2.45 \mathrm{~mm}$. Kraft softwood pulp fibers are typically about 30 microns in diameter. Since dilute cellulose fiber suspensions have the propensity to separate when left stagnant for an extended time period, the water-fiber slurry in each tank is gently stirred by a variable speed Lightnin mixer to homogenize the slurry. The long residence time of fluid in these tanks provides for the bulk of the entrained gas to leave the system. Visual observation confirmed that there were virtually no visible bubbles near the pipe intakes in the 
tanks. Small bubbles may of course be trapped in the fiber networks and remain in the tank. The volume fraction of these entrapped bubbles is not more than a few percent even under quiescent flow conditions, however, and their effect is therefore neglected ${ }^{29,30}$. The water-fiber mixture is then circulated at a continuous basis by a 1-hp, 1725-rpm Discflo pump, and the pulp flow rates are monitored with a Krohne IFC080 Smart magnetic flow meter.

Filtered air from the building, at flow rates measured by two Top Trak flow meters, is injected into the flowing liquid in a $2.5 \mathrm{~cm}$ diameter tube prior to the Hydrosonic pump. The gasliquid-fiber mixture exiting from the column is channeled into the receiving tank, via a series of fittings.

The test section is a PVC schedule 40 pipe that is $1.80 \mathrm{~m}$ in length and has a $5.08 \mathrm{~cm}$ inner diameter. The geometric configuration of industrial systems precludes fully developed flow conditions. The unavailability of general scaling laws for multiphase flows renders the experimental simulation of prototypical systems very difficult. This experimental study is thus meant to shed light on the fundamental hydrodynamic issues associated with the multiphase flows of interest, rather than directly simulating prototypical systems. We expect that while the numerical models created may not be directly scalable or transferable, the approach that created them is transferable.

The hydrosonic pump ${ }^{31}$ is a patented mixer design that uses a proprietary technology for mechanical-to-thermal energy conversion based on shock waves, generates intimate mixing of the gas and liquid, and breaks down the gas phase into micro-bubbles.

The column is mounted on a sturdy pipe frame, and is well instrumented. Among the instruments are differential pressure transducers, a high-speed video camera, an X-ray flash photography system, and a Gamma-ray densitometer. The sealed source of the Gamma-ray densitometer and detector can be moved manually in both lateral directions via thumbscrews so that measurements can be made at various chord positions across any given cross sectional plane of the test section.

The principal objective of the experiments in this study was to record and analyze the pressure fluctuations for various flow regimes in the column. For this purpose, three piezoresistive dynamic pressure sensors (Model 8510B-2, ENDEVCO Corp.), which are designed for measurements requiring a combination of small size, high sensitivity $(10.878 \mathrm{mV} / \mathrm{kPa}$ or 150 $\mathrm{mV} / \mathrm{psi}$ ), and wideband frequency response (resonance frequency of 70,000 $\mathrm{Hz}$ ), were installed in the bubble column wall. Figure 2.2 depicts the manner the pressure sensors were installed. The nearly flush fitting was meant to minimize flow disturbance by the sensors. The pressure 
transducers have a 10-32 mounting thread, and $3.8 \mathrm{~mm}$ face diameter. Five consecutive plugged holes with a spacing of $10 \mathrm{~cm}$ were drilled into the test section, starting from $120 \mathrm{~cm}$ above the inlet of the column. Three of these five holes can be selected for installing our available three sensors. Different combinations of positions allow us to examine the effects of operating parameters on axial profiles of the basic statistical characteristics, and provide flexibility in the joint analysis of pressure fluctuations. The output signals of the pressure sensors, which are proportional to the dynamic component of pressure, are fed to a signal conditioner for $A / D$ conversion and filtering. A Labview application was programmed to control the logging frequency and collect the data.

In the experiments, tests were carried out over $21 \leq \overline{U_{L S}} \leq 51 \mathrm{~cm} / \mathrm{s}$ and $0 \leq \overline{U_{G S}} \leq 26 \mathrm{~cm} / \mathrm{s}$ superficial velocity ranges for the liquid slurry and the gas phase, respectively. Flow regimes were identified, and gas holdup values were measured in the tests following the procedures described in Xie et al. ${ }^{28}$ The typical and maximum uncertainties associated with phase superficial velocities were $\pm 3.0 \%$ and $\pm 4.5 \%$ for $\overline{U_{L S}}$; and $\pm 9.6 \%$ and $\pm 33.0 \%$ for $\overline{U_{G S}}$, respectively. In every test, the pressure fluctuations were recorded using the aforementioned dynamic pressure sensors, located at heights of $120 \mathrm{~cm}, 130 \mathrm{~cm}$, and $140 \mathrm{~cm}$ from the inlet of the bubble column. However, since flow regime identification based on a single pressure sensor was the objective, only the signals generated by the sensor located at $120 \mathrm{~cm}$ above the test section inlet are presented and analyzed here. The sampling rate was conservatively set at $100 \mathrm{~Hz}$, as prior literature suggests that the most informative pressure fluctuations in the bubble columns occur in the range from 0 to 20 $\mathrm{Hz}^{25}$. The acquisition time (run length) was 20 seconds, providing a uniformly spaced time series of 2000 points for each run condition. Typical pressure traces for each major flow regime (to be discussed shortly) are shown in Figure 2.3 (a) - (d). (Figure 2.3(a) represents the dispersed bubbly flow depicted schematically in the forthcoming Figure 2.4(a), hence the approximately uniform signal frequency.)

\subsection{Flow Regimes}

The flow regimes were identified by direct visualization with assistance of flash X-ray images and Gamma-ray densitometry. Based on visual observations six distinct flow regimes could be identified, as schematically depicted in Fig. 4. The faint large arrows in these figures display the curvilinear passage of large bubbles. A detailed description of each flow pattern can be found in Xie et al. ${ }^{28}$ However, analysis with ANNs, described in the forthcoming section, 
indicated that the flow regimes depicted in Figure 4(a), 4(b) and 4(c) had essentially similar statistical pressure fluctuation characteristics that could not be readily distinguished from one another by the neural networks, suggesting that their common basic hydrodynamic characteristics are more significant than their apparent morphological differences. Accordingly, the three flow regimes depicted in Figure 4(a), 4(b) and 4(c) will be addressed as the bubbly flow regime in the forthcoming discussions.

The experimental data points generated in this study are depicted in Figure 2.5(a), 2.5(b) and 2.5(c), for $0.5 \%, 1.0 \%$ and 1.5\% water-pulp consistencies, respectively. The data points, 200 in total number, are shown in gas and liquid/pulp mixture superficial velocity coordinates, leading to the displayed experimental flow regime transition lines.

\subsection{Neural Network Models}

As described earlier, an artificial neural network makes a good candidate as a class of algorithms to perform flow regime identification. To some extent, a neural network pattern recognition approach involves a trainable black box ${ }^{32}$. It can be trained to learn the correct output or classification for each of the training samples. After training, the neural network can interpolate (or even extrapolate) when faced with new, similarly behaving patterns ${ }^{24}$.

Supervised neural networks, which are often used as associative memories or classifiers, were developed to function as a classifier for identifying flow regimes. The principles of ANNs have been described in numerous publications, and will not be repeated here, and only the major characteristics of the design are presented. The standard deviation, coefficient of skewness, coefficient of kurtosis, and second-order correlation terms T(2), T(5), T(10), T(20), T(50), T(100), and T(200), of the normalized pressure signals are chosen to represent characteristics of pressure fluctuations, and used as input to the neural network. The commonly accepted mathematical definitions of standard deviation, skewness, and kurtosis were used. The second-order correlation terms of normalized pressure signals are:

$$
T(d)=\overline{p^{*}(t) p^{*}(t+\tau)}
$$

Where, the normalized pressure fluctuation $p^{*}$ is defined as

$$
p^{*}=(p-\bar{p}) / \sqrt{\overline{(p-\bar{p})^{2}}}
$$

The parameter $\tau$ is the time shift, and is defined as $\tau=d / N$, where $N$ represents the rate of pressure signal measurements (100 Hz in these experiments). 
The rationale for the selection of the above input parameters was as follows. We want our classification algorithm to be, as much as possible, independent of the run length or logging frequency of the pressure signals. To achieve this type of invariance, we pre-process the signals in a manner that, at least for high enough logging frequencies, leads to invariant intermediate variables. The pattern recognition algorithm is then trained to use these variables as its inputs. The second order correlations of equation (2.1) are appropriate invariants, provided that the shift $d$ is properly scaled with the logging frequency. Those terms embody the translation invariant relationships between the input data stream and the output ${ }^{33}$.

The output of the system is an indicator of flow regimes, including bubbly flow, plug flow, churn-turbulent flow, and slug flow. The ANN is feed-forward, and has three neuron layers (i.e., one hidden layer). The neurons in the input layer have a piecewise linear activation function, while the neurons in the hidden and the output layers use a sigmoidal activation function. The backpropagation learning paradigm was used. A commercial software package ${ }^{34}$ was used for the design and training of the neural network models.

Two neural network structures were developed each using a different output layer configuration, and their schematics are shown in Figure 2.6(a) and 2.6(b). In configuration A, the targeted output values were designated to $0.3,0.5,0.7$, and 0.9 corresponding to bubbly flow, plug flow, churn-turbulent flow, and slug flow, respectively. The flow regime is treated like an ordinal variable in this configuration, having a natural ordering based on the observed typical sequence of regime transitions - a more typical approach to classification treats the classes symmetrically without assumed ordering. The output value of this configuration is continuous, and $0.4,0.6$, and 0.8 were set as the decision boundaries between the flow regimes. This design was consistent with the nearly linear transition boundaries in the flow regime maps depicted in Figure 5, and proposed earlier by Xie et al. ${ }^{28}$

The ANN with configuration B has four neurons in the output layer, each of which represents a distinct flow regime. During training and calibration, the output of the neuron corresponding to the correct flow regime is assigned the value 1 , while the others are assigned zero. The outputs of the trained network can be perceived as probabilities of each flow regime for any given set of input parameters, with the node possessing the largest output showing the most probable regime. The number of hidden layer neurons was experimented with, and the optimal number of nodes was found to be 7 for both of configurations.

The training data set is a subset of all the possible examples of the mapping. Following common practice, a fraction of the obtained data (60\%) was used for training the ANNs and 
another $17 \%$ of the samples were used for calibration (i.e., validation of the data set), which prevented the networks from being over-trained. The remainder of the data (45 data points), which the networks had never "seen" during the training process, was used to test the networks. The test set of data was randomly chosen to avoid a memorized-patterns effect. For each network type, the training was stopped when either 20,000 training events were reached, or the validation error showed incipient over-training.

\subsection{Performance of the Trained ANNs}

The predictions of the ANN with configuration A are compared with the test subset of the experimental data in Figures 2.7(a), 2.7(b), and 2.7(c), for the three consistencies of 0.5\%, 1\% and $1.5 \%$, respectively. In these figures the depicted regime transition lines are experimental, and are the same as those in Figures 5. The data points, however, are what the ANN predicts. Similar results, depicting the performance of the ANN with configuration B, are shown in Figures 2.8(a), 2.8(b) and 2.8(c). As noted, both ANNs predict the flow regimes well, with either model misclassifying only 4 out of the 45 test data points. However, the misclassified cases only confused neighboring flow regimes. The misclassified cases, furthermore, all evidently represent near-transition conditions for two adjacent flow regimes. This is particularly important for the ANN with configuration $B$, since it was not aware of which flow regimes are adjacent on the flow regime map based on the information it had been trained with. For both configurations, furthermore, all misclassifications occur with respect to the plug flow regime. A possible reason for the observed misclassifications is that plug flow regime itself represents a transition between bubbly and churn flow regimes.

Figure 2.9 presents contribution factors for each input of the ANN with configuration A; these factors provide a rough measure of the importance of each input variable towards the network's output, relative to the other inputs. The higher the contribution factor, the more that variable is contributing to the classification. The contribution factors were calculated based on the internal weights using a proprietary algorithm in the commercial neural network package. It should be noted, however, that these contribution factors sometimes be misleading for nonlinear models due to the local nature of any linearization. For nonlinear models it is well known that the feature selection problem is very complicated, and a variable that seems insignificant within one group of inputs can shine when pooled with some other inputs. Therefore, any typical method of 
estimating an input's significance is at best suggestive, and should not be the basis for hard decisions. A discussion of saliency measures in ANNs is available in Duda et al. ${ }^{35}$

The above results clearly support the feasibility of using a single, minimum-intrusive pressure sensor for flow regime identification. However, more experiments are needed. In particular, the feasibility of this method for much larger industrial systems needs experimental verification. Furthermore, the transportability of trained ANNs, whereby an ANN trained with a sensor, and/or a scaled-down system, can be manipulated and applied with another similar sensor and/or a prototypical-scale system, needs to be investigated.

\subsection{Concluding Remarks}

In this paper the feasibility of using ANNs for the identification of major flow regimes in three-phase gas/liquid/pulp fiber systems based on the pressure signals recorded by a single pressure sensor was examined. Experiments were performed in a transparent vertical column 5.08 $\mathrm{cm}$ in inner diameter and $1.8 \mathrm{~m}$ tall, with upward through flows of mixed air and aqueous Kraft softwood pulp suspensions. The aqueous pulp suspensions had consistencies of $0.5 \%, 1.0 \%$, and 1.5\%. Dynamic pressure signals were recorded near the test section wall at the rate of $100 \mathrm{~Hz}$, at a point $1.2 \mathrm{~m}$ above the test section inlet. A total of two hundred data records covering bubbly, plug, churn, and slug flow regimes were obtained.

Two supervised, feed-forward ANNs were designed and trained against a subset of the data for flow regime identification using several easily calculated statistical characteristics of the normalized dynamic pressure signals as input parameters. The designed networks predicted the flow regimes in the remainder of the data points (the test subset of the data) very well. It was concluded that an ANN-aided flow regime classifier based on a single pressure sensor may be feasible for industrial systems. Experimental verification in industrial systems, which are typically much larger than the test section used in this study, was recommended. 


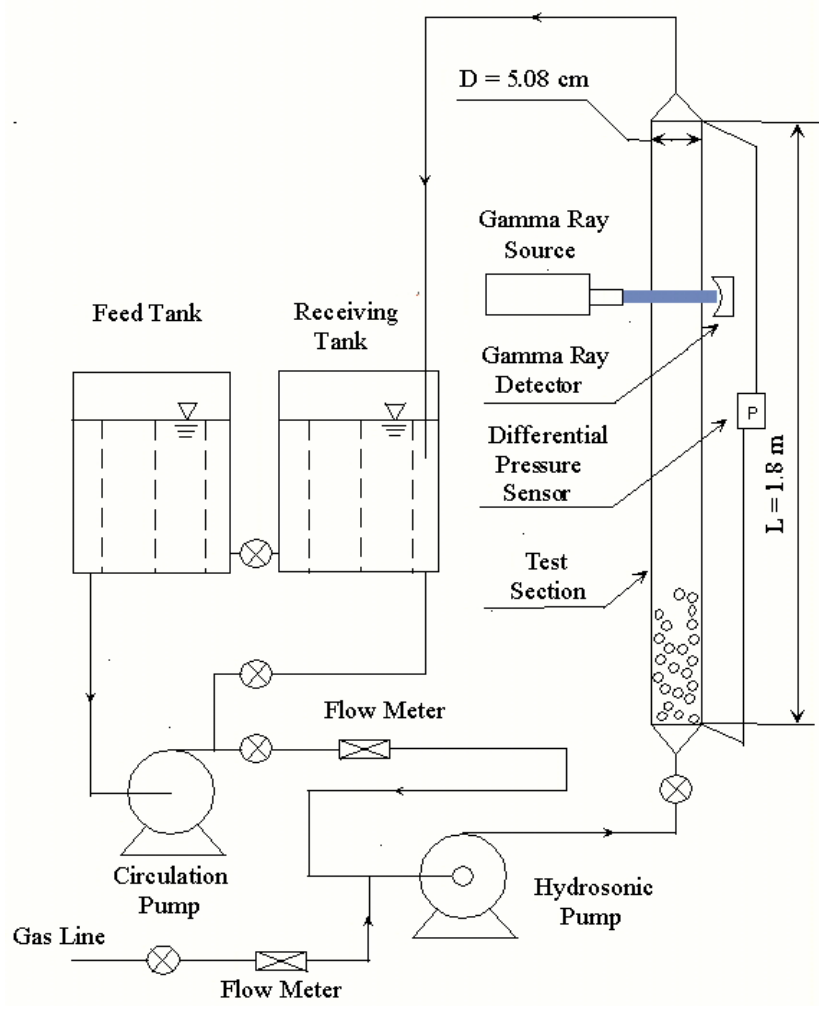

Figure 2.1: Schematic of the test loop

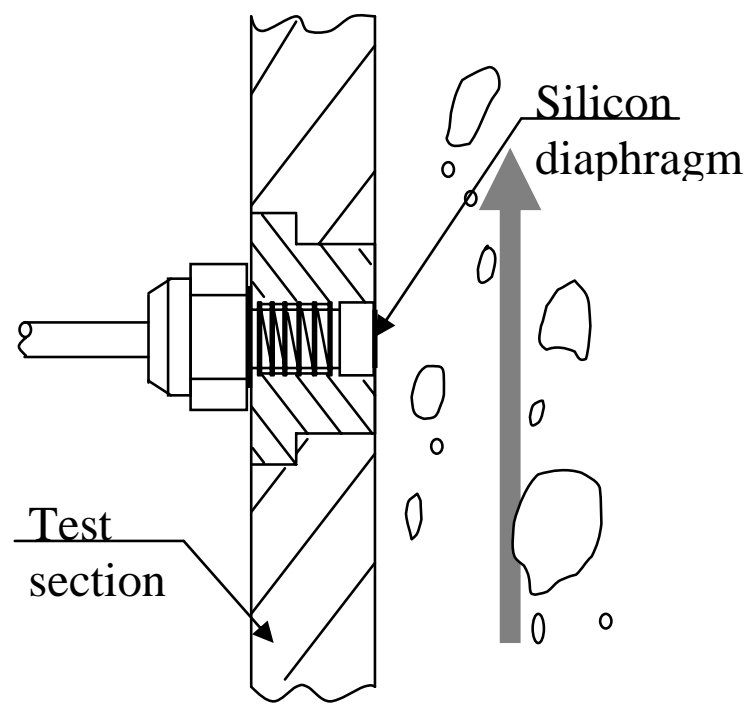

Figure 2.2: Typical installation of dynamic pressure transducer 


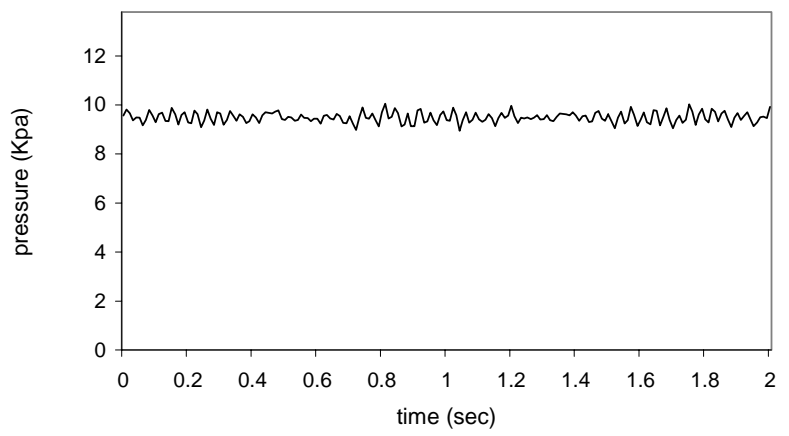

(a)

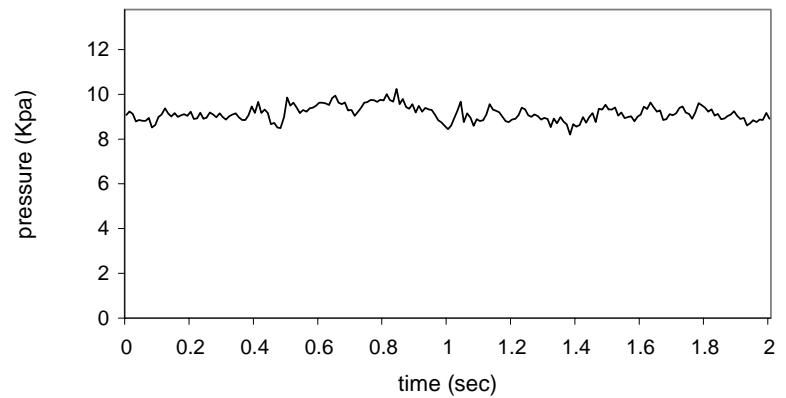

(b)

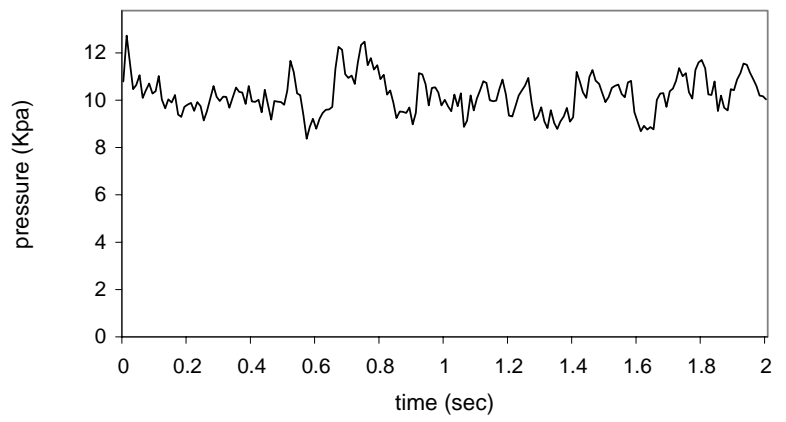

(c) 


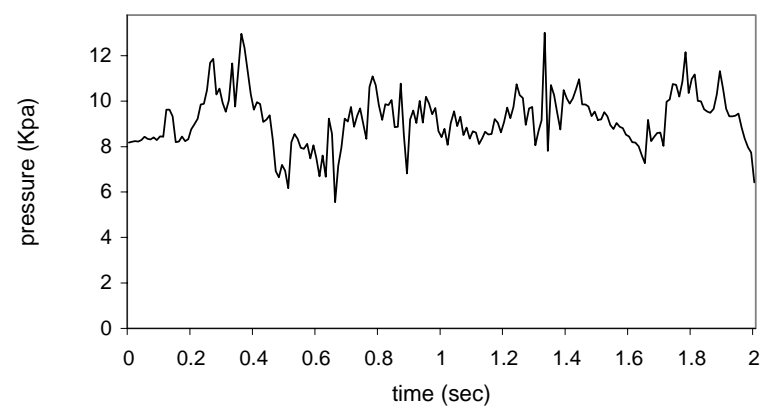

(d)

Figure 2.3: Pressure transducer measurements: (a) bubbly flow; (b) plug flow; (c) churn-turbulent flow; (d) slug flow

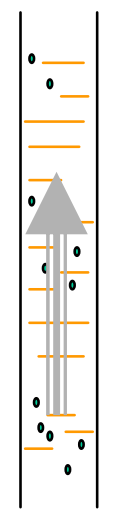

(a)

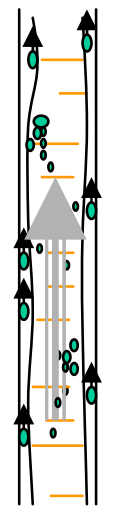

(b)

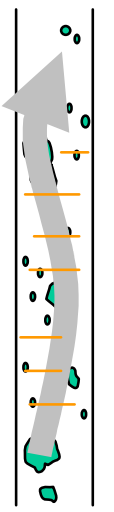

(c)

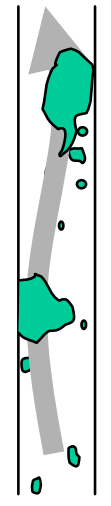

(d)

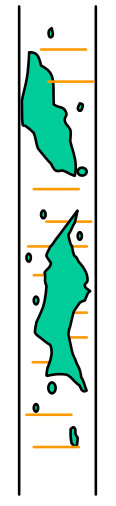

(e)

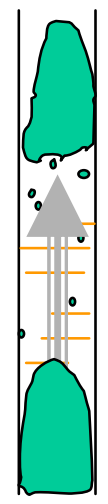

(f)

Figure 2.4: Schematic of the flow regimes: (a) Dispersed bubbly flow; (b) Layered bubbly flow;

(c) Incipient Plug flow; (d) Plug flow; (e) Churn-Turbulent flow; (f) Slug flow 


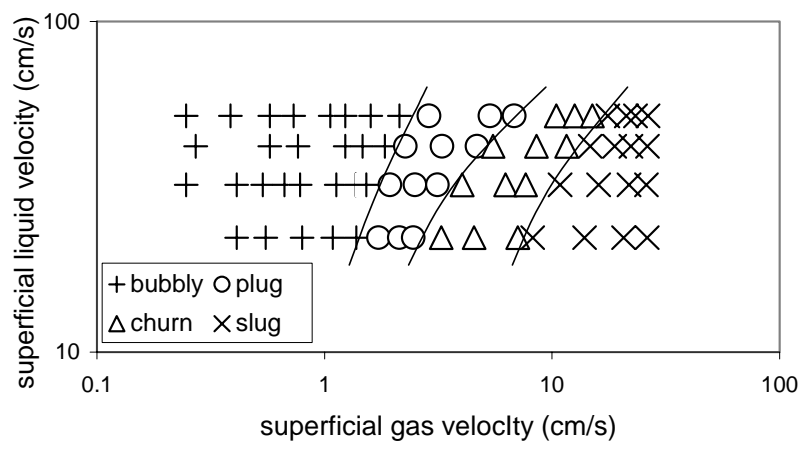

(a)

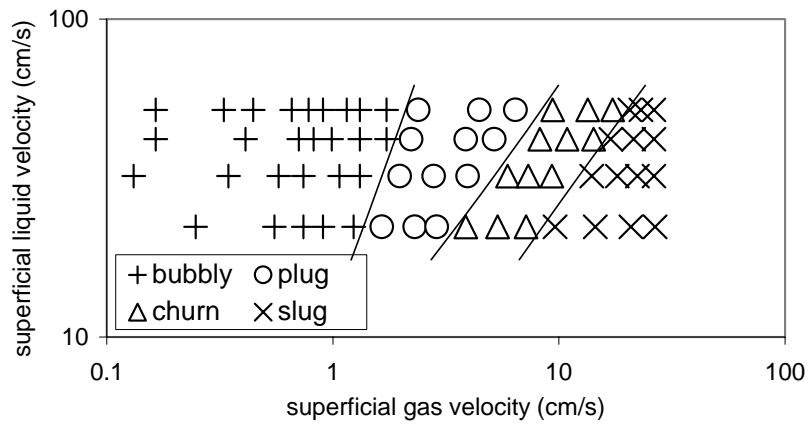

(b)

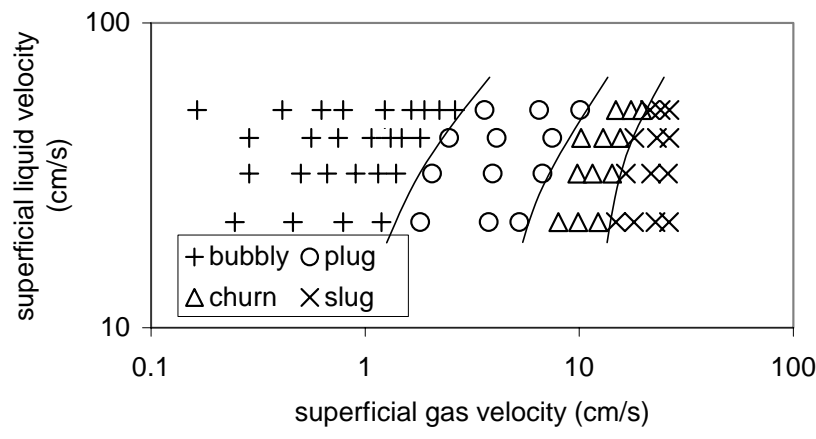

(c)

Figure 2.5: Experimental flow regime data: (a) 0.5\% pulp consistency; (b) 1.0\% pulp consistency; (c) $1.5 \%$ pulp consistency 


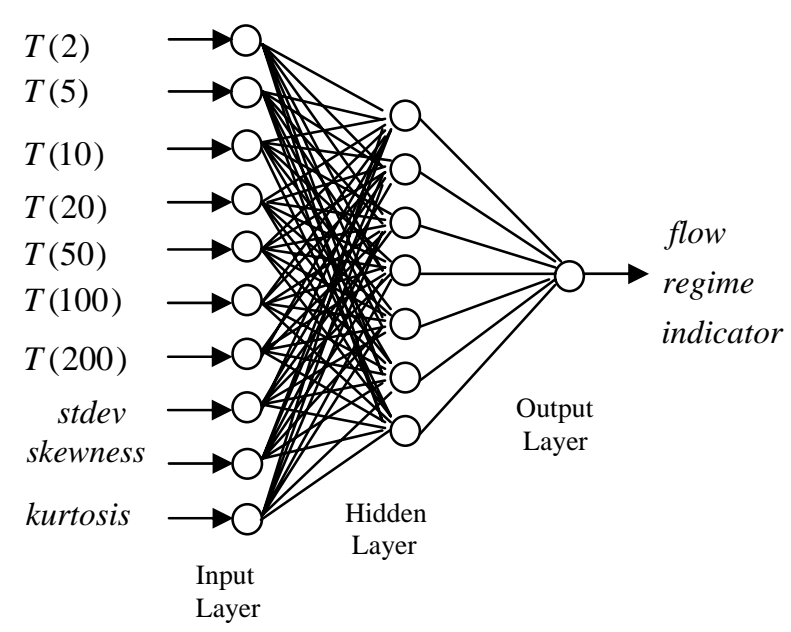

(a)

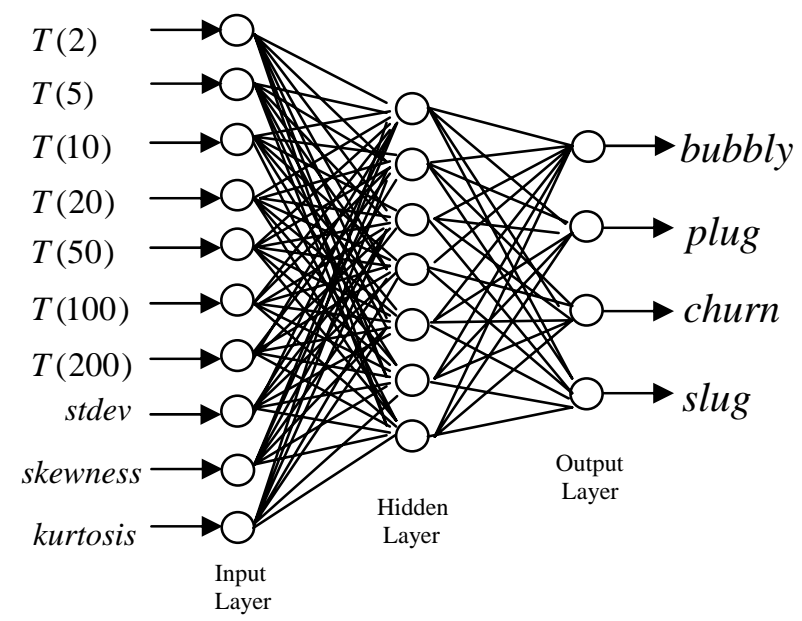

(b)

Figure 2.6: Schematics of neural networks: (a) Configuration A; (b) Configuration B 


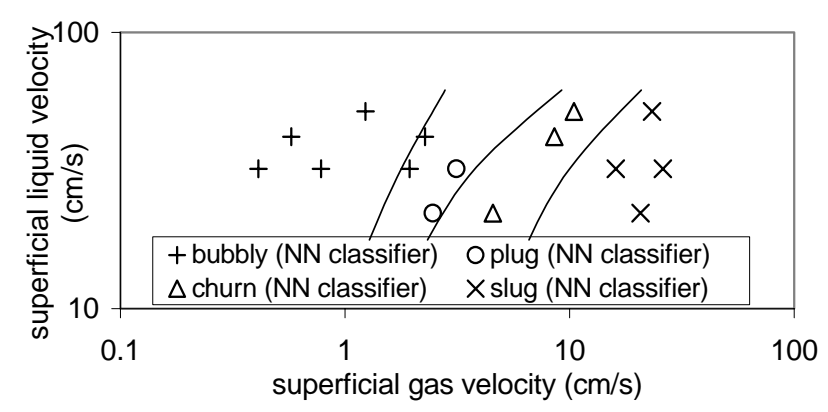

(a)

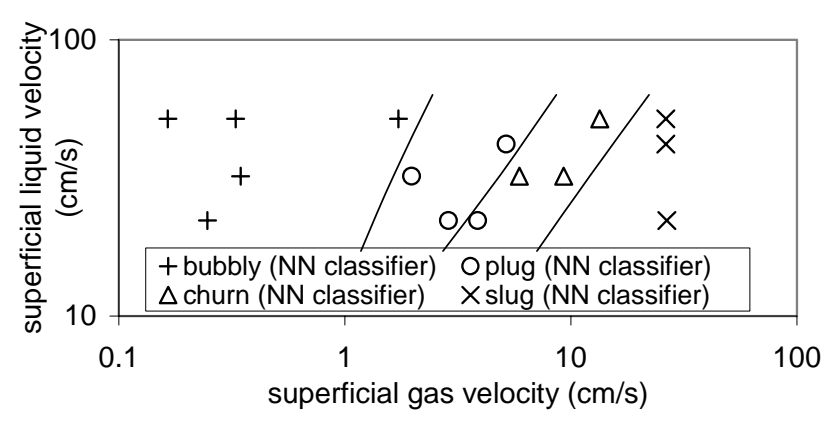

(b)

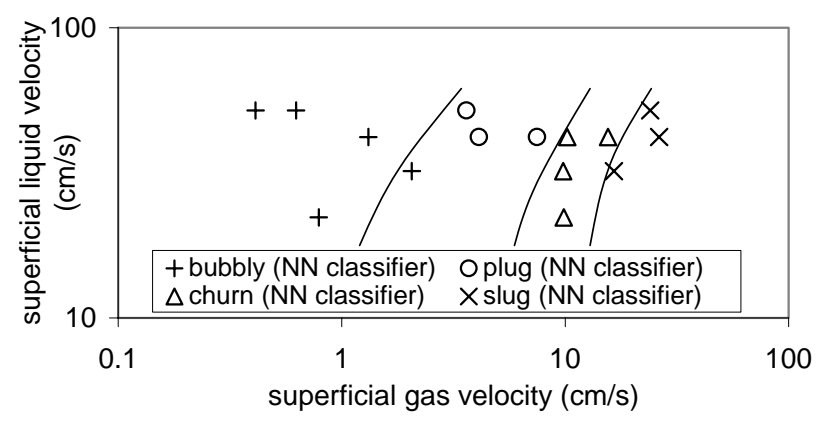

(c)

Figure 2.7: Comparison between the predictions of the ANN with configuration A and the test subset of the data: (a) $0.5 \%$ pulp consistency; (b) 1.0\% pulp consistency; (c) 1.5\% pulp consistency 


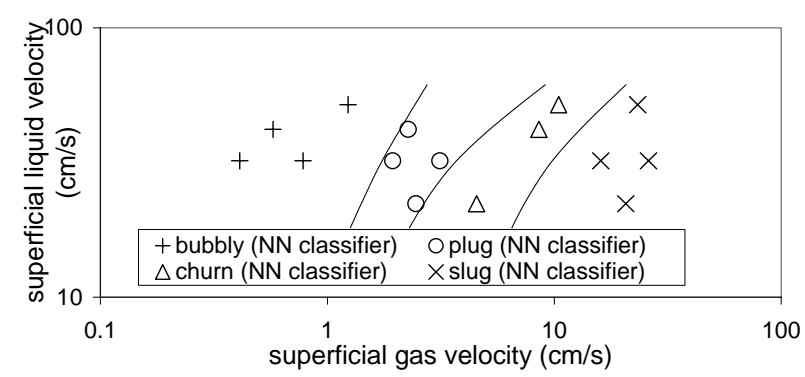

(a)

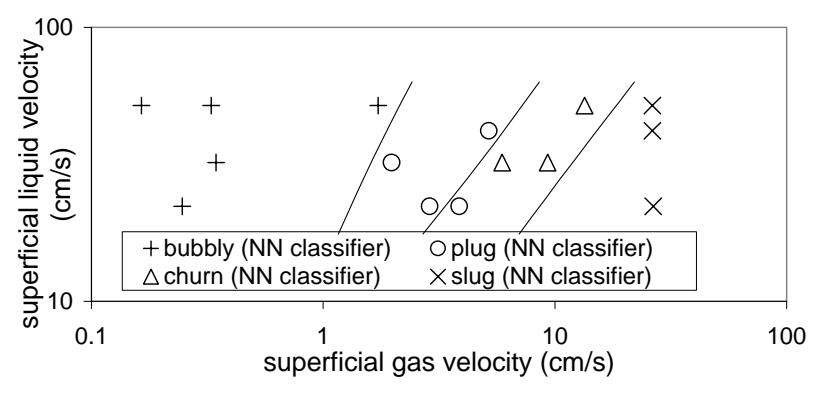

(b)

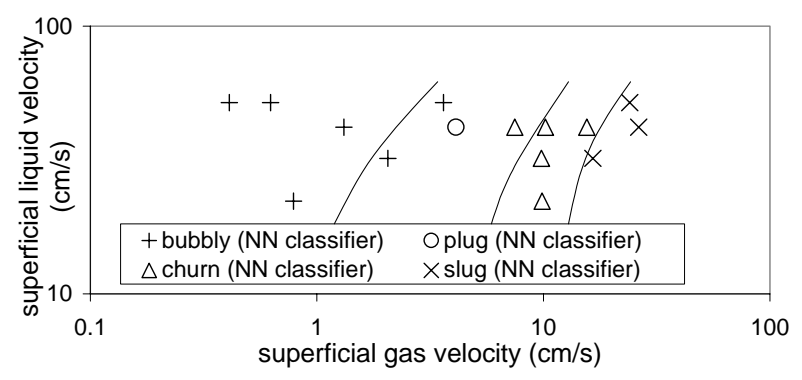

(c)

Figure 2.8: Comparison between the predictions of the ANN with configuration B and the test subset of the data: (a) $0.5 \%$ pulp consistency; (b) 1.0\% pulp consistency; (c) 1.5\% pulp consistency 


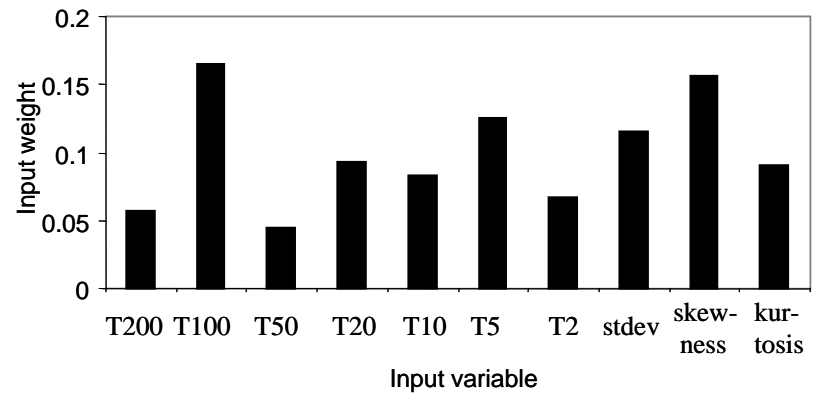

Figure 2.9: Contribution factor analysis for the ANN with configuration A 


\subsection{References for Chapter 2}

(1) Smook, G. A. Handbook for pulp \& paper technologists, $2^{\text {nd }}$ Ed., Angus Wilde Publications, Vancouver, British Columbia, 1992.

(2) Duffy, G. G.; Titchener, A. L. The disruption shear stress of pulp networks. Svensk Papperslidn 1975, 13, 474-479.

(3) Duffy, G. G.; Titchener, A. L.; Lee, P. F. W.; Moller, K. The mechanism of flow of pulp suspensions in pipes. Appita 1976, 29, 363-370.

(4) Bennington, C. P. J.; Azevedo, G.; John, D. A.; Birt, S. M.; Wolgast, B. H. The yieldstress of medium- and high-consistency mechanical pulp fiber suspensions at high gas contents. $J$. Pulp Paper Science 1995, 21, 111-118.

(5) Bennington, C. P. J.; Kerekes, R. J.; Grace, J. R. Mixing in pulp bleaching. J. Pulp Paper Science 1989, 15, 186-195.

(6) Walmsley, M. R. W. Air bubble motion in wood pulp fiber suspension. Appita J. 1992, 45, 509-515.

(7) Lindsay, J. D.; Ghiaasiaan, S. M.; Abdel-Khalik, S. I. Macroscopic flow structures in a bubbling paper pulp-water slurry. Ind. Eng. Chem. Research 1995, 34, 3342-3354.

(8) Fang, L. S.; Sunil, S.; Wisecarver, K. Pressure fluctuation measurements and flow regime transitions in gas-liquid-solid fluidized beds. AICHE J. 1986, 32, 338-340.

(9) Zhang, J.-P.; Grace, J. R.; Epstein, N.; Lim, K. S. Flow regime identification in gasliquid flow and three-phase fluidized beds. Chem. Eng. Science 1997, 52, 3979-3992.

(10) Mandhane, J. M.; Gregory, G. A.; Aziz, K. A flow pattern map for gas-liquid flow in horizontal pipes. Int. J. Multiphase Flow 1974, 1, 537-553.

(11) Taitel, Y.; Barnea, D.; Dukler, A. E. Modeling flow pattern transitions for steady upward gas-liquid flow in vertical tubes. AICHE J. 1980, 26, 345-354.

(12) Mishima, K.; Ishii, M. Flow regime transition criteria for upward two-phase flow in vertical tubes. Int. J. of Heat and Mass Transfer 1983, 27, 723-737.

(13) Jones, O. C.; Zuber, N. The interrelation between void fraction fluctuations and flow patterns in two-phase flow. Int. J. Multiphase Flow 1975, 2, 273-306.

(14) Heindel, T.J.; Monefeldt, J. L. Flash X-ray radiography for visualizing gas flows in opaque liquid/fiber suspension. 1997 ASME Fluids Engineering Division Summer Meeting 1997, 97-3526. 
(15) Merilo, M.; Dechene, R. L.; Cichowlas, W. M. Void fraction measurement with a rotating field conductance gauge. J. Heat Transfer, Transactions of ASME 1977, 99, 330-332.

(16) Mi, Y.; Ishii, M.; Tsoukalas, L. H. Vertical two-phase flow identification using advanced instrumentation and neural networks. Nuclear Eng. Design 1998, 184, 409-420.

(17) Hubbard, M.G.; Dukler, A.E. The characterization of flow regimes for horizontal twophase flow. Proc., Heat Transfer and Fluid Mech. Inst., Standford University Press, 1966.

(18) Weisman, J.; Duncan, O.; Gibson, J.; Crawford, T. Effect of fluid properties and pipe diameter in two-phase flow patterns in horizontal lines. Int. J. Multiphase Flow 1979, 5, 437-462.

(19) Matsui, G. Identification of flow regimes in vertical gas-liquid two-phase flow using differential pressure fluctuations. Int. J. Multiphase Flow 1984, 10, 711-720.

(20) Matsui, G. Automatic identification of flow regimes in vertical two-phase flow using differential pressure fluctuations. Nucl. Eng. Design 1986, 95, 221-231.

(21) Lin, P. Y.; Hanratty, T. J. Detection of slug flow regimes in vertical two-phase flow using differential pressure fluctuations. Nucl. Eng. Design 1986, 95, 221-231.

(22) Spedding, P.L.; Spence, D.R. Flow regimes in two-phase gas-liquid flow. Int. J. Multiphase Flow 1993, 19, 245-280.

(23) Cai, Y.; Wambsganss, M. W.; Jendrzejczyk, J. A. Application of chaos theory in identification of two-phase flow patterns and transitions in a small, horizontal, rectangular channel. J. Fluids Eng. 1996, 118, 383-390.

(24) Mi, Y.; Ishii, M.; Tsoukalas, L. H. Flow regime identification methodology with neural networks and two-phase flow models. Nuclear Engineering and Design 2001, 204, 87-100.

(25) Drahos, J.; Zahradnik, J.; Puncochar, M.; Fialova, M.; Bradka, F. Effect of operating conditions on the characteristics of pressure fluctuations in a bubble column. Chem. Eng. Process 1991, 29, 107-115.

(26) Cai, S.; Toral, H.; Qiu, J.; Archer, J. S. Neural network based objective flow regime identification in air-water two-phase flow. Can. J. Chem. Eng. 1994, 72, 440-445.

(27) Gupta, S.; Liu, P. H.; Svoronos, S. A. Hybrid first-principles/neural networks model for column flotation. AICHE J. 1999, 45, 557-566.

(28) Xie, T.; Ghiaasiaan, S. M.; Karrila, S.; McDonough, T. Flow regimes and gas holdup in paper pulp-water-gas three-phase slurry flow. Chem. Eng. Sci. 2003, 58, 1417-1430.

(29) Pelton, R.; Piette, R. Air bubble hold-up in quiescent wood pulp suspensions. Can. J. Chem. Eng. 1992, 70, 660-663. 
(30) Taylor, K. E. An experimental investigation of a bubbling three-phase pool. Master Thesis, G. W. Woodruff School of Mechanical Engineering, Georgia Institute of Technology, Atlanta, GA, 1993.

(31) Hydrosonic pump operation manual, Hydrodynamics Inc., Rome, GA 30165.

(32) Tsoukalas, L. H.; Uhrig, R. E. Fuzzy and neural approaches in engineering, John Wiley \& Sons, New York, 1997.

(33) Giles, C. L.; Maxwell, T. Learning, invariance, and generalization in high-order neural networks. Applied Optics 1987, 26(23), 4972-4978.

(34) NeuroShell $\circledast 2$ release 4.0, Copyright $\odot$ 1993-1998, Ward Systems Group, Inc.

(35) Duda, R. O.; Hart, P. E.; Stork, D. G. Pattern classification, $2^{\text {nd }}$ Edition, WileyInterscience, 2000. 
Chapter 3: Artificial Neural Network Approach for Flow Regime Classification in Gas-Liquid-Fiber Flows Based on Frequency Domain Analysis of Pressure Signals 


\title{
Notation
}

\author{
$f \quad$ Frequency $(\mathrm{Hz})$ \\ $f_{s} \quad$ Sampling frequency $(\mathrm{Hz})$ \\ $k \quad$ Discrete time shift \\ $N \quad$ Finite length of a discrete time signal \\ $P_{x} \quad$ Power spectral density function (dB) \\ $p \quad$ Pressure $(\mathrm{Pa})$ \\ $p^{*} \quad$ Normalized pressure signal \\ $R_{x} \quad$ Autocorrelation function \\ $U_{G S} \quad$ Superficial gas velocity $(\mathrm{cm} / \mathrm{s})$ \\ $U_{L S} \quad$ Superficial pulp-water mixture velocity $(\mathrm{cm} / \mathrm{s})$ \\ $x(n) \quad$ Discrete time signal \\ $\sigma_{f}^{2} \quad$ Variance of spectrum \\ $\zeta \quad$ Fiber consistency in mixture (\%)
}

Superscript
$\wedge \quad$ Estimated
- $\quad$ Time average 


\subsection{Introduction}

Objective flow regime identification in multi-phase flow process systems using minimally intrusive sensors is of great interest to various branches of industry. In paper making and recycling, in particular, opaque gas-liquid-pulp fiber three-phase mixtures are encountered in large delignification, bleaching, and deinking devices. An objective and minimally intrusive regime classification technique can help the development of online diagnostic or control methods for such systems. Hydrodynamic characteristics of gas-liquid-pulp fiber slurry flows have been investigated in the past (Duffy and Titchener, 1975; Duffy et al., 1976; Bennington et al., 1995; etc), and more recently their flow regimes and gas holdup characteristics have been studied (Lindsay et al., 1995; Reese et al., 1996; Heindel, 1999; Heindel and Garner, 1999; Xie et al., 2003a, 2003b). Brief reviews of the recent studies can be found in Xie et al. (2003a, 2003b).

Attempts at the characterization of two-phase flow patterns based on a combination of subjective judgments and objective methods have also been made in the past (Hubbard and Dukler, 1966; Mandhane et al., 1974; Jones and Zuber, 1975; Merilo et al., 1977; Weisman et al., 1979; Taitel et al., 1980; Mishima and Ishii, 1983; Matsumi et al., 1984; Lin and Hanratty, 1986; Fang et al., 1986; Franca et al., 1991; Drahos et al., 1991; Spedding and Spence, 1993; Lindsay et al., 1995; Cai et al., 1996; Zhang et al., 1997; Heindel et al., 1997; Shim and Jo, 2000). Pressure fluctuations that result from the passage of gas and liquid pockets, and their statistical characteristics, are particularly attractive for objective characterization of flow regimes because the required sensors are robust, inexpensive and relatively well-developed, and therefore more likely to be applied in the industrial systems (Drahos et al., 1991). Power spectral density (PSD) and probability density function (PDF) of pressure drop fluctuations recorded by two pressure transducers were studied by Franca et al. (1991), and more recently by Shim and Jo (2000), for regime identification in gas-liquid two-phase flows. Based on the analysis of experimental data in 
a horizontal tube, Franca et al. noted that, although PSD and PDF could not easily be used for regime identification, objective discrimination between separated and intermittent regimes might be possible by fractal techniques. Based on PSD and PDF analyses, Shim and Jo could characterize bubbly, churn, and slug flow patterns in low flow experiments in a vertical tube. At high flow rates, however, their technique could only distinguish the bubbly flow regime.

To avoid subjective judgment, artificial neural network (ANN) modeling and frequency estimation methods have been employed to implement non-linear mappings from measurable physical parameters to flow regimes (Cai et al., 1994; Mi et al., 1998; Mi et al., 2001) . Artificial neural networks are analytical tools that imitate the neural aspect of the human brain, whereby learning is based on experience and repetition rather than the application of rule-based principles and formulas. An ANN (in its most typical form, so-called feed-forward network) consists of a layered network of neurons (nodes), with each neuron connected to a large number of others. The input signal to the network is passed among the neurons, with each neuron calculating its own output using weighting associated with connections. Learning is achieved by the adjustment of the weights associated with inter-neuron connections. ANNs provide capabilities such as learning, self-organization, generalization (response to new problems using incomplete information), and training; and are excellent for pattern recognition and trend prediction for processes that are nonlinear, poorly-understood, and/or too complex for accurate first-principle mathematical modeling. They seem ideal for applications to multiphase flow systems, and when properly designed and trained, can potentially improve on-line monitoring and diagnostics.

ANNs have recently been applied for the prediction of complex thermal systems rather extensively. Although the application of neural networks to multiphase flow problems has started only recently, the published studies have clearly demonstrated their enormous potential. Mi et al. (1998, 2001) applied a neural network for two-phase flow regime identification in a vertical channel using signals from electric capacitance probes with excellent results. Gupta et al. (1999) 
successfully applied a hybrid method based on four neural networks along with simple firstprinciple models (the latter intended to render the model independent of specific device geometry), for prediction of the attachment rate constant in flotation columns.

This chapter follows the investigation described in Chapters 1 and 2 (also, see Xie et al., 2003a, 2003b). Chapter 1 ( as also described in Xie et al., 2003a) reported on a detailed investigation of the flow patterns and gas holdup of gas-water-pulp three-phase flows in a vertical, upward column. The range of pulp consistency (i.e., weight fraction of dry pulp in the pulp-water mixture) in the experiments was varied in the $0.0 \sim 1.5 \%$ range, which represents the low consistency (LC) pulp suspension range. The aforementioned test facility, with some modifications, was subsequently used in Chapter 2 (also described in Xie et al., 2003b), whereby local pressure fluctuations recorded by a single high-sensitivity pressure transducer at a particular location on the test section wall (1.2 $\mathrm{m}$ above the test section inlet) were measured and utilized for the development of an ANN-based method for flow regime identification. Two feed-forward backpropagation ANNs were developed, each having a single hidden layer, and they were shown to predict the flow regimes well using inputs based on the pressure signal: the standard deviation, coefficients of skewness and kurtosis, and several time shift autocorrelations of normalized signals.

Although the aforementioned studies have shown that ANNs are capable of learning to recognize flow regimes based on pressure fluctuation and some other flow-induced signals, a number of important issues need to be resolved before they can find widespread industrial applications. Practical functional transportability of trained ANNs is among these crucial issues. This transportability is defined here as the capability of a single ANN to function with several sensors in the following sense: trained with a sensor, and/or a scaled-down system, it performs acceptably with another reasonably similar sensor and/or a prototypical-scale system. The ANN 
must then use somewhat sensor-independent, invariant characteristics of the input signal; we will help it along by preprocessing these signals to promote such invariance in the inputs.

In this chapter, using the data obtained with the aforementioned test facility (Xie et al., 2003b), the transportability of an ANN trained for regime classification, between pressure signals from three separate but in principle similar sensors, is addressed. The sensors represent different observation points in flow that is not fully developed, and their signal characteristics are therefore somewhat different in addition to differences in calibration (zero, gain, and linearity) - also minor differences in the physical installation of the sensors can affect their signals. Transportability with respect to multiple similar sensors applied to the same system scale (i.e., no scale-change difference) is considered here. This type of transportability is important since small differences among similar sensors (caused by sensor drift, for example) are often inevitable. An ANN is developed that uses the power spectral characteristics of the normalized pressure fluctuations as input, and is shown to have good transportability. An ANN-based method is furthermore developed that enhances the transportability of the aforementioned ANNs. While a redundant system with multiple sensors is an obvious target application, such robustness of algorithms that provides transportability will also contribute to performance with a single sensor, shielding against effects of calibration changes or sensor replacements.

\subsection{Experiments}

The experimental test loop has been described in detail in Chapter1 1 and 2, and by Xie et al. (2003a, 2003b), and will be reviewed here briefly. A schematic of the experimental facility is shown in Figure 3.1. The main components of the loop include a feed tank, a receiving tank, a circulation pump (1-hp, 1725-rpm Discflo pump), a Hydrosonic pump (also known as a Shock Pulse Generator or SPG), and the test section. The flow in the test loop was established by the 
circulation pump in these tests, and the Hydrosonic pump was not used except as a passive component in the loop. Pulp of the proper consistency was first loaded into the feed tank and the receiving tank, both $0.144 \mathrm{~m}^{3}$ in volume. The pulp used in this study was washed, unbleached Kraft softwood. The average fiber length was measured to be $2.45 \mathrm{~mm}$. Kraft softwood pulp fibers are typically about 30 microns in diameter. Filtered air from the building at measured flow rates was injected into the flowing liquid-pulp mixture in a $2.5 \mathrm{~cm}$ diameter tube prior to the Hycrosonic pump. The gas/liquid/fiber mixture exiting from the column was channeled into the receiving tank via a series of fittings. Among the instruments are differential pressure transducers, a high-speed video camera, an X-ray flash photography system, and a Gamma-ray densitometer. The test section was a PVC schedule 40 pipe that was $1.8 \mathrm{~m}$ in length and has a $5.08 \mathrm{~cm}$ inner diameter. The geometric configuration of industrial systems precludes fully developed flow conditions. The unavailability of general scaling laws for multiphase flows renders the experimental simulation of prototypical systems difficult. This experimental study was thus meant to shed light on fundamental hydrodynamic issues, rather than directly simulating prototypical systems.

The principal objective of the experiments in this study was to record and analyze the pressure fluctuations for various flow regimes in the column. For this purpose, three piezoresistive dynamic pressure sensors (Model 8510B-2, ENDEVCO Corp.), which are designed for measurements requiring a combination of small size, high sensitivity $(10.878 \mathrm{mV} / \mathrm{kPa}$ or 150 $\mathrm{mV} / \mathrm{psi}$ ), and wideband frequency response (resonance frequency of 70,000 $\mathrm{Hz}$ ), were installed in the bubble column wall. Figure 2 depicts how the pressure sensors were installed: nearly flush fitting is intended to minimize the flow disturbance. The pressure transducers have a 10-32 mounting thread, and $3.8 \mathrm{~mm}$ face diameter. The output signals of the pressure sensors, which are proportional to the dynamic component of pressure, are fed to a signal conditioner for A/D 
conversion and filtering. A Labview application was programmed to control the logging frequency and collect the data.

In the experiments, tests were carried out over $21 \leq \overline{U_{L S}} \leq 51 \mathrm{~cm} / \mathrm{s}$ and $0 \leq \overline{U_{G S}} \leq 26 \mathrm{~cm} / \mathrm{s}$ superficial velocity ranges for the pulp-liquid slurry and the gas phase, respectively. Flow regimes were identified in the tests following the procedures described in Chapter 2, and in Xie et al. (2003b). The typical and maximum uncertainties associated with phase superficial velocities were $\pm 3.0 \%$ and $\pm 4.5 \%$ for $\overline{U_{L S}}$; and $\pm 9.6 \%$ and $\pm 33.0 \%$ for $\overline{U_{G S}}$, respectively. In every test, the pressure fluctuations were recorded using the aforementioned dynamic pressure sensors, located at heights of $120 \mathrm{~cm}$ (Sensor 1), $130 \mathrm{~cm}$ (Sensor 2), and $140 \mathrm{~cm}$ (Sensor 3) from the inlet of the bubble column. Acquisition frequency and length of time series data are important factors for the estimation of statistical properties of random data. The former was selected as 100 samples/sec so that the Nyquist rate exceeded the maximum frequency contained in the data, as prior literature suggests that the most informative pressure fluctuations in the bubble columns occur in the range from 0 to $20 \mathrm{~Hz}$ (Drahos et al., 1991). The record length of 2000 data points (20 seconds duration) was chosen on the basis of preliminary experiments to satisfy wide-sense stationarity. Further details about the test apparatus, schematics of the major flow regimes, typical pressure traces for each flow regime, and experimental flow regime maps, can be found in Xie et al. (2003b).

\subsection{Spectral Analysis}

Periodic phenomena pervade in engineering systems, and the hydrodynamic processes in bubble columns are no exception. Spectral analysis is commonly used to reveal the periodicity in a timeseries. The power spectral density is a frequency domain characteristic of a time series and is appropriate for the detection of frequency composition in a stochastic process (Matsumoto and Suzuki, 1984). Assuming the process to be stationary and ergodic, the power spectral density 
function $P_{x}(f)$ of a discrete-time signal $x(n)$ is defined as the Fourier transform of the autocorrelation sequence $R_{x}(k)$ :

$$
P_{x}(f)=\sum_{k=-\infty}^{\infty} R_{x}(k) e^{-i 2 \pi k f / f_{s}}
$$

where, $f_{s}$ is the sampling frequency.

For an autocorrelation-ergodic real-valued process and an unlimited amount of data, the autocorrelation sequence may in theory be approached by a time-average:

$$
R_{x}(k)=\lim _{N \rightarrow \infty} \frac{1}{2 N+1} \sum_{n=-N}^{N} x(n+k) x(n)
$$

The record length of the signal we actually work with is of course limited. To diminish the distortion of the spectrum due to finite length of data record, the averaged modified periodogram method (Welch's method) was adopted. If $x(n)$ is only measured over a finite interval, say $n=0$, $1, \ldots, N-1$, then periodogram method estimates the power spectral density as:

$$
\hat{P}_{x}(f)=\sum_{k=-N+1}^{N-1} \hat{R}_{x}(k) e^{-i 2 \pi k f / f_{s}}
$$

where, the autocorrelation is given as:

$$
\hat{R}_{x}(k)=\frac{1}{N} \sum_{n=0}^{N-1-k} x(n+k) x(n)
$$

Welch (1967) modified the periodogram method by subdividing the N-point sequence into overlapping segments. He then applied window function to each data segment and computed the corresponding periodograms for each segment. Finally, he averaged the periodograms to obtain the power spectrum estimate. More details of this method are available in Proakis and Manolakis (1996).

In our study, the normalized pressure fluctuations, defined below, were the time series of interest.

$$
p^{*}=(p-\bar{p}) / \sqrt{\overline{(p-\bar{p})^{2}}}
$$

The power spectrum was estimated using segments with a length of 256 points and a Hanning window of the same size in order to lower the variance of the estimate. All the power spectrum analyses were performed using the signal processing toolbox of Matlab 6.1 (MATLAB 6.1 Tutorial, The Mathworks, Inc., 2003). 
Examples of power spectra for all the major flow regimes are shown in Figure 3.3(a), (b), (c) and (d). The power spectrum in the bubbly flow regime exhibits two clear peaks (approximately at $13 \mathrm{~Hz}$ and $27 \mathrm{~Hz}$ for the depicted case), which may correspond to the frequency of gas bubbles of two major different size groups. In the plug flow regime, the lower-frequency peak becomes more dominant. This may represent the passing-by of large gas plugs with dimensions comparable to the channel diameter. The power spectrum of churn flow regime shows several peaks spread over a wide frequency range from 0 to $15 \mathrm{~Hz}$ except for strong peaks at the small frequency range (less than about $3 \mathrm{~Hz}$ ). The peaks may represent the coalescence and collisions of gas pockets. The slug flow regime has a very strong spike (at about $2 \mathrm{~Hz}$ in the displayed case). It is also noted that the frequency components over $30 \mathrm{~Hz}$ do not contribute much to the power spectral density.

The above examples indicate that the power spectral structure of each hydrodynamic regime in a gas-liquid pulp mixture flow is distinct, and therefore it may be possible to identify the hydrodynamic regimes of the gas-liquid-pulp slurry fiber flow in a bubble column based on their estimated pressure power spectral characteristics.

\subsection{Neural Network Model for Regime Identification Using the Power Spectral \\ Characteristics of Pressure}

The principles of ANNs have been described in numerous publications, and will not be repeated here, and only the major characteristics of the designed ANNs are presented. ANNs represent a class of algorithms that can be designed and trained to perform flow regime identification. To some extent, an ANN pattern recognition approach involves a trainable black box (Tsoukalas and Uhrig, 1997). An ANN can be trained to learn the correct output or classification for each of the training samples. After training, the fixed neural network will interpolate or extrapolate with new inputs, and can perform well if the training data "taught" patterns essential to the current case (Mi et al., 2001). The feasibility of an ANN for regime identification was demonstrated in Chapter 2 (Xie et al., 2003b), using as inputs the standard deviation, coefficients of skewness and kurtosis, and several second-order correlation terms of the normalized pressure signals recorded by a single sensor. The feasibility of using normalized pressure power spectral characteristics is now examined, as our current goal is to promote a certain type of invariance (indifference to zero and gain at least). 
To characterize the hydrodynamics of the flow based on the power spectral density function, it is necessary to first implement parameterization of the information contained in the spectral patterns. Based on the recorded power spectra, we focus on a frequency range up to 30 Hz. Each spectrum is normalized to one in its integral over the $0-30 \mathrm{~Hz}$ range (which provides invariance against changes in gain). The frequency range over $0-30 \mathrm{~Hz}$ is then divided into five bandwidths: 0-3 Hz, 3-8 Hz, 8-13 Hz, 13-25 Hz, and 25-30 Hz. According to Parseval's relation, the integral of the power spectral density across the entire band is a measure of the total energy of the signal. To approximate the percentage of energy the signal has in a given frequency band, we need to sum the estimated average power spectral density over the desired frequency band. The mean value of power in each of the aforementioned bands, denoted as $P^{*}{ }_{0-3 \mathrm{~Hz}}, P^{*}{ }_{3-8 \mathrm{~Hz}}, P^{*}{ }_{8-13 \mathrm{~Hz}}$, $P^{*}{ }_{13-25 \mathrm{~Hz}}$, and $P^{*}{ }_{25-30 \mathrm{~Hz}}$, respectively, is then used as representative of the individual band. Other parameters of interest are mean frequency, $\bar{f}$, given by:

$$
\bar{f}=\frac{\sum_{i} f_{i} P_{x}\left(f_{i}\right)}{\sum_{i} P_{x}\left(f_{i}\right)},
$$

and spectrum variance $\sigma_{f}{ }^{2}$, estimated from:

$$
\sigma_{f}^{2}=\frac{\sum_{i}\left(f_{i}-\bar{f}\right)^{2} P_{x}\left(f_{i}\right)}{\sum_{i} P_{x}\left(f_{i}\right)} .
$$

The above 7 discrete parameters, suggested by Drahos and Cermak (1989), were selected to represent the characteristics of power spectrum of pressure fluctuations. Along with the fiber consistency of the three-phase flow $\zeta$, they constitute the inputs to the forthcoming neural networks - the consistency is regulated and known in real process applications, and provides essential prior information. The output of the neural network is an indicator of flow regimes. The commercial software package (NeuroShell 2) was used for the design and training of the neural network models. Based on the experience described in Chapter 2 (Xie et al., 2003b), the targeted output values were designated to $0.3,0.5,0.7$, and 0.9 corresponding to bubbly flow, plug flow, churn-turbulent flow, and slug flow, respectively. The flow regime is therefore treated like an ordinal variable in the neural network, having a natural ordering based on the observed typical 
sequence of regime transitions. The output value from the ANN is continuous, and 0.4, 0.6, and 0.8 were set a priori as the decision boundaries between the flow regimes. This design was consistent with the nearly linear transition boundaries in the (log-log plotted) flow regime maps reported earlier (Xie et al., 2003b).

A three-neuron-layer ANN was designed. The neurons in the input layer had a piecewise linear activation function, while the neurons in the hidden and the output layers used the logistic activation function. The back-propagation learning paradigm was used. The number of neurons in the hidden layer was experimented with, and the optimal number of nodes was found to be 5 . The configuration of this neural network (referred to as ANN-1) is shown in Figure 3.4.

The pressure data measured by Sensor 1 were used first. A total of 197 data records were available. Following common practice, a fraction of the obtained data (77\%, or 152 data records) was selected for training ANN-1, which constituted the so-called 'calibration data'. The remainder of the data (45 data records), which the network had never 'seen' during the training process, was used to test the network. The test set of data was of course randomly chosen to avoid a memorized-patterns effect. During training, to prevent incipient over-training, the process was stopped when 20,000 training events since the minimum average error for the calibration data set were reached.

The predictions of the designed and trained ANN are compared with the test subset of the experimental data in Figures 3.5(a), (b), and (c), for the three consistencies of $0.5 \%, 1 \%$ and 1.5\%, respectively. In these figures the depicted regime transition lines are experimental. The data points, however, are what the ANN predicts. The solid lines in these figures represent the observed flow regime transitions in the experiments where the aforementioned pressure signals were also recorded, as described in Chapter 2 (Xie et al, 2003b). The dashed lines are the regime transitions observed in an earlier series of experiments using essentially the same test facility, as described in Chapter 1 (Xie et al, 2003a). With the exception of bubbly-plug transition in Fig 3.5(a), the two 
sets of regime transition lines are in agreement. In the analysis of the data associated with the latter tests, three different bubbly flow patterns (dispersed bubbly, layered bubbly, and incipient bubbly) were reported (Xie et al., 2003a). Analysis with ANNs, however, indicated that these flow patterns had similar pressure fluctuation characteristics (Xie et al., 2003b). The apparent discrepancy between the bubbly-plug transition lines in Fig 3.5(a) is likely due to difficulty associated with distinction between incipient plug and plug flow patterns in our earlier experiments (Xie et al., 2003a). The experimental regime transition lines depicted in all the forthcoming figures are the same as the solid lines in 3.Figs 5(a-c).

As noted in Figs 3.5(a)-(c), the neural network ANN-1 predicts the flow regimes successfully, misclassifying only 5 out of the 45 test data records. Only neighboring flow regimes were confused: the misclassified cases in fact all represent near-transition conditions. It is also worth noting that most of the misclassification cases occur in experiments with the highest consistency (1.5\%), which may indicate that the data with $1.5 \%$ consistency were contaminated with an interfering signal, and that the noise level in the pressure signals can be significantly boosted by the presence of more fiber. The interfering noise displayed low frequency characteristics and could not be fully eliminated by low-pass filtering during signal processing.

The above results further support the feasibility of using a single, minimum-intrusive pressure sensor for flow regime identification. However, more experiments are needed. In particular, the feasibility of this method for much larger industrial systems needs experimental verification.

Using the ANN-1 design, a voting scheme was developed and tested with the objective of improving the regime predictions by taking advantage of the multiplicity of the pressure sensors. Accordingly, three separate ANNs, all having the configuration depicted in Figure 3.4, were used, each trained using the signals recorded by one of the three sensors. The training was done using a common set of 158 data points. The signals recorded by each sensor for the remainder of the data 
points (the test data) were then used as input for that particular sensor. The correct flow regime associated with each test data would then depend on the majority vote among the three ANNs. The results of this method are compared with the test data in Figs 6(a)-(c). Overall, these predictions show an improvement over those depicted in Figs 3.5(a)-(c), as expected. The relatively high confusion rates associated with the $\zeta=1.5 \%$ consistency persist, however, confirming that these confusions may be caused by noise signals.

\subsection{Transportability}

Transportability of a model is often defined as the capability to produce accurate predictions of data not included in the development of the prediction model, and drawn from a different but plausible related population (Justice et al., 1999). For ANNs of interest in flow regime classification, where the system scale and the characteristics of the sensor are also important, the transportability concept needs to be extended to not only address a different but plausible population, but the system scale and sensors as well. A transportable ANN-based method should ideally be trained on a reference system using a set of reference sensors, and be able to correctly classify the flow regimes when applied to a system with a significantly different scale and using somewhat different sensors, but subject to a similar flow field. The signals recorded in the latter (prototypical) system may evidently need to be manipulated before they can be used as input to the trained reference ANN. The development of a method appropriate for this manipulation is a crucial step towards transportability.

As a first step, the transportability of the ANN-1 for the interpretation of the signals recorded by Sensor 2 and Sensor 3 without any manipulation of the ANN and data, was examined. Accordingly, the pressure signals recorded by Sensor 2 and Sensor 3 were normalized and were directly (without any manipulation) used for the calculation of input parameters for ANN-1. The 
predictions of ANN-1 are compared with the entire experimental data in Figs 3.7(a)-(c) and Figs 3.8(a)-(c) for Sensor 2 and Sensor 3, respectively. The agreement is encouraging, and only about $13 \%$ of the data are misclassified, with the misclassified data points all representing conditions close to regime transition.

A similar test was performed using the ANN discussed in Chapter 2 (Xie et al., 2003b). The latter ANN, as mentioned earlier, uses the standard deviation, coefficients of skewness and kurtosis, and several time-shift auto correlations of normalized pressure signals from a sensor as input. The result obtained by directly applying the ANN trained and tested for Sensor 1 to the data recorded by Sensors 2 and 3 (not shown here for brevity) were inferior to those depicted in Figs 3.7 and 3.8, and led to about 16\% mismatches. This particular net was using inputs that were not indifferent to gain and shift of zero point: the standard deviation is proportional to gain.

To further improve the transportability of ANN-1 to Sensor 2 and 3, a method similar to the one proposed by Balaban et al. (2000) was attempted. The pressure signals from Sensor 2 and Sensor 3 were normalized and their power spectra were obtained. The three-layer backpropagation ANN depicted in Fig. 3.9 (hereafter referred to as ANN-2) was then developed. ANN2 was meant to be trained in order to convert all the input parameters needed by ANN-1 that represent either Sensor 2 or Sensor 3, such that they could be correctly interpreted by ANN-1. An ANN similar to ANN-2 was trained for each of Sensor 2 and Sensor 3. For training ANN-2 with respect to Sensor 2, the 7 parameters representing the power spectral density characteristics associated with 152 data points ('calibration data' subset) obtained with Sensor 2 were used as input to ANN-2, while the corresponding parameters obtained with Sensor 1 constituted the outputs. Once trained in this way, ANN-2 was then utilized for the conversion of the 45 unseen Sensor 2 data records, and the output parameters generated by ANN-2 were then used as input for ANN-1. The predictions of ANN-1 for the latter 45 data records are compared with the experimental data in Figs. 3.10(a)-(c). A similar procedure for Sensor 3 led to Figs. 3.11(a)-(c). 
The results, as noted, are encouraging. The misclassifications are few, and represent relatively minor confusion for data points associated with regime transition zones. It is also worth emphasizing that mismatches associated with $\zeta=1.5 \%$ are more severe, confirming the added complexity of the flow field due to higher consistency.

Our investigation thus confirms the feasibility of the development of transportable ANNs that use pressure signal characteristics, at least with respect to similar pressure sensors in systems that are of the same size scale. Further investigations are evidently needed. Transportability with respect to system size scales, in particular, needs to be investigated.

\subsection{Concluding Remarks}

In this paper, the feasibility of using a transportable artificial neural network (ANN)-based technique for the identification of flow regimes in a gas/liquid/pulp fiber three-phase flow system was examined. Experimental data were obtained using an instrumented test loop that included a transparent vertical column (test section) that was $1.8 \mathrm{~m}$ long and had an inner diameter of 5.08 cm. Flow regimes, including bubbly, plug, churn and slug, were identified visually. Measurements included pressure fluctuations recorded by three similar highly sensitive sensors. A three-layer, feed-forward ANN was designed that used seven input parameters all representing the characteristics of the spectral power density distributions of normalized pressure fluctuations associated with a single pressure sensor, and was shown to perform well. A voting scheme, whereby ANNs trained for the three sensors would be used for regime identification for an unseen data set based on the majority vote, resulted in an improvement in the accuracy of the predictions. The ANN that had been trained based on signals recorded by one of the sensors (Sensor 1), furthermore, was directly applied to the signals recorded by the other two sensors, and was shown to predict the flow regimes reasonably well. An ANN-based method was then developed for the 
conversion of the spectral power density characteristics of one sensor such that they approximated similar characteristics obtained with another sensor, to enable the use of a classification algorithm created for the latter sensor. The results were good, and confirmed the suitability of the proposed method for improving transportability.

The results of this investigation indicate that the developed ANN-based regime classification method that uses the normalized pressure power spectral density characteristics is reasonably transportable when high-sensitivity sensors are used on analogous systems of the same size scale. Transportability with respect to sensors that are significantly different, and with respect to systems with different size scales remains to be resolved, however, and further investigations are recommended. 


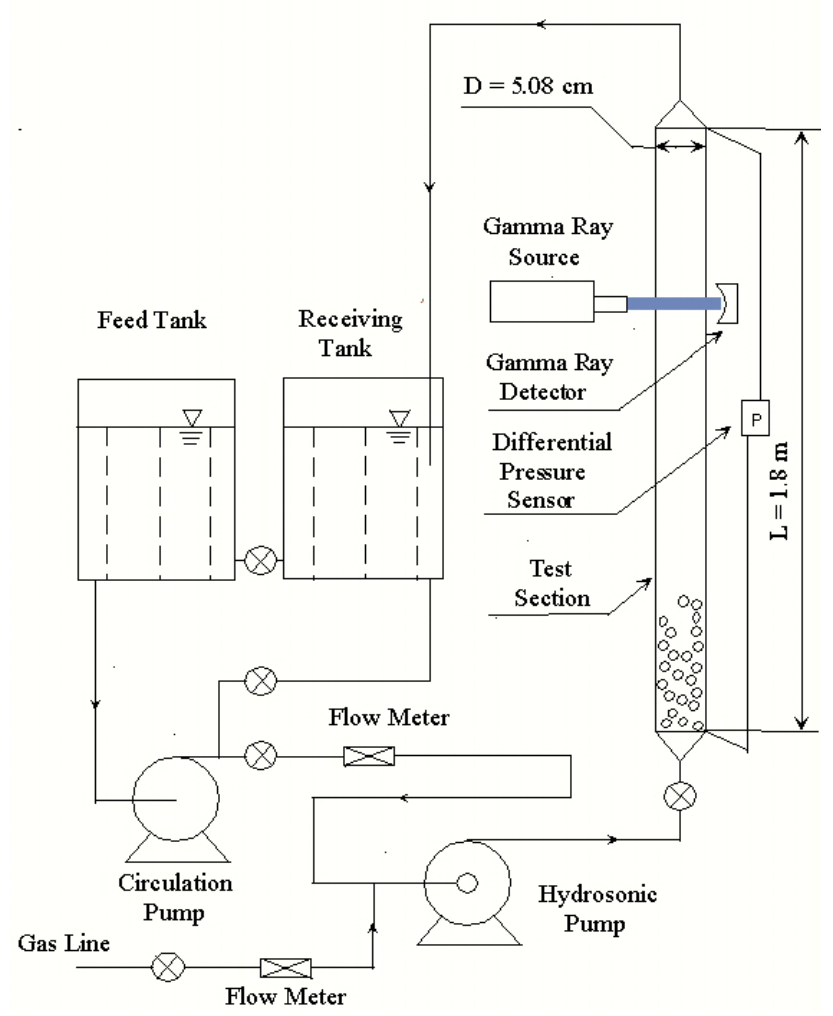

Figure 3.1: Schematic of the test loop.

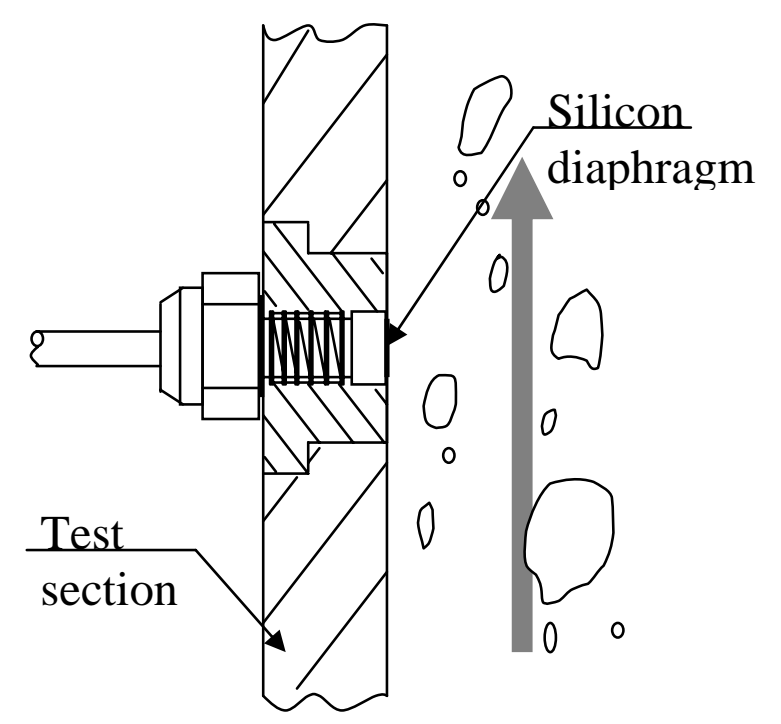

Figure 3.2: Typical installation of dynamic pressure transducer. 


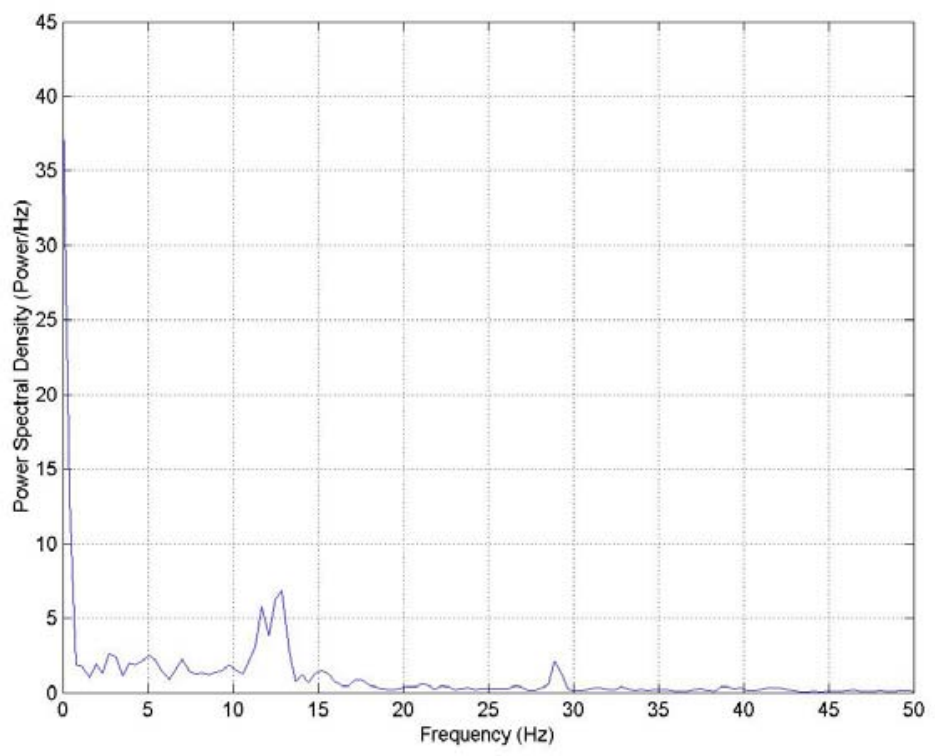

(a)

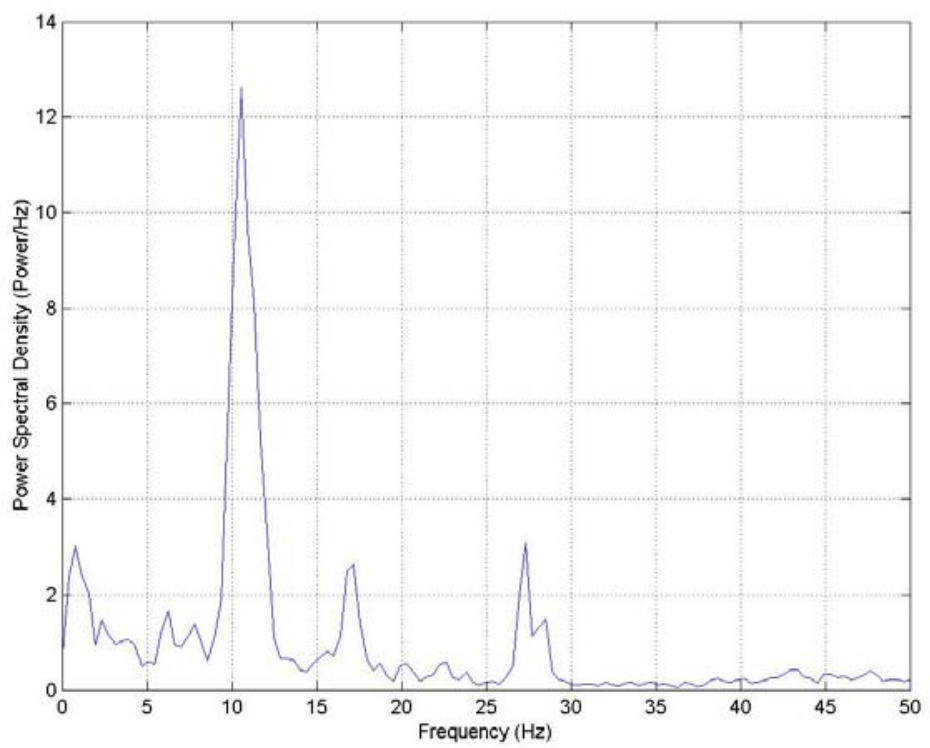

(b) 


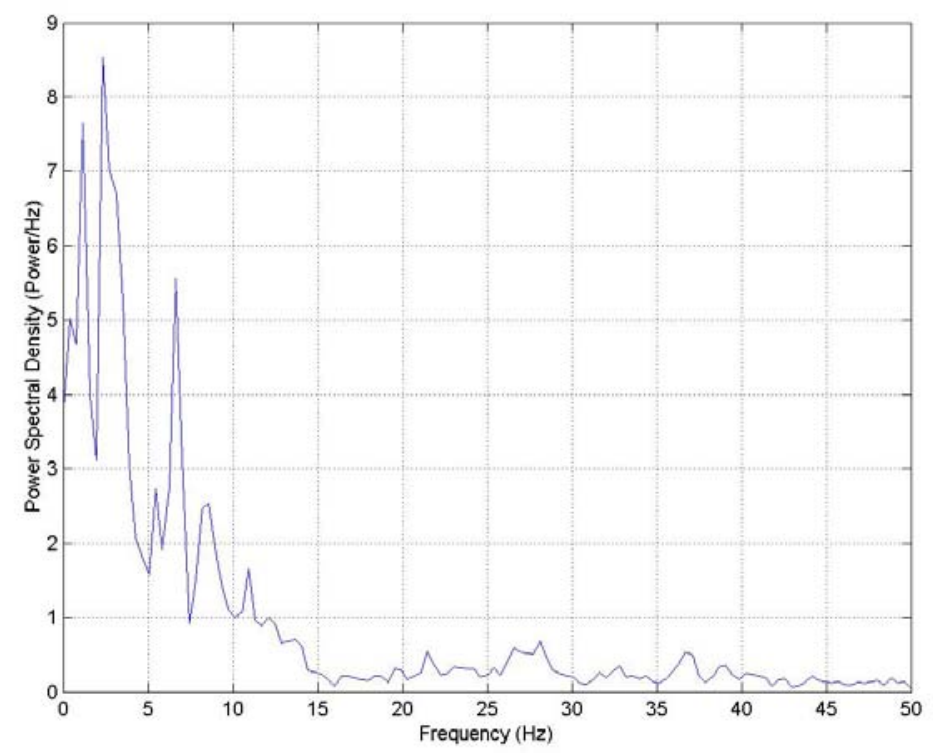

(c)

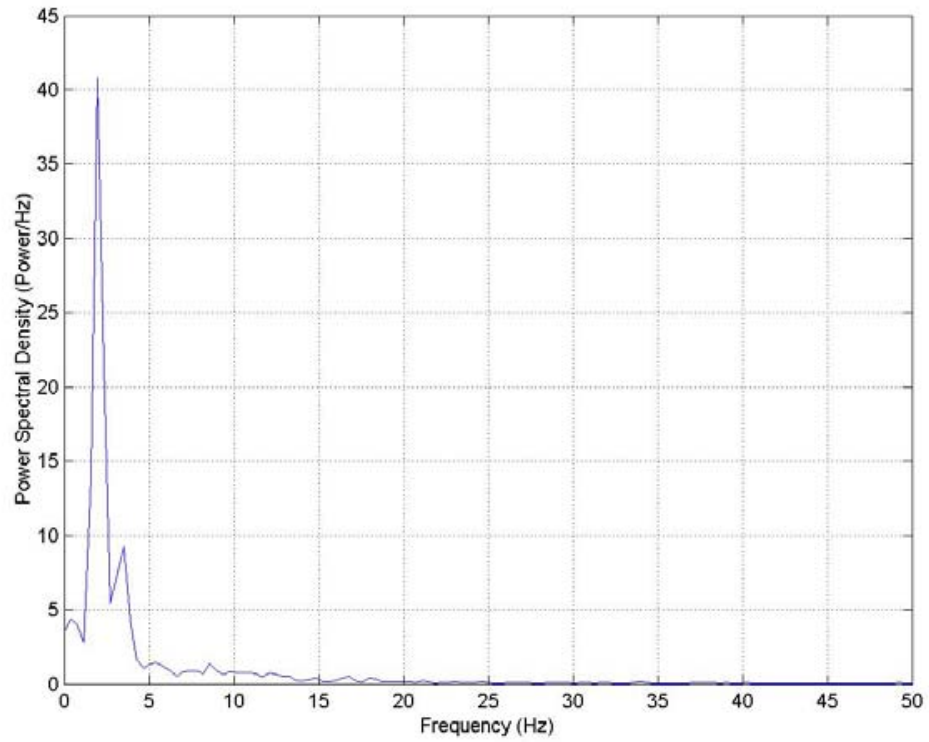

(d)

Figure 3.3: Examples of the power spectral density functions of pressure fluctuation: (a) bubbly flow; (b) plug flow; (c) churn-turbulent flow; (d) slug flow. 


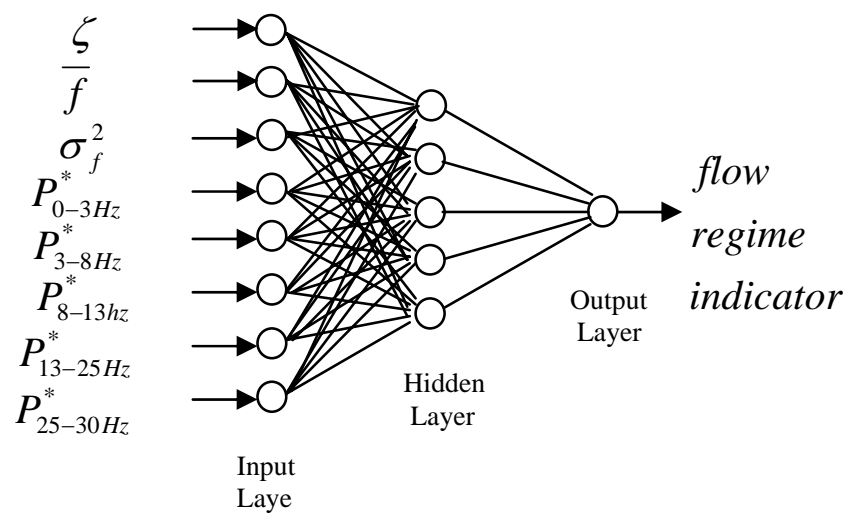

Figure 3.4: Schematic of the configuration of ANN-1. 


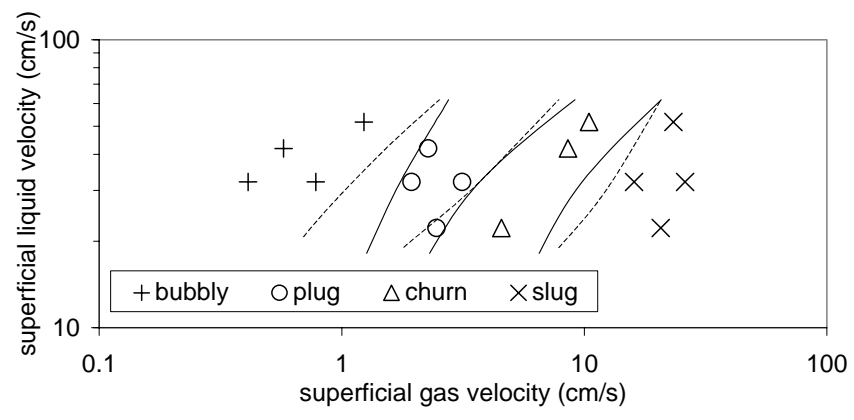

(a)
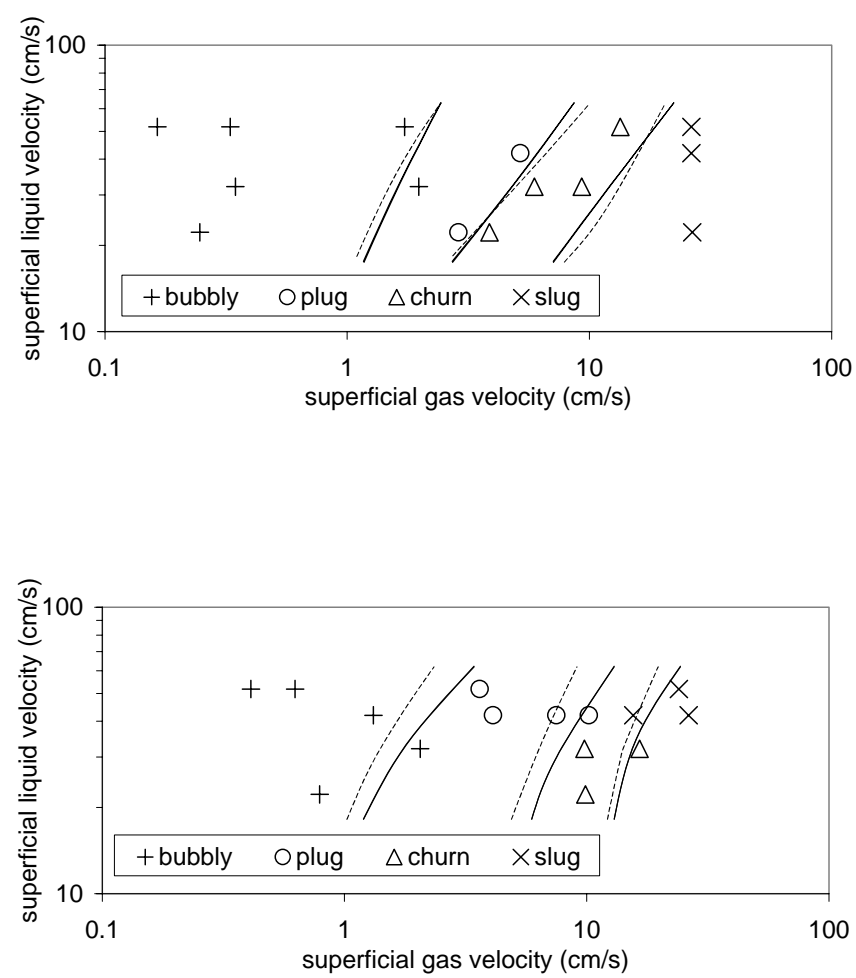

(b)

(c)

Figure 3.5: Comparison between the predictions of ANN-1 and the test subset of the data: (a) 0.5\% pulp consistency; (b) 1.0\% pulp consistency; (c) 1.5\% pulp consistency. Transition lines are experimental and symbols are ANN predictions. Dashed lines are from the previous experiments (Xie et al., 2003a). 


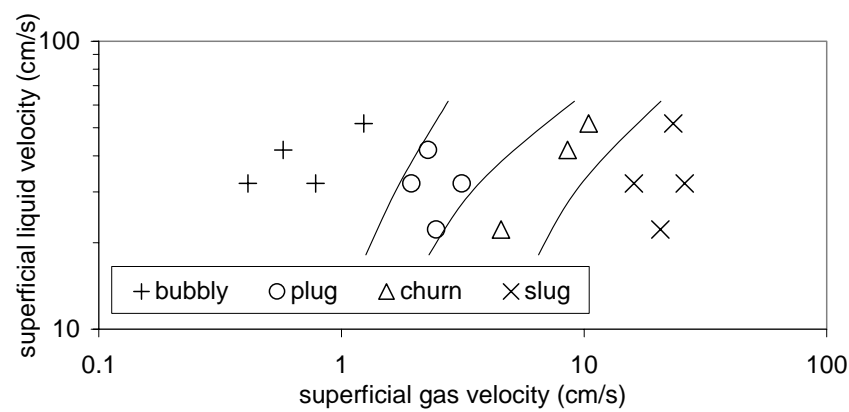

(a)

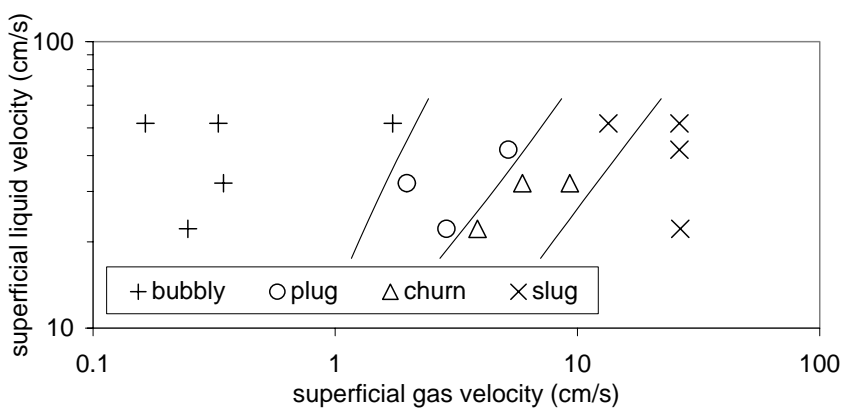

(b)

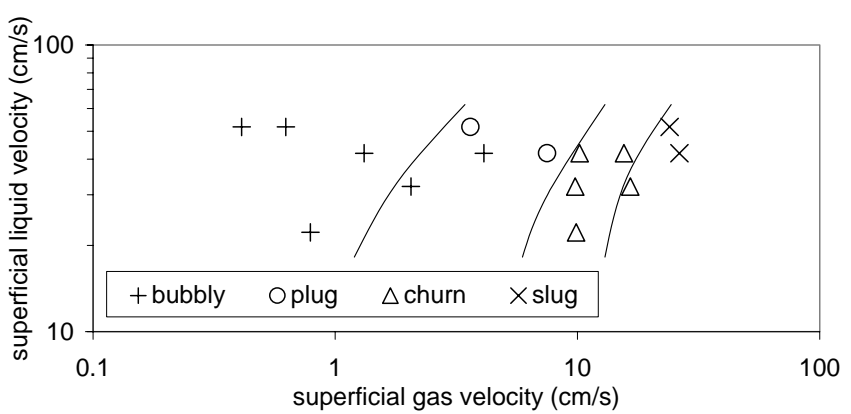

(c)

Figure 3.6: Comparison between the predictions based on the voting scheme and experiment. (Regime boundaries are from experiments; symbols are model predictions.) 


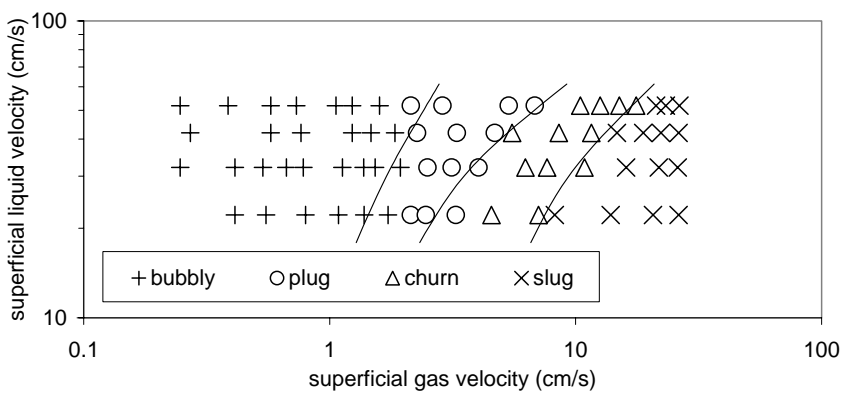

(a)

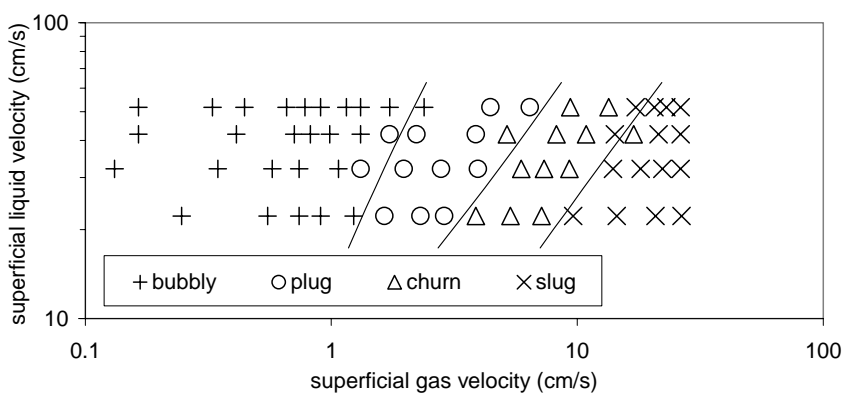

(b)

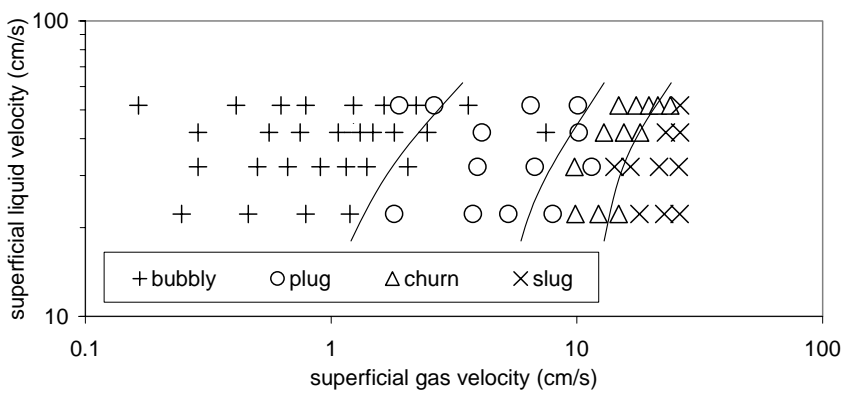

(c)

Figure 3.7: Comparison between the predictions of ANN-1 and the experimental data when pressure signals of Sensor 2 are directly used for the calculation of NN input parameters. (Regime boundaries are from experiments; symbols are model predictions.) 


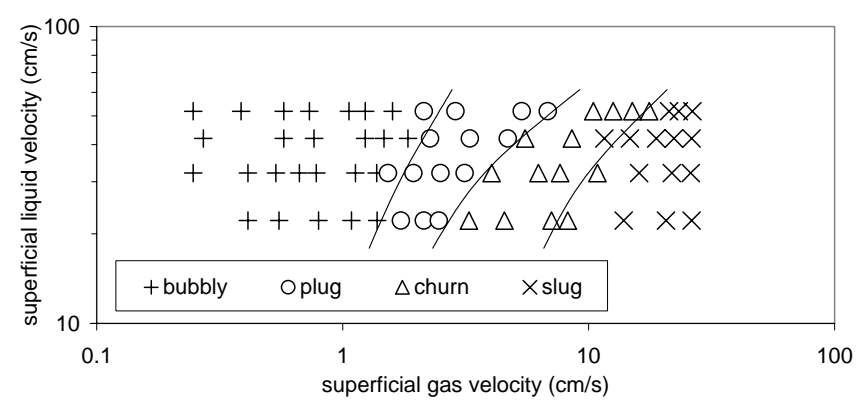

(a)

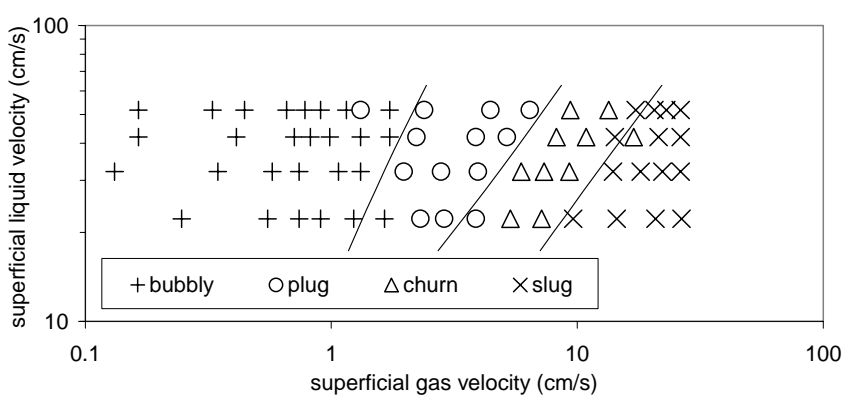

(b)

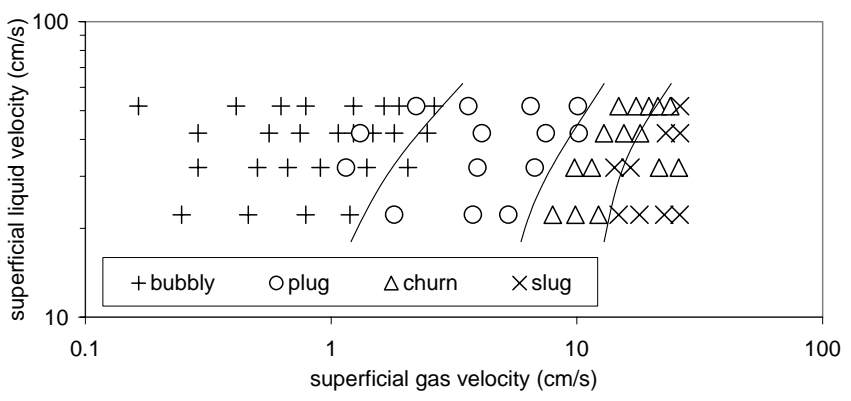

(c)

Figure 3.8: Comparison between the predictions of ANN-1 and the experimental data when pressure signals of Sensor 3 are directly used for the calculation of NN input parameters. (Regime boundaries are from experiments; symbols are model predictions.) 


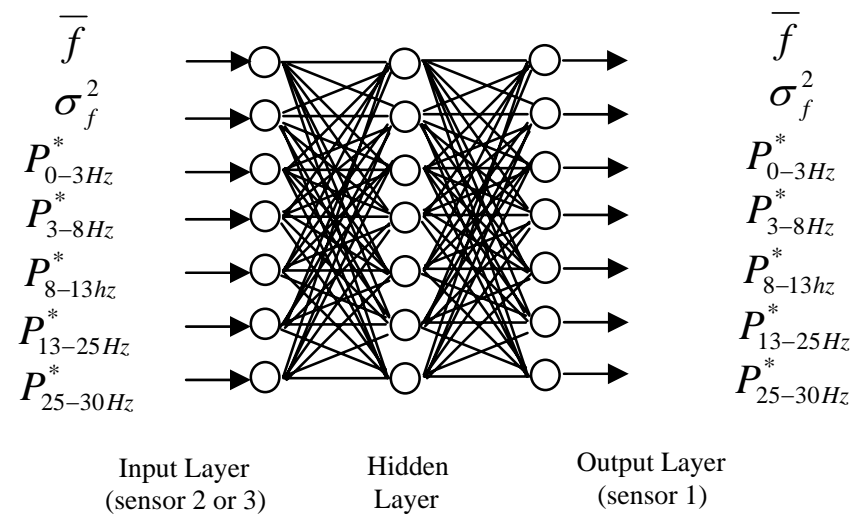

Figure 3.9: Representation of the configuration of ANN-2. For training, input parameters are from either Sensor 2 or Sensor 3, while output parameters are from Sensor 1. 


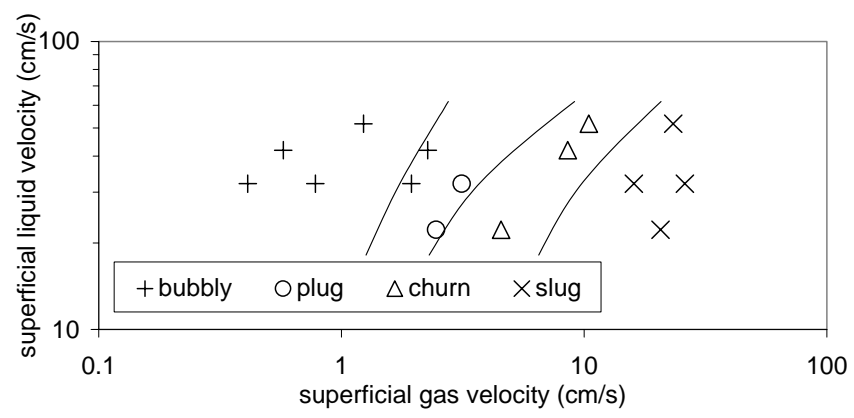

(a)

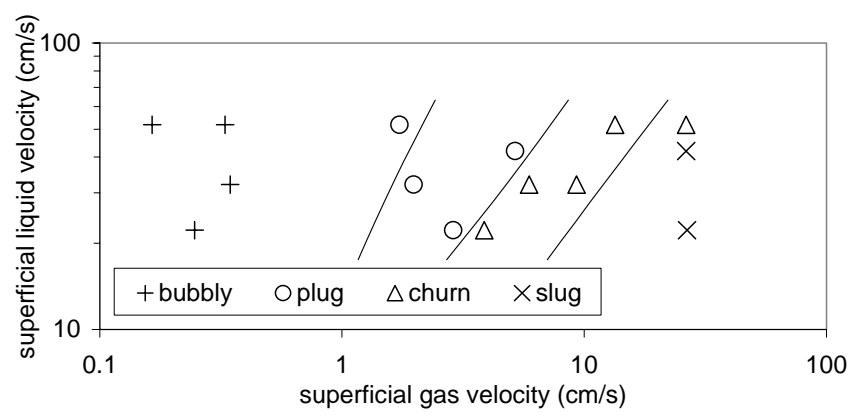

(b)

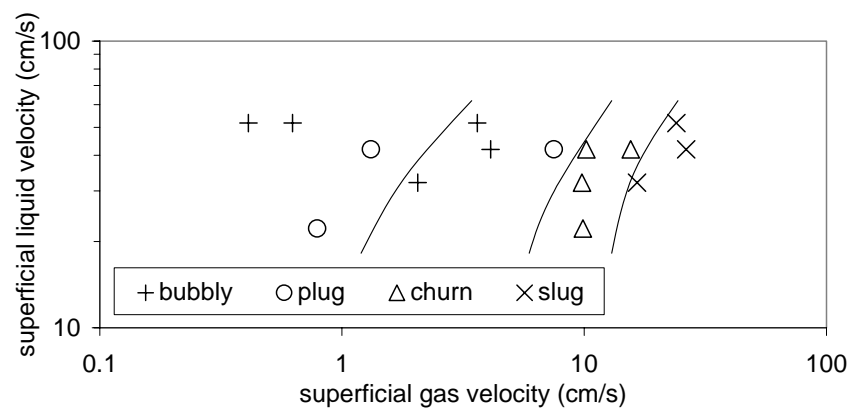

(c)

Figure 3.10: Comparison between the prediction of the ANN and the test subset of data for Sensor 2: (a) $0.5 \%$ pulp consistency; (b) 1.0\% pulp consistency; (c) 1.5\% pulp consistency. (Regime boundaries are from experiments; symbols are model predictions.) 


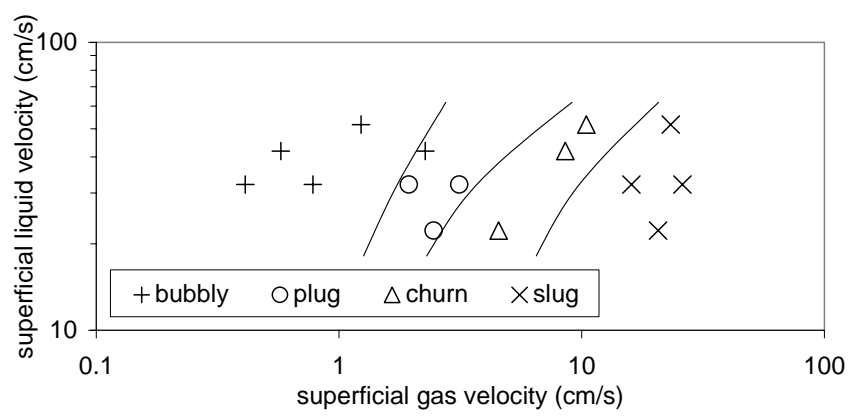

(a)

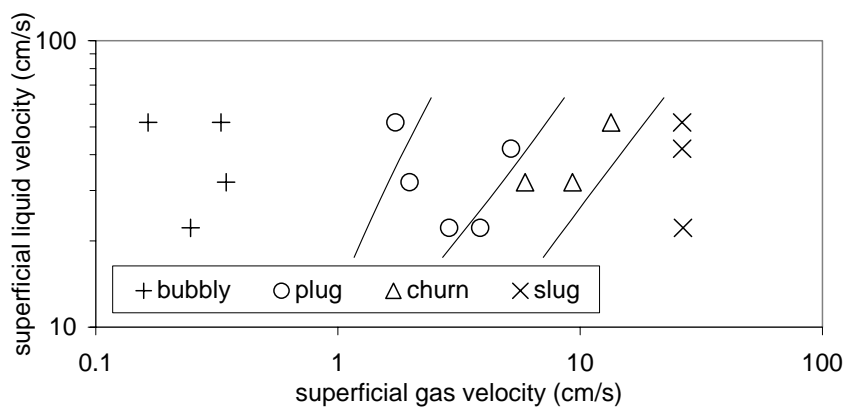

(b)

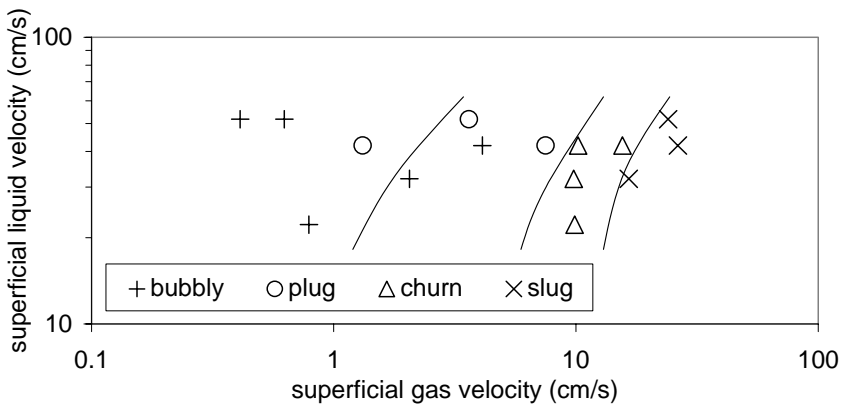

(c)

Figure 3.11: Comparison between the prediction of the ANN and the test subset of data for Sensor 3: (a) $0.5 \%$ pulp consistency; (b) 1.0\% pulp consistency; (c) 1.5\% pulp consistency. (Regime boundaries are from experiments; symbols are model predictions.) 


\subsection{References for Chapter 3}

Balaban, M. O., Korel, F., Odabasi, A. Z., and Folkes, G. (2000). Transportability of data between electronic noses: mathematical methods, Sensors and Actuators, B 71, 203-211.

Bennington, C. P. J., Azevedo, G., John, D. A., Birt, S. M., and Wolgast, B. H. (1995). The yieldstress of medium- and high-consistency mechanical pulp fiber suspensions at high gas contents, J. Pulp Paper Science, 21, 111-118.

Cai, S., Toral, H., Qiu, J., and Archer, J. S. (1994). Neural network based objective flow regime identification in air-water two-phase flow, Can. J. Chem. Eng., 72, 440-445.

Cai, Y., Wambsganss, M. W., and Jendrzejczyk, J. A. (1996). Application of chaos theory in identification of two-phase flow patterns and transitions in a small, horizontal, rectangular channel, J. Fluids Eng., 118, 383-390.

Chen, R. C., Reese, J., and Fan, L.-S. (1994). Flow structure in a three-dimensional bubble column and three-phase fluidized bed, AICHE J., 40, 1093-1104.

Dence, C. W. and Reeve, D. W., editors (1996). Pulp bleaching: principles and practice, TAPPI Press, Atlanta, GA.

Drahos, J., and Cermak, J. (1989). Diagnostics of gas-liquid flow patterns in chemical engineering systems, Chem. Eng. Process., 26, 147-164.

Drahos, J., Zahradnik, J., Puncochar, M., Fialova, M., Bradka, F. (1991). Effect of operating conditions on the characteristics of pressure fluctuations in a bubble column, Chem. Eng. Process, 29, 107-115.

Duffy, G. G., Lee, P. F. W. (1978). Drag reduction in the turbulent flow of wood pulp suspensions, Appita, 31, 280-286.

Duffy, G. G., Titchener, A. L. (1975). The disruption shear stress of pulp networks, Svensk Papperstidn, 13, 474-479.

Duffy, G. G., Titchener, A. L., Lee, P. F. W., Moller, K. (1976). The mechanism of flow of pulp suspensions in pipes, Appita, 29, 363-370.

Fang, L. S., Sunil, S., and Wisecarver, K. (1986). Pressure fluctuation measurements and flow regime transitions in gas-liquid-solid fluidized beds, AICHE J., 32, 338-340.

Franca, F., Acikgoz, M., Lahey, R.T., Jr., and Clausse, A. (1991). The use of fractal techniques for flow regime identification, Int. J. Multiphase Flow, 17, 545-552. 
Garner, A.E., and Heindel, T.J. (2000). The effect of fiber type on bubble size. J. Pulp Paper Sci., 26, 266-269.

Gupta, S., Liu, P. H., Svoronos, S. A. (1999). Hybrid first-principles/neural networks model for column flotation. AICHE J., 45, 557-566.

Hayes, M. (1996). Statistical digital signal processing and modeling. John Wiley \& Sons.

Heindel, T.J. (1999). Bubble size measurement in a quiescent fiber suspension. J. Pulp Paper Sci., 25, 104-110.

Heindel, T.J., and Garner, A.E. (1999). The effect of fiber consistency on bubble size. Nord. Pulp Paper Res. J., 14, 171-178.

Heindel, T. J.; Monefeldt, J. L. Flash X-ray radiography for visualizing gas flows in opaque liquid/fiber suspension. $6^{\text {th }}$ Intl. Symp. Gas-Liquid Two-Phase Flows, Vancouver, BC, ASME Press, June 22-26, 1997.

Hubbard, M.G. and Dukler, A.E. (1966). The characterization of flow regimes for horizontal twophase flow, Proc., Heat Transfer and Fluid Mech. Inst., Standford University Press.

Jones, O. C. and Zuber, N. (1975). The interrelation between void fraction fluctuations and flow patterns in two-phase flow, Int. J. Multiphase Flow, 2, 273-306.

Justice, A. C., Covinsky, K. E., and Berlin, J. A. (1999). Assessing the generalizability of prognostic information, Ann Intern Med., 130, 515-524.

Lin, P. Y., and Hanratty, T. J. (1986). Detection of slug flow regimes in vertical two-phase flow using differential pressure fluctuations, Nucl. Eng. Design, 95, 221-231.

Lindsay, J. D., Ghiaasiaan, S. M., and Abdel-Khalik, S. I. (1995). Macroscopic flow structures in a bubbling paper pulp-water slurry, Ind. Eng. Chem. Research, 34, 3342-3354.

Mandhane, J. M., Gregory, G. A., and Aziz, K. (1974). A flow pattern map for gas-liquid flow in horizontal pipes, Int. J. Multiphase Flow, 1, 537-553.

MATLAB 6.1 Tutorial, The Mathworks, Inc., 2003.

Matsumi, G. (1984). Identification of flow regimes in vertical gas-liquid two-phase flow using differential pressure fluctuations, Int. J. Multiphase Flow, 10, 711-720.

Matsumoto, S., and Suzuki, M. (1984). Statistical analysis of fluctuations of froth pressure on perforated plates without downcomers, Int. J. Multiphase Flow, 10, 2, 217-228.

Merilo, M., Dechene, R. L., and Cichowlas, W. M. (1977). Void fraction measurement with a rotating field conductance gauge, J. Heat Transfer, Transactions of ASME, 99, 330-332.

Mi, Y., Ishii, M., and Tsoukalas, L. H. (1998). Vertical two-phase flow identification using advanced instrumentation and neural networks, Nuclear Eng. Design, 184, 409-420. 
Mi, Y., Ishii, M., Tsoukalas, L. H. (2001). Flow regime identification methodology with neural networks and two-phase flow models, Nuclear Eng. Design, 204, 87-100.

Mishima, K., and Ishii, M. (1983). Flow regime transition criteria for upward two-phase flow in vertical tubes, Int. J. of Heat and Mass Transfer, 27, 723-737.

NeuroShell ${ }^{\circledR} 2$ release 4.0, Copyright@ 1993-1998, Ward Systems Group, Inc, Frederick, MD 21703.

Proakis, J. G., and Manolakis, D. G. (1996). Digital signal processing: principles, algorithms, and applications. New Jersey: Prentice-Hall.

Reese, J., Jiang, P. and Fan, L. -S. (1996). Bubble characteristics in three-phase systems used for pulp and paper processing, Chem. Eng. Sci., 51, 2501-2510.

Shim, W., and Jo, C.H. (2000). Analysis of pressure fluctuations in two-phase vertical flow in annulus, J. Industrial and Eng. Chem. (Seoul), 6, 167-173.

Spedding, P.L. and Spence, D.R. (1993). Flow regimes in two-phase gas-liquid flow, Int. J. Multiphase Flow, 19, 245-280.

Taitel, Y., Barnea, D., and Dukler, A. E. (1980). Modeling flow pattern transitions for steady upward gas-liquid flow in vertical tubes, AICHE J., 26, 345-354.

Tsoukalas, L. H., and Uhrig, R. E. (1997). Fuzzy and neural approaches in engineering. New York: John Wiley \& Sons.

Wambsganss, M. W., Jendrzejczyk, J. A., and France, D. M. (1994) Determination and characteristics of the transition to two-phase slug flow in small horizontal channels, $J$. Fluids Eng., 116, 140-146.

Weisman, J., Duncan, O., Gibson, J., and Crawford, T. (1979). Effect of fluid properties and pipe diameter in two-phase flow patterns in horizontal lines, Int. J. Multiphase Flow, 5, 437462.

Welch, P. D. (1967). The use of fast Fourier transform for the estimation of power spectra: a method based on time averaging over short, modified periodograms, IEEE Trans. Audio Electroacoustics, AU-15, 70-73.

Xie, T., Ghiaasiaan, S. M., Karrila, S., and McDonough, T. (2003a). Flow regimes and gas holdup in paper pulp-water-gas three-phase slurry flow, Chem. Eng. Sci., 58, 1417-1430. 
Xie, T, Ghiaasiaan, S. M., and Karrila, S. (2003b). Flow regime identification in gas-liquid-pulp fiber slurry flows based on pressure fluctuations using artificial neural networks, to appear in Industrial and Engineering Chemistry Research.

Zhang, J.-P., Grace, J. R., Epstein, N., and Lim, K. S. (1997). Flow regime identification in gasliquid flow and three-phase fluidized beds, Chem. Eng. Science, 52, 3979-3992. 
Chapter 4: Experimental Study of the Gas-Liquid Interfacial Surface Area Concentration 


\section{NOTATIONS}

$A_{i}^{\prime \prime} \quad$ Dimensionless average interfacial area concentration $\left(=a_{i}{ }^{\prime \prime} \sqrt{\sigma /(g \Delta \rho)}\right)$

$a_{i}^{\prime \prime} \quad$ Average effective interfacial surface area concentration $\left(\mathrm{m}^{2} / \mathrm{m}^{3}\right)$

C Concentration ( $\mathrm{kmol} / \mathrm{m}^{3}$ or $\left.\mathrm{mol} / \mathrm{lit}\right)$

D Column diameter (m)

$D_{L} \quad$ Diffusivity of reacting component in the liquid phase $\left(\mathrm{m}^{2} / \mathrm{s}\right)$

$g \quad$ Gravitational acceleration $\left(\mathrm{m} / \mathrm{s}^{2}\right)$

$k_{2} \quad$ Second order rate constant of $\mathrm{CO}_{2}$ and $\mathrm{NaOH}$ reaction $\left(\mathrm{m}^{3} / \mathrm{kmol}-\mathrm{s}\right)$

$k_{L} \quad$ Liquid-side mass transfer coefficient $\left(\mathrm{kg} / \mathrm{m}^{2}-\mathrm{s}\right)$

$H \quad$ Test section height (m)

$\mathrm{He}_{\mathrm{CO}_{2}} \quad$ Henry's coefficient for $\mathrm{CO}_{2}-$ water (Pa)

$M \quad$ Molar mass $(\mathrm{kg} / \mathrm{kmol})$

$N_{i, \mathrm{CO}_{2}}^{\prime \prime} \quad$ Interfacial molar flux of $\mathrm{CO}_{2}\left(\mathrm{kmole} / \mathrm{m}^{2}\right.$-s $)$

$P \quad$ Pressure $(\mathrm{Pa})$

$R \quad$ Universal gas constant $\left(\mathrm{J} \mathrm{kmol}^{-1} \mathrm{~K}^{-1}\right)$

Re Reynolds number

$T \quad$ Temperature (K)

$U_{G S} \quad$ Gas superficial velocity (m/s)

$U_{L S} \quad$ Liquid superficial velocity $(\mathrm{m} / \mathrm{s})$

$X \quad$ Mole fraction

Z Axial coordinate (m)

Greek characters

$\Delta \quad$ Algebraic difference

$\eta \quad$ Consistency; or mass fraction of oven dried fiber in pulp-water mixture w/w (\%)

$\rho \quad$ Density $\left(\mathrm{kg} / \mathrm{m}^{3}\right)$

$\sigma \quad$ Surface tension (N/m); standard deviation

$\xi \quad$ Parameter defined in Eqn. (14)

Subscripts

$\mathrm{CO}_{2} \quad$ Carbon Dioxide

ex Exit

$G \quad$ Gas

$g \quad$ Saturated water vapor

in Inlet

L Liquid

$\mathrm{N}_{2} \quad$ Nitrogen

$\mathrm{OH} \quad$ Alkali

Sat Saturation

$u \quad$ Liquid-side interface

w Water

Superscript

Average 


\subsection{Introduction}

The importance of gas-liquid-solid slurry three-phase flows in various branches of chemical, petrochemical, and process industries is well recognized, and numerous studies have addressed its various aspects (Dudukovic, Larachi and Mills, 1999). Relatively little is understood about the basic hydrodynamics and transport phenomena in gas-liquid-fiber slurry three phase flow systems, however, despite its crucial role in several important branches of industry. The scarcity of published investigation dealing with three-phase fibrous slurries is primarily a result of the complexity of these systems.

Gas-liquid fiber slurry three-phase flow occurs in a number of stages of paper production and recycling, including delignification and bleaching. Bleaching is achieved by dissolving an oxidizing agent such as chlorine, oxygen or ozone in an aqueous fiber suspension. The oxidizing agent is typically introduced into the mixture as fine bubbles. It must dissolve in water, be transported to the suspended pulps, and diffuse towards the fiber-liquid interface, before it can chemically react with lignin. The relatively low solubility of oxygen and ozone in water can cause poor efficiency in oxygen and ozone-based bleaching devices, and the performance of these devices can be improved by increasing the gas-liquid interfacial area. Understanding the role and effect of pulp fibers on the hydrodynamics of fiber-liquid-gas three-phase slurries is evidently crucial for the development of practical methods that would lead to the optimization of bleaching devices.

The main cause of the complexity of pulp slurry hydrodynamics is flocculation (entanglement of fiber groups to conformations that possess mechanical strength) that leads to the formation of three-dimensional networks (flocs) that resist shear, blocks the passage of bubbles through the networks, and complicates the mixture hydrodynamics.

Some important hydrodynamic characteristics of liquid-pulp fiber gas slurries have been experimentally studied in the recent past (Lindsay et al., 1995; Reese, Jiang and Fan, 1996; Heindel, 1999; Heindel and Garner, 1997; Garner and Heindel, 2000; Xie et al., 2003). More recent studies dealing with fundamentals of very dilute fiber suspensions include (Dong et al., 2003). Recent studies also include investigations dealing with the mechanisms of fiber-level oxidation (Zhang, 1998; Bennington, Zhang and Heiningen, 1999), and the efficient design of 
low and medium consistency in high-shear mixers (Bennington, Owusen and Francis, 1997; Rewatkar and Bennington, 2000).

In this paper we report on an experimental investigation into the effect of pulp fibers on the average interfacial surface area concentration in a short vertical column subject to co-current upward flows of gas-aqueous pulp slurry mixtures. To our knowledge, no other similar study has been reported in the open literature. The experimental study is performed using the test apparatus, previously utilized for hydrodynamics studies, as described in Chapters 1, 2 and 3 (Xie et al., 2003). The test section, however, has been modified. The interfacial surface area measurement is done using the gas $\left(\mathrm{CO}_{2}\right)$ chemical absorption technique. Various approaches including optical, ultrasonic, multiple probe, and chemical methods, have been used in the past for interfacial surface area measurement (Akita and Yoshida, 1974; Al Taweel et. al, 1984; Banerjee and Lahey, 1981; Serizawa et al., 1975; Greaves and Kobbacy, 1984; Dankwerts and Sharma, 1966). The chemical method is among the most popular, and is based on the determination of the absorption rate of a gaseous substance by the liquid followed by a chemical reaction with a fast, irreversible, first or second order reaction, the average interfacial area concentration can be measured according to the surface renewal theory of Danckwerts (1955).

\subsection{Experimental Apparatus}

Except for some important modifications, the experimental apparatus used in this study was the same as the apparatus previously used by Xie et al. (2003). Therefore, only a brief description of the apparatus is provided here, and more detail can be found in the aforementioned reference.

A schematic of the test loop is shown in Fig. 4.1. The main components of the loop are a feed tank and a receiving tank, a circulation pump, one variable speed static Lightning mixer in each tank, and a test section. The purpose of the mixers is to keep the liquid-fiber slurry as wellmixed as possible by not allowing the pulp fibers to settle down at the bottom of the tanks. The test section is a $1.83 \mathrm{~m}$ long transparent acrylic vertical bubble column with an inner diameter of $5.08 \mathrm{~cm}$. The gas mixture is injected at the bottom of the test section. Two pressure gauges are attached to the test section at the depicted locations, and their readings are taken during the tests. A conical constriction at the top of the test section channels the gas-water-fiber mixture from the 
column into a $8 \mathrm{~cm}$ diameter pipe. The latter pipe is constructed as a "T" section with one end open to atmosphere to facilitate gas escape, while the other end allows the mixture to enter the receiving tank. The receiving and feed tanks are interconnected and are both open to atmosphere in order to provide time for entrained gas to leave the system. The water/fiber mixture is circulated continuously during tests by a Diskflow pump, which was tested to operate at up to $11 \%$ consistency without plugging. The pulp flow rates are monitored with a Krohne IFC080 Smart magnetic flow meter and encompass a range of 0 to 2 lit/s.

Research grade $\mathrm{CO}_{2}$ and $\mathrm{N}_{2}$ gases are supplied from capsules at desired flow rates measured by two Top Trak flow meters, and mixed in a single tube before injection into the test section. The flow meter used for $\mathrm{N}_{2}$ has a flow rate range of $0 \sim 40$ SLPM (Standard Liter Per Minute), while the second one used for $\mathrm{CO}_{2}$ has a range of $0 \sim 50$ SLPM; and both are calibrated against nitrogen gas. The flow meter used for $\mathrm{CO}_{2}$ thus needed a flow rate correction factor of 0.74 (a value provided by the manufacturer).

The gas mixture was injected from the mixing tube into the test section via four identical tubes that had inner diameters of $6.3 \mathrm{~mm}$ each, and were connected to the column, perpendicular to the test section inner wall, at the lower end of the column. The tubes were installed at $90^{\circ}$ intervals around the column periphery.

The column is mounted on a standby pipe frame, with a guided carriage affixed to the pipe frame and designed to travel along the length of the test section. A Gamma-ray densitometer equipped with a $45 \mathrm{mCi}$ Americium-241 source and an Ortec Model 276 detector is housed on the carriage. The source and detector provide for the passage of a beam of Gamma rays approximately $5 \mathrm{~mm}$ in diameter, through the test section. The source and detector can be moved manually in vertical and lateral directions, and can be used for the measurement of chordaverage void fractions at various parts of the test section (see Lindsay et al. 1995, for further details).

Two sampling ports are provided in the test loop, one in the piping about $35 \mathrm{~cm}$ upstream from the test section inlet, the other one at the exit of the test section. These sampling ports are connected to $12.7 \mathrm{~mm}$ inner diameter stainless steel collector pipes equipped with quick stop valves. 
It should be noted that industrial paper making systems in which gas-liquid-pulp threephase flow takes place are typically much larger than our test section. The geometric configurations of the industrial systems, furthermore, preclude fully developed flow conditions. The unavailability of general scaling laws for multiphase flows renders the precise experimental simulation of prototypical systems very difficult. This experimental study is thus meant to shed

light on the hydrodynamics and interfacial transport issues associated with the multiphase flows of interest rather than directly simulating prototypical systems.

\subsection{Experimental Procedures}

Appropriate amounts of fully bleached Kraft (FBK) softwood pulp and de-ionized (DI) water were added into the tanks. The pulp was dispersed by hand as much as possible before putting into the tanks. The mixer and circulating pump were then kept on for an hour or more to ensure effective mixing. Continuously flowing paper pulp suspensions can trap and maintain small bubbles well after through put gas has been terminated. In their experiments, Lindsay et al. (1995) found that the residual void fraction in continuously circulating paper pulp slurries is small, however, typically only up to $2 \%$. Residual void fraction also can happen in pure water (without any pulp) due to continuous circulation into the system. For such cases the residual void fraction is even less than that of the pulp slurry cases. Therefore, attempt was not taken to eliminate the possible residual entrapped air from the paper pulp slurry before tests were conducted. Sodium hydroxide was added to the mixture as mixing was underway. Sufficient caustic was added to obtain a pH value in the 13.16 to 13.9 range. High concentration of $\mathrm{NaOH}$ was needed in order to ensure a fast first-order, chemical reaction with $\mathrm{CO}_{2}$. The pulp appeared to absorb much of the caustic, and we typically had to mix $28 \mathrm{~mL}$ of $50 \%$ (w/w) aqueous $\mathrm{NaOH}$ per liter of the mixture to obtain the aforementioned $\mathrm{pH}$ values. Following the adjustment of mixture $\mathrm{pH}$ and its effective mixing, the desired gas and liquid flow rates were established. The circulating pump was kept running for several more minutes to have a well mixed caustic solution. Almost all solution was then transferred to the beginning tank, and the inter-tank valves were closed. The pump, gas flow valves, and the valve leading to the bubble column all were then turned on, and all flow rates for the run were set at their desired values. At this point, one mass transfer batch run would be conducted, whereby samples were simultaneously extracted from the two sampling ports. One or more replications of the case were also 
performed. Following the completion of sample extractions, Gamma-Ray Densitometry was performed along the diameter of the column at two vertical positions: $50 \mathrm{~cm}$ up from the bottom and $50 \mathrm{~cm}$ down from the top. An average value of these two measured void fractions was used in the analysis. The samples taken from the batch run were titrated within 5 to 10 hrs of the experiment. Ranges of the flow rates and other parameters, all representing the test column inlet, are as follows: pulp consistency $=0.0 \sim 2.18 \%$; caustic molarity (based on the titration) $=0.146$ $\sim 0.772 \mathrm{~mol} /$ lit, liquid superficial velocity $=15 \sim 94 \mathrm{~cm} / \mathrm{s}$; average gas superficial velocity $=17 \sim$ $54.5 \mathrm{~cm} / \mathrm{s}$; average $\mathrm{CO}_{2}$ mole fraction in the gas mixture $=0.19 \sim 0.95$. Standard titration procedure was followed for determining the concentrations of $\mathrm{OH}, \mathrm{CO}_{3}$, and $\mathrm{HCO}_{3}$ in samples, using METTLER DL 70 ES titrator with electrode model 'METTLER TOLEDO DG 111 - Sc'. The titrator was calibrated daily before the first titration of the day. The collected samples from the experiment were filtrated by glass fiber filter papers to remove the interferences of the pulp fibers. Sub-samples for titration were drawn from the filtered sample solution by either volumetric (using a pipette) or gravimetric (using a scale) method. Each of the sub-samples was approximately $20 \mathrm{~cm}^{3}$ or $20 \mathrm{~g}$.

The viscosity of the pulp slurries was not directly measured in this study. Pulp consistency did not exceed $2 \%$ in our experiments. The frictional loss for a pulp consistency below $2 \%$ is approximately equal to that of water (Heald, 1988), implying that at such low consistencies pulp stocks have a viscosity close to water. The viscosity for a $2 \% \mathrm{NaOH}$ solution at $25^{\circ} \mathrm{C}$ is about $1 \times 10^{-3} \mathrm{~N}-\mathrm{s} / \mathrm{m}^{2}$, and the latter is a good estimate for the viscosity of the pulp slurries in our experiments.

\subsection{Data Analysis}

Sources of uncertainty in the experiments included the usual instrument and measurement precision errors; possible presence of entrained micro-bubbles in the samples; the change in chemical make-up of the liquid during sampling; and the possibility of backflow near the sampling ports. The Gamma-ray densitometer void fraction measurements also included the uncertainty associated with the random nature of Gamma-ray counts. In addition, the data scattering common in multiphase flow experiments of this type must be considered. In view of these issues, experimental runs representing individual cases in the test matrix to be presented later were repeated 3 to 9 times. For any individual entry in the test matrix, a set of repetition 
runs were accepted only if the measured results showed good reproducibility. Lack of good reproducibility, which was observed in a few cases, was assumed to indicate error in measurement procedures. The data that lacked reproducibility would therefore be discarded, and fresh sets of experiments would be performed instead. The effects of various experimental uncertainties were included in the data analysis, although for most cases the cumulative effect of experimental uncertainties was smaller than the data scatter.

The effective average column interfacial area concentration, $a_{i}{ }^{\prime \prime}$, is calculated for each run assuming: (1) quasi-steady state, one-dimensional flow; (2) liquid side-controlled mass transfer; (3) pseudo first-order chemical reaction between absorbed $\mathrm{CO}_{2}$ and dissolved $\mathrm{NaOH}$ in water; and (4) negligible effect of absorption / desorption of species other than $\mathrm{CO}_{2}$ on the modeled mass transfer process. Assumption 1 is a simplifying idealization and given that time averaged measurements are of interest, is reasonable. Assumption 3 is widely accepted (Nijsing et. al. 1959, Kasturi and Stepanek 1974). All other assumptions are also reasonable.

The liquid and gas-side species conservation equations can then be written as:

Conservation of alkaline species in liquid:

$$
\frac{\rho_{L} U_{L S}}{M_{L}} \frac{d}{d z} X_{\mathrm{OH}, L}=-2 a_{i}^{\prime \prime} N_{i, \mathrm{CO}_{2}}^{\prime \prime}
$$

Conservation of $\mathrm{CO}_{2}$ species in the gas phase:

$$
\frac{d}{d z}\left(\frac{\rho_{G} U_{G S}}{M_{G}} X_{\mathrm{CO}_{2}, G}\right)=-a_{i}^{\prime \prime} N_{i, \mathrm{CO}_{2}}^{\prime \prime}
$$

Overall mass conservation for the gas phase:

$$
\frac{d}{d z}\left(\frac{\rho_{G} U_{G S}}{M_{G}}\right)=-a_{i}^{\prime \prime} N_{i, C_{2}}^{\prime \prime}
$$

where

$$
\begin{aligned}
& C_{\mathrm{OH}}=\left[O H^{-}\right]=C_{L} X_{\mathrm{OH}, L} \\
& C_{L}=\rho_{L} / M_{L}
\end{aligned}
$$

The molar flux of $\mathrm{CO}_{2}$ at the interface, in accordance with Danckwerts' surface renewal theory (Danckwerts 1955), is represented by 


$$
N_{i, \mathrm{CO}_{2}}^{\prime \prime}=C_{\mathrm{CO}_{2}, u} \sqrt{D_{L} k_{2} C_{\mathrm{OH}}}
$$

where

$$
\begin{aligned}
& X_{\mathrm{CO}_{2}, u}=\frac{X_{\mathrm{CO}_{2}, \mathrm{G}} \mathrm{P}}{\mathrm{He} \mathrm{CO}_{2}} \\
& C_{\mathrm{CO}_{2}, u} \approx C_{w} X_{\mathrm{CO}_{2}, u} \\
& M_{G}=\left(X_{\mathrm{CO}_{2}, \mathrm{G}} M_{\mathrm{CO}_{2}}\right)+\left(1-X_{\mathrm{CO}_{2}, \mathrm{G}}-X_{g}\right) M_{N_{2}}+\left(X_{g} M_{w}\right) \\
& X_{g}=\frac{P_{\mathrm{Sat}}}{P}
\end{aligned}
$$

where, $P$ is total local pressure, and is estimated from

$$
P=P_{i n}-\frac{P_{i n}-P_{e x}}{H} Z
$$

where $H$ is the height of the test section. Also, assuming ideal gas:

$$
\rho_{G}=\rho_{g}+\frac{\left(P-P_{S a t}\right)}{R T_{L} / M_{G}}
$$

The rate constant $\mathrm{k}_{2}$, for the irreversible reaction between $\mathrm{CO}_{2}$ and $\mathrm{NaOH}$, was estimated from (Danckwerts, 1970):

$$
\log _{10} k_{2}=13.635-\frac{2895}{T}
$$

For each experimental case, the ordinary differential equations (4.1- 4.3) were numerically integrated starting from the test section inlet $(z=0)$, to the exit $(z=H)$. The numerical calculations were repeated, and $a_{i}$ " was iteratively changed until the estimated $X_{O H, L}$ at exit matched the experimentally measured value.

\subsection{Results and Discussion}

\subsubsection{Test Matrix and Data}

The parameters that could potentially influence $a_{i}$ " in a run include the liquid superficial velocity $U_{L S ;}$ the average $\mathrm{NaOH}$ concentration, $\bar{C}_{O H}$; the average superficial gas velocity, $\bar{U}_{G S}$; the average mole fraction of $\mathrm{CO}_{2}$ in the gas, $\bar{X}_{\mathrm{CO}_{2}, G}$; and the column average void fraction (gas holdup). Parameters $\bar{X}_{\mathrm{CO}_{2}, G}$ and $\bar{U}_{G S}$ can be calculated by performing an overall species mass 
balance on the test section based on sampling results. Since the extent of total rate of $\mathrm{CO}_{2}$ absorption in each test case is not known a priori, however, the test matrix was designed based on the inlet values of all parameters. Parameters $\mathrm{COH}_{\mathrm{OH}}$ and $X_{\mathrm{CO}_{2}, \mathrm{G}}$ of course should not directly influence $a_{i}{ }^{\prime \prime}$. Parameter $C_{\mathrm{OH}}$ was included among the important parameters for the test matrix design for testing the validity of Danckwerts' theory for our experiments. Furthermore, parameter $X_{\mathrm{CO}_{2}, \mathrm{G}}$ was included since its value varies between the test section inlet and outlet, leading to a reduction in $U_{G S}$ along the test section, and therefore a reduction in $a_{i}{ }^{\prime \prime}$.

The test matrix was determined using a rotatable, uniform-precision, central-composite method. This method, described in detail in Neter et. al. (1996), allows for an optimum design of a test matrix with a minimal number of tests that can provide for the estimation of all the important parametric dependencies. With 5 controllable variables (factors) at five levels, 33 runs were needed for this design. However, as mentioned earlier, to verify repeatability of these 33 tests, each was repeated 3 to 9 times.

\subsubsection{Parametric Dependencies}

The parametric effects of various factors on the average effective interfacial surface area concentration are discussed in this section. These parametric effects are deduced from the statistical analysis of the data, using the main factor effects (as described in Neter et al., 1996, for example). All parameters are presented in dimensionless form for convenience. Figure 4.2, plotted using the commercial software Minitab (Minitab, Inc., 2000), shows the effects of the main variables on the dimensionless interfacial area concentration, $A_{i}{ }^{\prime \prime}$. The plots depicted in Fig. 4.2 are basically components of the matrix plot generated by the aforementioned software. A matrix plot is a two-dimensional matrix of individual plots that provide the two-variable relationships among a number of variables all at once. The parametric dependence of $A_{i}$ " on any factor depends on the average trend of the depicted data points. Random scatter of the data points around an approximately horizontal mean, as noted for example, for the case of alkali, indicates that $A_{i}$ " is insensitive to the concentration of alkali. This trend is consistent with the assumed validity of the surface renewal theory. The data scatter also shows a weak dependence of $A_{i}$ " on the liquid superficial velocity (the latter represented by $R e_{L}=U_{L S} D / v_{L}$ ). $A_{i}{ }^{\prime \prime}$ depends strongly on the void fraction and gas superficial velocity (represented by 
$\overline{R e}_{G}=\bar{U}_{G S} D / \bar{v}_{G}$, with $\bar{U}_{G S}$ and $\bar{v}_{G}$ defined as mean gas superficial velocity and gas mixture viscosity in the test section). Gas mixture properties were calculated using the rules described in Edwards et al. (1979). The positive overall slope of the distributions of data points for the aforementioned factors, furthermore, indicates that $A_{i}$ " is an increasing function of both parameters, a trend that is well expected. The distribution of the data showing the effect of the mean mole fraction of $\mathrm{CO}_{2}$ in the gas mixture $\left(\bar{X}_{\mathrm{CO}_{2}}\right)$ suggests that $A_{i}$ " would decrease with increasing $\bar{X}_{\mathrm{CO}_{2}}$ in the experiments. However, this apparent dependence of $A_{i}$ " on $\bar{X}_{\mathrm{CO}_{2}}$ is primarily due to the fact that a significant fraction of the injected $\mathrm{CO}_{2}$ is absorbed in the test section, and this can lead to a sizable reduction in mean gas superficial velocity and therefore a reduction in $a_{i}{ }^{\prime \prime}$. An important parametric effect is caused by fiber consistency. There is little scatter in the consistency plot of Fig. 4.2 because we had good control over consistency. Evidently, $A_{i}$ " tends to decrease as consistency is increased up to a consistency of about $1.6 \%$. The effect of fibers and fiber consistency on the column hydrodynamic processes, and in particular on the interfacial area concentration is complicated, and has several attributes. The fibers modify turbulence, influence bubble coalescence and bubble rise velocity, and modify the overall flow patterns in the column. With respect to bubble coalescence, for example, fibers enhance coalescence as long as bubbles move faster than the pulp networks, while the opposite may occur when the velocity of bubbles is in fact lower than the velocity of the liquid-pulp mixture (Lindsay et al., 1995). Increased coalescence among bubbles in the lower part of the bubble column (where bubble coalescence leads to churn/slug flow regime in the remainder of the column), on the average, with increasing consistency for $\eta \leq 1.6 \%$, is likely to lead to the decreasing trend of $A_{i}$ " with increasing $\eta$ in the latter range. At higher consistencies the flocs are likely to be large and sturdy, and therefore capable of entrapping and maintaining some of the smaller bubbles, thereby leading to the apparent increasing $A_{i}{ }^{\prime \prime}$ with $\eta$. The effect of fiber consistency on the intricate flow pattern characteristics also obviously influences the interfacial area concentration. The complexity of the fiber consistency on all hydrodynamic and transport processes must be emphasized. Rewatkar and Bennington (2000) had used commercial laboratory-scale pulp mixer to measure the volumetric mass-transfer coefficient $\left(k_{L} a_{i}^{\prime \prime}\right)$. It is interesting to note that, although their system is totally different from that of the present study, 
they also found that volumetric mass transfer coefficient depends positively on the void fraction and negatively on the fiber consistency.

Table 4.1 shows the statistical correlation among different variables and $A_{i} "$. These correlation levels were calculated using the aforementioned Minitab (Minitab, Inc., 2000) statistical software. A positive correlation number between two variables implies a mutual positive effect between them (i.e., increasing either one would increase the other parameter), and vice versa. The levels of correlation between $A_{i}$ " and each of the depicted factors are of course consistent with the trends displayed in Fig. 4.2. The correlations between pairs of other parameters also depict some important internal associations. For example, the large and positive correlation between the gas flow rate (represented by $\overline{R e}_{G}$ ) and the void fraction indicates that they are correlated, as expected. As expected, there is also a strong effect of fiber consistency on void fraction. The effect of $\bar{X}_{\mathrm{CO}_{2}, \mathrm{G}}$, and its cause, have been discussed earlier. Other pair correlations are all small, as expected.

\subsubsection{Empirical correlations of the Data}

For convenience of the correlation development, the effect of pulp consistency is represented by the parameter

$$
\xi=10-\eta
$$

where $\eta$ is the pulp consistency, in weight percent of dry pulp in water. Attempt was made to develop empirical correlations of the forms:

$$
\begin{aligned}
& A_{i}{ }^{\prime \prime}=c_{1} \bar{\alpha}^{c_{2}} \operatorname{Re}_{L}^{c_{3}} \xi^{c_{4}} \\
& A_{i}{ }^{\prime \prime}=b_{1} \overline{R e}_{G}{ }^{b_{2}} \operatorname{Re}_{L}^{b_{3}} \xi^{b_{4}}
\end{aligned}
$$

These correlations can be useful for estimating the relative effect of various important factors on a column's average interfacial surface area concentration, although the correlations may not be directly applicable to columns with significantly different geometric characteristics. As discussed earlier, there was a strong association between $\bar{\alpha}$ and $\overline{R e}_{G}$; therefore only one of these two parameters was explicitly maintained in each expression. The results for Eqn. (4.15) were: 


$$
\begin{aligned}
& c_{1}=1.378 \times 10^{-4} \\
& c_{2}=1.26 \\
& c_{3}=0.311 \\
& c_{4}=2.62
\end{aligned}
$$

The standard deviation and the coefficient of determination for this fit are 0.1153 and 0.93 , respectively. The predictions of Eqn. (4.15) are compared with the experimental results in Fig. (4.3).

For Eqn. (4.16), the best fit was obtained with:

$b_{1}=1.448 \times 10^{-4}$

$b_{2}=0.763$

$b_{3}=-0.186$

$b_{4}=1.57$

The standard deviation and the coefficient of determination for this fit are 0.1562 and 0.85 , respectively. It should be pointed out that the apparent conflict between Eqns (4.15) and (4.16) with respect to the sign of the power of $R e_{L}$ is due to the relatively strong correlation between $\alpha$ and $R e_{L}$ (see Table 4.1). Equation (4.15) includes $\alpha^{C_{2}}$ on its right side, and this modifies its explicit dependence on $R e_{L}$. The true correlation between $A_{i}{ }^{\prime \prime}$ and $R e_{L}$ is negative, as noted in Table 4.1 and Fig. 4.2. The predictions of the latter expression are compared with the experimental results in Fig. 4.4. Equation (4.15) is evidently a better correlation, although Eqn. (4.16) is easier to apply.

\subsection{Concluding Remarks}

In this chapter we reported on an investigation into the effects of various parameters on the effective, average interfacial surface area concentration in a short vertical column subject to a through-flow of a paper pulp-water-gas three-phase mixture. The experiments were performed 
in a $1.83 \mathrm{~m}$-long column that was $5.08 \mathrm{~cm}$ in inner diameter. The average interfacial area concentration was quantified using the gas absorption technique, with $\mathrm{CO}_{2}$ as the transferred species, and sodium hydroxide as the reacting agent in the liquid. The test matrix was designed using the central-composite, uniform precision rotatable design method with 5 factors, each represented at 5 levels. A total of 33 test cases, each repeated 3 to 9 times, were performed, the tabulated experimental data were presented, and their statistical characteristics were analyzed, whereby important parametric dependencies were identified. The results confirmed that pulp affects all major hydrodynamic processes, including the interfacial surface area concentration. The experimental data were then empirically correlated. 


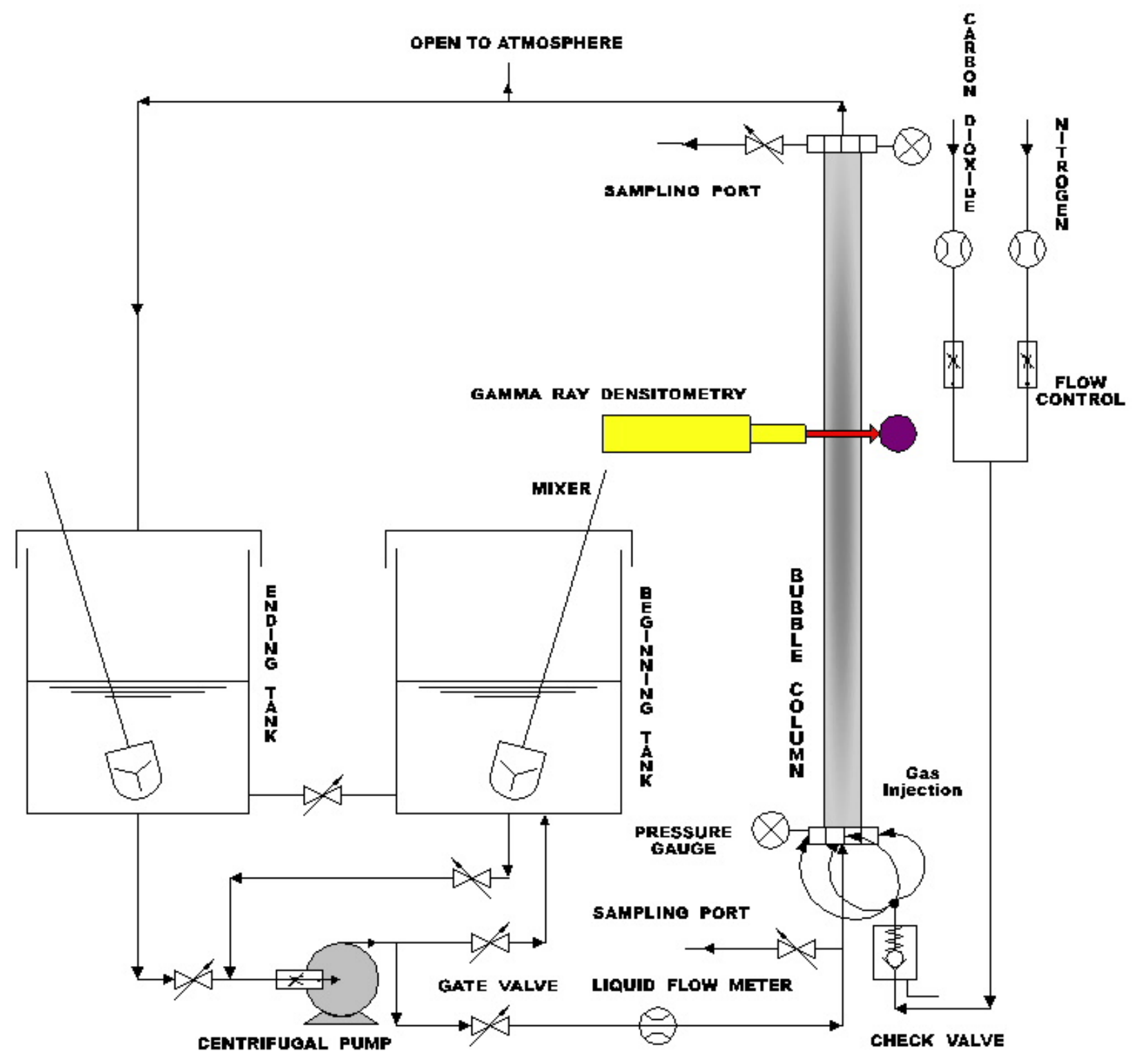

Figure 4. 1: The test loop 


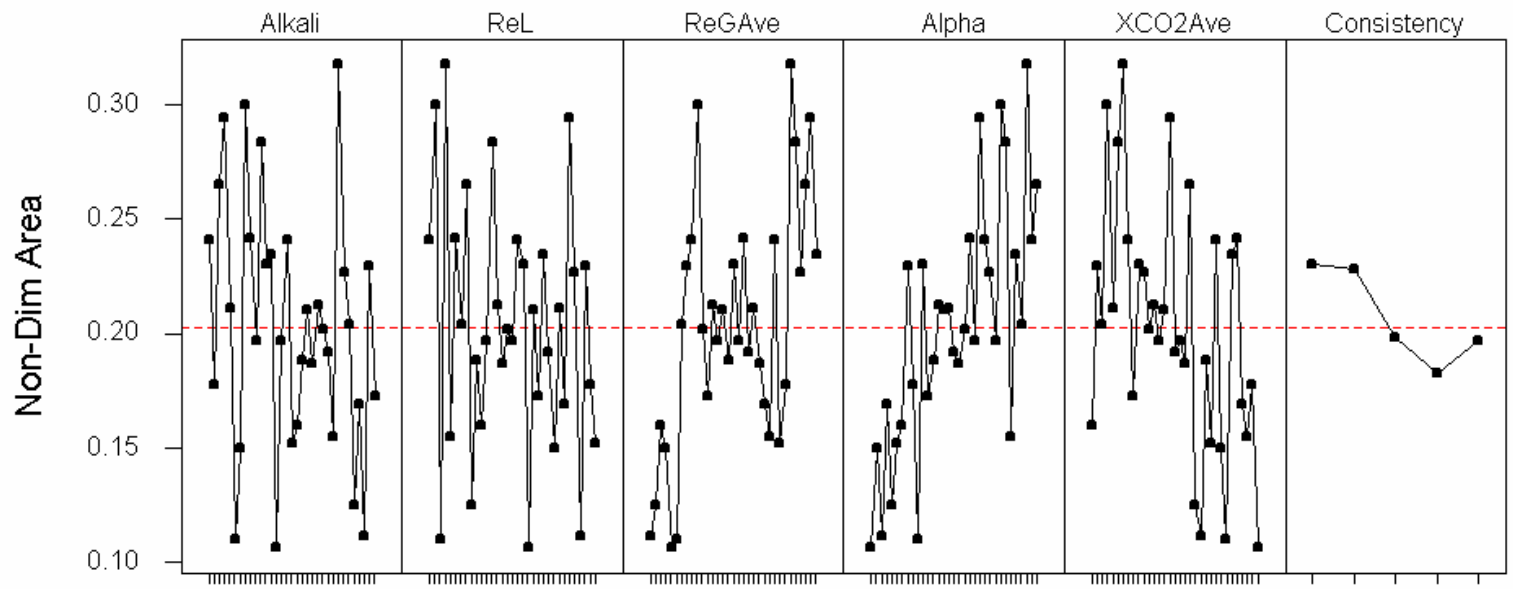

Figure 4.22: Main factor effects plots showing the effects of predictor variables on the response variable. 


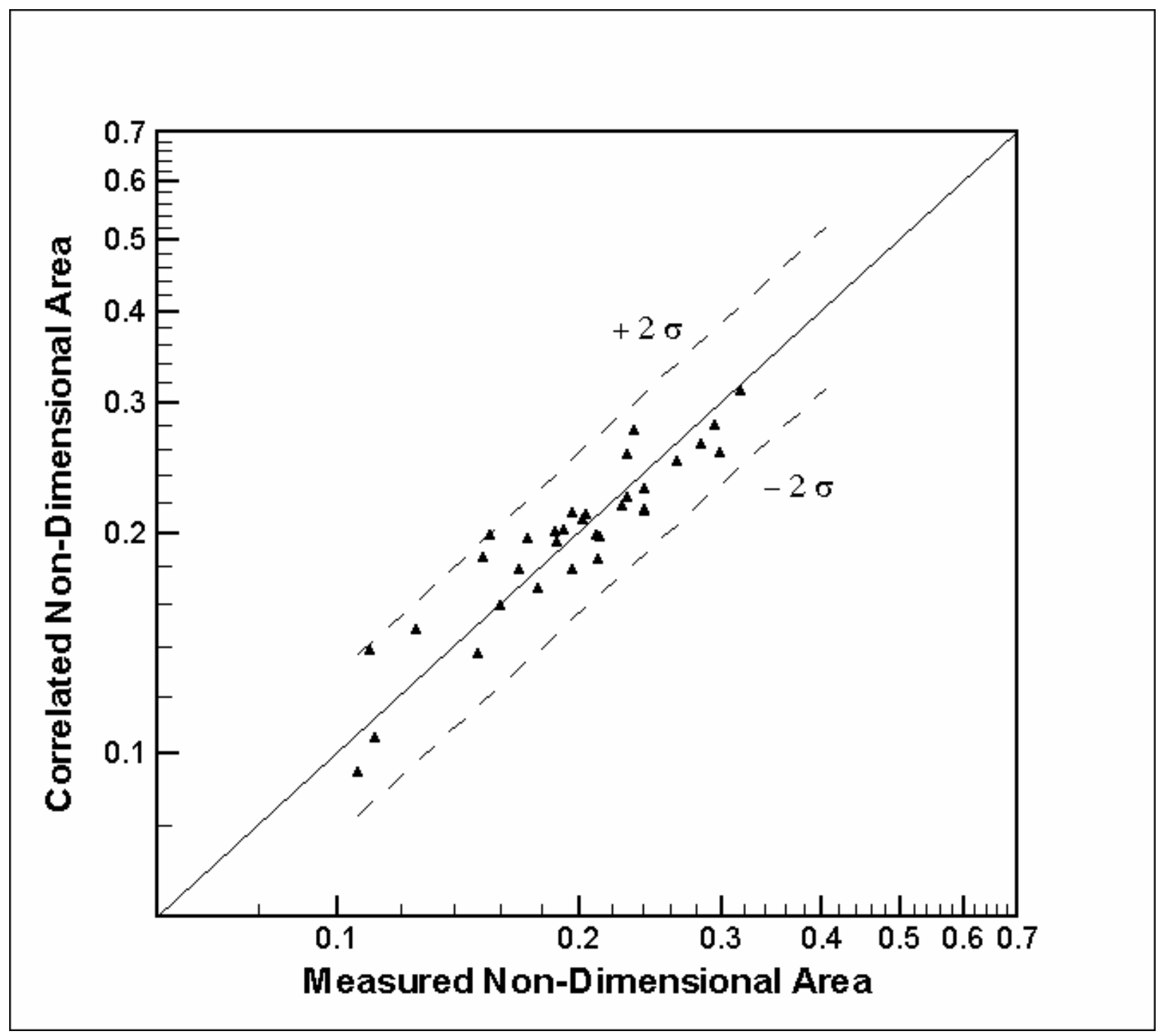

Figure 3: Comparison of the interfacial surface area concentration values obtained from the experimental and the correlation (Eqn. 15). 


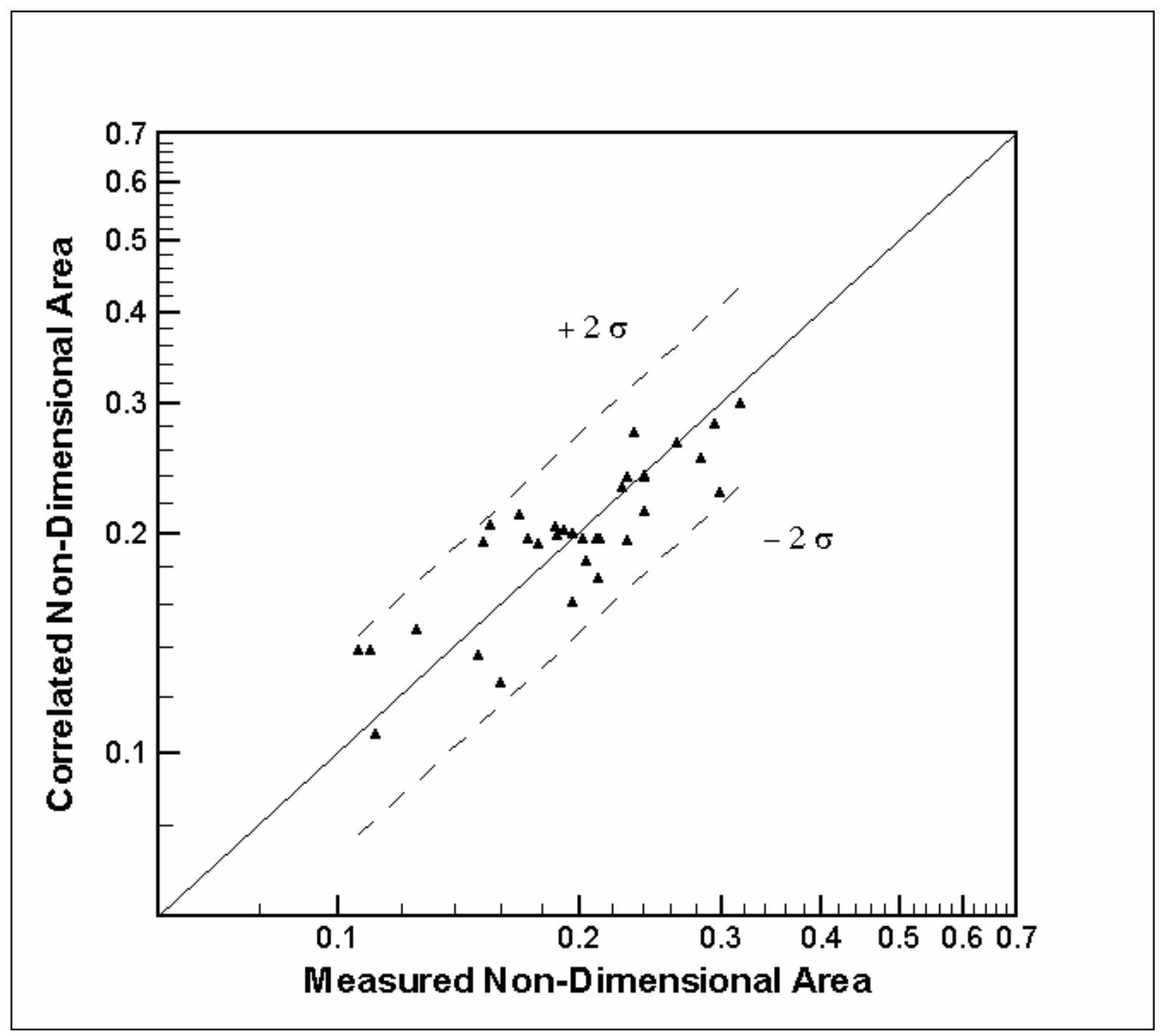

Figure 4.4: Comparison of the interfacial surface area concentration values obtained from the experimental and the correlation (Eqn. 16). 
Table 4.1: Correlations among the main variables and the interfacial surface area

\begin{tabular}{|c|c|c|c|c|c|c|}
\hline & $C_{\mathrm{OH}, \text { in }}$ & $R e_{L}$ & $\overline{R e}_{G}$ & $\bar{\alpha}$ & $\bar{X}_{\mathrm{CO}_{2}, \mathrm{G}}$ & $\eta$ \\
\hline$R e_{L}$ & 0.031 & & & & & \\
\hline$\overline{R e}_{G}$ & -0.125 & 0.099 & & & & \\
\hline $\bar{\alpha}$ & -0.099 & -0.574 & 0.658 & & & \\
\hline $\bar{X}_{\mathrm{CO}_{2}, \mathrm{G}}$ & -0.107 & 0.042 & -0.016 & -0.299 & & \\
\hline$\eta$ & -0.023 & 0.006 & 0.053 & 0.229 & 0.045 & \\
\hline$A_{i}^{\prime \prime}$ & -0.245 & -0.216 & 0.723 & 0.716 & -0.403 & -0.288 \\
\hline
\end{tabular}




\subsection{References for Chapter 4}

Akita, K., \& Yoshida, F. (1974). Bubble size, interfacial area, and liquid-phase mass transfer coefficient in bubble columns. Ind. Eng. Chem., Process Des. Develop., 13 (1), 84-90.

Al Taweel, A.M., Divakarla, R., \& Gomaa, H.G. (1984). Measurement of large gas-liquid interfacial areas. Can. J. Chem. Eng., 62, 73-77.

Banerjee, S., \& Lahey, R.T. (1981). Advances in two-phase flow instrumentation. Advances in Nuclear Science and Technology (Edited by Lewins, J., and Becker, M.), 13, 227-414, Plenum Press, New York.

Bennington, C.P.J., Owusu, G., \& Francis, D.W. (1997). Gas-Liquid Mass Transfer in Pulp Suspension Mixing Operations. Can. J. Chem. Eng., 75 (2), 53-61.

Bennington, C.P.J., Zhang, X.Z., \& Van Heiningen, A.R.P. (1999). Effect of fibre-width distribution on ozone bleaching. J. Pulp and Paper Sci., 25 (4), 124-129.

Danckwerts, P.V. (1955). Gas absorption accompanied by chemical reaction. A.I.Ch.E.J., December, 456-463.

Danckwerts, P.V., \& Sharma, M.M. (1966). The absorption of carbon dioxide into solutions of alkalis and amines. The Chemical Engineer, 244-280.

Dong, S., Feng, X., Salcudean, M., \& Gartshore, I. (2003). Concentration of pulp fibers in 3D turbulent channel flow. Int. J. Multiphase Flow, 29, 1-21.

Dudukovic, M.P., Larachi, F., \& Mills, P.L. (1999). Multiphase reactors-revisited. Chem. Eng. Sci., 55, 1975-1995.

Edwards, D.K., Denny, V.E., \& Mills, A.F. (1979). Transfer Processes - An introduction to diffusion, convection, and radiation, 2nd Ed., McGraw-Hill Book Company.

Ellis, J.E., \& Jone, E.L. (1970). Two phase flow symposium, Exeter, England, June 1965, as cited by Mashelkar, R.A. Bubble Columns. Br. Chem. Eng., 15, 1297.

Garner, A.E., \& Heindel, T.J. (2000). The effect of fiber type on bubble size. J. of Pulp Paper Science, 26, $266-269$. 
Greaves, M., \& Kobbacy, K.A.H. (1984). Measurement of bubble size distribution in turbulent gas-liquid dispersions. Chem. Eng. Res. Des., 62, 3-12.

Heald, C.C. (1988). Cameron Hydraulic Data. Seventh Ed., Ingersoll-Rand Co., New Jersey, USA.

Heindel, T.J. (1999). Bubble size measurement in a quiescent fiber suspension. J. of Pulp Paper Science, 25, 104-110.

Heindel, T.J., \& Garner, A.E. (1997). The effect of fiber consistency on bubble size. Nordisk Pulp Paper Research Journal, 14, 171-178.

Lindsay, J.D., Ghiaasiaan, S.M, \& Abdel-Khalik, S.I. (1995). Macroscopic flow structures in a bubbling paper pulp-water slurry. Ind. Eng. Chem. Res., 34, 3342-3354.

Kasturi, G., \& Stepanek, J.B. (1974). Two-phase flow-III. Interfacial area in cocurrent gas-liquid flow. Chem. Eng. Sci., 29, 713-719.

Minitab Statistical Software (2000). Minitab Inc., Release 13 for Windows.

Neter, J., Kutner, M.H., Nachtsheim, C.J., Wasserman, W. (1996). Applied Linear Statistical Models. Fourth Ed., McGraw Hill.

Nijsing, R.A.T.O., Hendriksz, R.H., \& Kramers, H. (1959). Absorption of $\mathrm{CO}_{2}$ in jets and falling films of electrolyte solutions, with and without chemical reaction. Chem Eng. Sci., 10, 88-104.

Reese, J., Jiang, P.,\& Fan,L.-S. (1996). Bubble characteristics in three-phase systems used for pulp and paper processing. Chem. Eng. Sci., 51, $2501-2510$.

Rewatkar, V.B., \& Bennington, C.P.J. (2000). Gas-Liquid Mass Transfer in Low- and MediumConsistency Pulp Suspensions. The Can. J. Chem. Eng., 78 (6), 504-512.

Serizawa, A., Kataoka, I., \& Michiyoshi, I. (1975). Turbulence structure of air-water bubbly flow - I. Measuring techniques. Int. J. Multiphase Flow, 2, 221-233.

Xie, T., Ghiaasiaan, S.M., Karrila, S., \& McDonough, T. (2003). Flow regimes and gas holdup in paper pulp-water-gas three-phase slurry flow. Chem. Eng. Sci., 58, 1417-1430.

Zhang, X.Z. (1998). Ozone bleaching of chemical pulp. PhD Thesis. The University of New Brunswick, Canada. 
